Análise da função renal em idosos com comprometimento cognitivo leve usuários de lítio em baixa dosagem: um estudo randomizado, duplo cego, placebo-controlado

Tese apresentada à Faculdade de Medicina da Universidade de São Paulo, para obtenção do título de Doutor em Ciências

Programa de Psiquiatria

Orientador: Prof. Dr. Orestes Vicente Forlenza

SÃO PAULO 
Dados Internacionais de Catalogação na Publicação (CIP)

Preparada pela Biblioteca da

Faculdade de Medicina da Universidade de São Paulo

Creprodução autorizada pelo autor

\section{Aprahamian, Ivan}

Análise da função renal em idosos com comprometimento cognitivo leve usuários de lítio em baixa dosagem : estudo randomizado, duplo cego, placebo-controlado / Ivan Aprahamian. -- São Paulo, 2013.

Tese(doutorado)--Faculdade de Medicina da Universidade de São Paulo. Programa de Psiquiatria.

Orientador: Orestes Vicente Forlenza.

Descritores: 1.Lítio/sangue 2.Lítio/efeitos adversos 3.Tolerância a medicamentos 4.Gerenciamento de segurança 5.Insuficiência renal/diagnóstico 6.Lesão renal aguda/diagnóstico 7.Idoso 8.Comprometimento cognitivo leve 9.Doença de Alzheimer

USP/FM/DBD-175/13 
DEDICATÓRIA

À minha família...

...pelo apoio constante e desinteressado, pela crença inabalável, pelo sonho compartilhado, pelo amor inigualável...e tantos outros sentimentos que as palavras nunca irão alcançar. 
Ao Instituto de Psiquiatria do Hospital das Clínicas da Faculdade de Medicina da Universidade de São Paulo, representado por inúmeros profissionais e pacientes com os quais pude adquirir um crescimento exponencial como médico e ser humano, o meu carinho.

Ao Laboratório de Neurociências, LIM27, minha referência em pesquisa clínica e experimental, representado por profissionais talentosos, dedicados e desprendidos de tantos valores em pró da ciência e da pesquisa, a minha admiração.

Aos membros de minha banca examinadora, pelos conselhos, por acreditarem neste tema e pelo tempo precioso dedicado ao crescimento deste projeto, deixo meu respeito e admiração.

Aos colegas, professores e funcionários do programa de pós-graduação, o meu agradecimento pelo companheirismo e pelos ensinamentos ao longo desses anos.

À Erika Hazome Hayashi, Maria Umbelina Santos de Jesus, Isabel Ataíde e Eliza Fukushima, o meu carinho pela ajuda fundamental durante todo o processo da execução da tese.

Ao caro estatístico Bernardo Pereira, o meu apresso pelas horas dedicadas ao estudo e discussão da desafiadora análise estatística desta tese.

Aos amigos Rodolfo Ladeira, Paula Nunes, Letícia Paranhos, Jouce Almeida, Márcia Radanovic e Franklin Santana Santos, o meu carinho pelo apoio direto durante a execução deste projeto. 


\section{AGRADECIMENTO ESPECIAL}

Ao Prof. Dr. Orestes Vicente Forlenza, meu orientador, por ter acreditado em meu potencial como médico e pessoa, e por ter confiado em meu caráter e competência. 


\section{SUMÁRIO}

LISTA DE GRÁFICOS .................................................................................................... viii

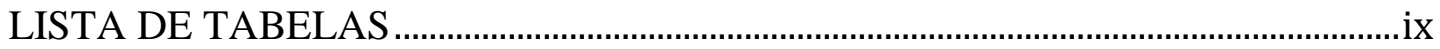

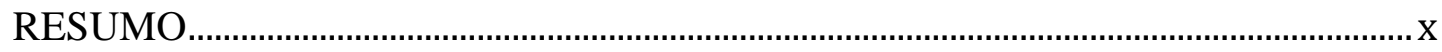

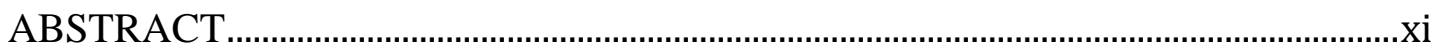

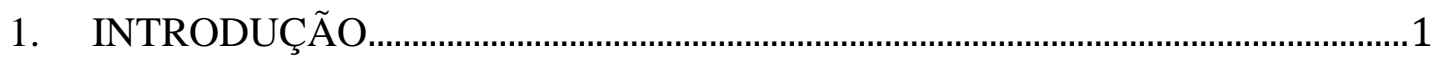

1.1. Por que estudar a segurança do tratamento com sais de lítio? ...............................1

1.2. Princípios da farmacologia do lítio ........................................................................

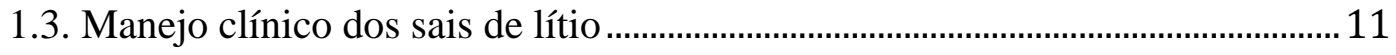

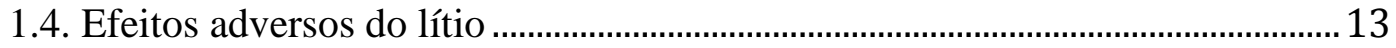

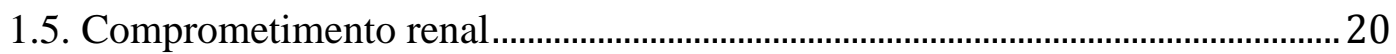

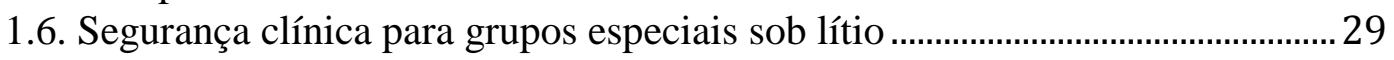

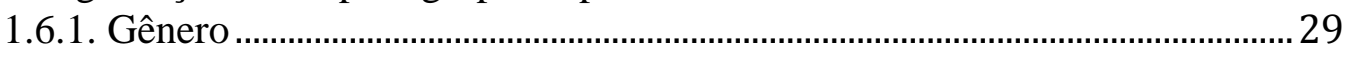

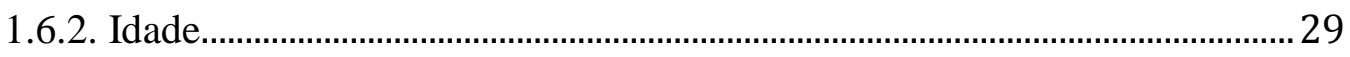

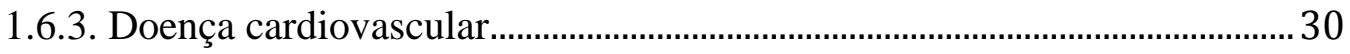

1.7. Particularidades na prescrição de lítio em idosos .................................................. 31

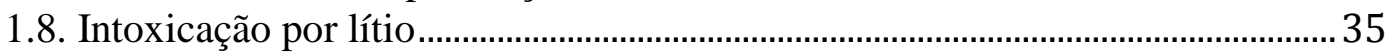

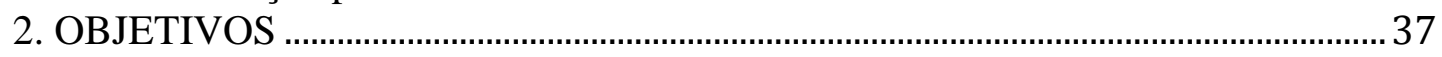

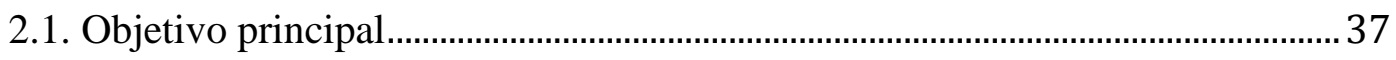

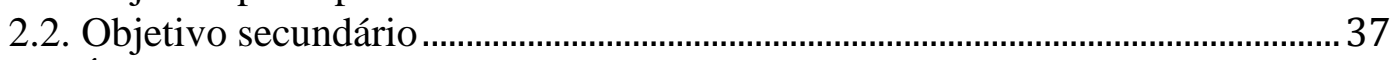

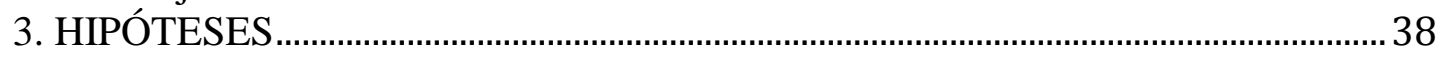

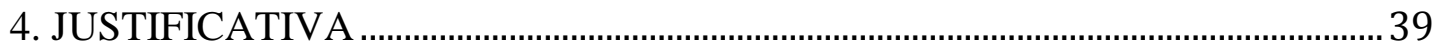

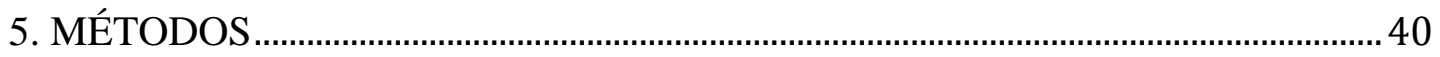

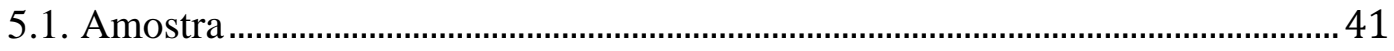

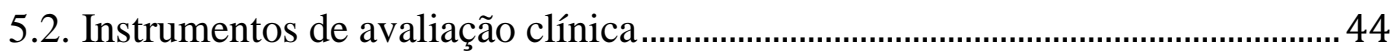

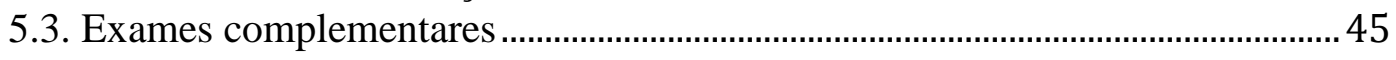

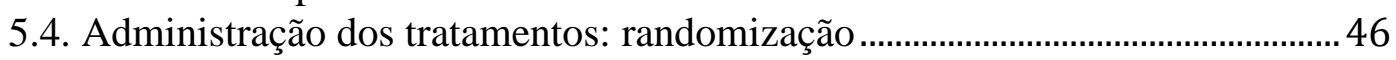

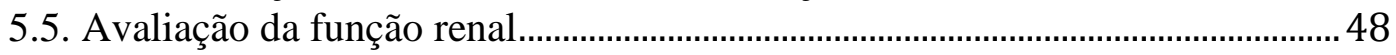

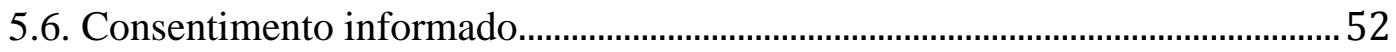

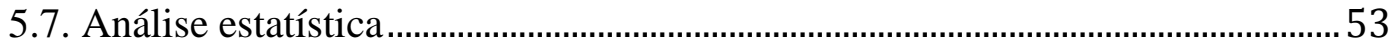

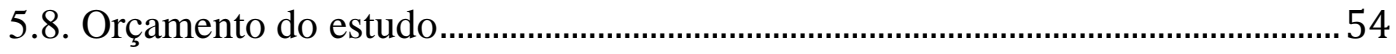

6. RESULTADOS

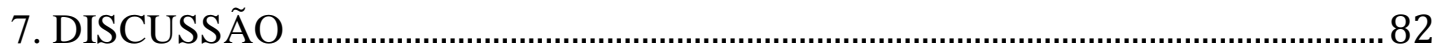

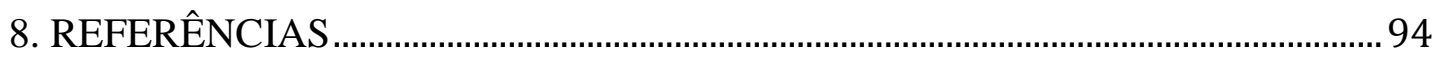

9. APÊNDICES 


\section{LISTA DE GRÁFICOS}

GRÁFICO 1. EVOLUÇãO DA CREATININA SÉRICA NOS GRUPOS AO LONGO DE 48 MESES ...........................59

GRÁFICO 2. EVOLUÇÃO DA AMDRD CALCULADA NOS GRUPOS AO LONGO DE 48 MESES .......................6 60

GRÁFICO 3. EVOLUÇÃO DA CKD-EPI ESTIMADA NOS GRUPOS AO LONGO DE 48 MESES ............................62

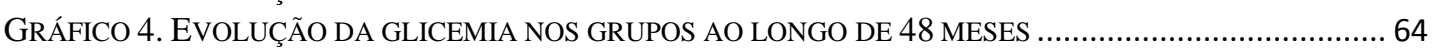

GRÁFICO 5. EVOLUÇÃO DA INSULINEMIA NOS GRUPOS AO LONGO DE 48 MESES ...................................... 65

GRÁFICO 6. EVOLUÇÃO DA RESISTÊNCIA INSULÍNICA NOS GRUPOS AO LONGO DE 48 MESES.................... 65

GRÁFICO 7.EVOLUÇãO DO NÚMERO DE LEUCÓCITOS NOS GRUPOS AO LONGO DE 48 MESES ....................66

GRÁFICO 8. EVOLUÇÃO DO NÚMERO DE LINFÓCITOS NOS GRUPOS AO LONGO DE 48 MESES.....................68

GRÁFICO 9. EVOLUÇÃO DO NÚMERO DE NEUTRÓFILOS NOS GRUPOS AO LONGO DE 48 MESES..................69

GRÁFICO 10 EVOLUÇÃO DA CONTAGEM DE NEUTRÓFILOS ENTRE OS GRUPOS DURANTE 48 MESES .... 69

GRÁFICO 11. EVOLUÇÃO DO T T LIVRE NOS GRUPOS AO LONGO DE 48 MESES ............................................. 71

GRÁFICO 12. NÚMERO DE SINTOMAS APRESENTADOS PELOS PACIENTES AO LONGO DE 48 MESES ......... 75 


\section{LISTA DE TABELAS}

TABELA 1. CARACTERÍSTICAS SOCIODEMOGRÁFICAS DOS PARTICIPANTES NO INÍCIO DO ESTUDO ........ 56

TABELA 2 - CARACTERÍSTICAS DOS PARTICIPANTES DE ACORDO COM O GRUPO DE TRATAMENTO........ 56

TABELA 3. GANHO PONDERAL OBSERVADO NOS GRUPOS AO FINAL DO ESTUDO .................................5 58

TABELA 4. TESTES DE EFEITOS FIXOS PARA A VARIÁVEL CREATININA AO LONGO DE 48 MESES ............ 59

TABELA 5. TESTES DE EFEITOS FIXOS PARA A VARIÁVEL AMDRD AO LONGO DE 48 MESES .................. 60

TABELA 6. TESTES DE EFEITOS FIXOS PARA A VARIÁVEL AMDRD SEGUNDO A PRESENÇA DE

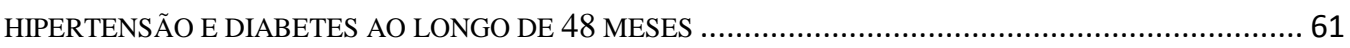

TABELA 7 . TESTES DE EFEITOS FIXOS PARA A VARIÁVEL MDRD SEGUNDO A PRESENÇA DE

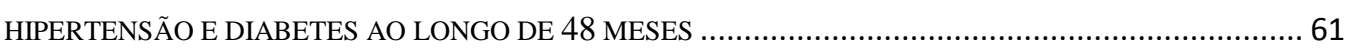

TABELA 8. MÉDIAS DOS VALORES DAS EQUAÇÕES AMDRD E CKD-EPI EM CADA GRUPO....................63

TABELA 9. TESTES DE EFEITOS FIXOS PARA A VARIÁVEL GLICEMIA AO LONGO DE 48 MESES ................63

TABELA 10. TESTES DE EFEITOS FIXOS PARA A VARIÁVEL INSULINEMIA AO LONGO DE 48 MESES......... 64

TABELA 11. TESTES DE EFEITOS FIXOS PARA A VARIÁVEL HOMA-IR AO LONGO DE 48 MESES .............64

TABELA 12. TESTES DE EFEITOS FIXOS PARA A VARIÁVEL LEUCÓCITOS AO LONGO DE 48 MESES...........66

TABELA 13. TESTES DE EFEITOS FIXOS PARA A VARIÁVEL LINFÓCITOS AO LONGO DE 48 MESES ............ 67

TABELA 14. TESTES DE EFEITOS FIXOS PARA A VARIÁVEL NEUTRÓFILOS AO LONGO DE 48 MESES........ 68

TABELA 15. TESTES DE EFEITOS FIXOS PARA A VARIÁVEL TSH AO LONGO DE 48 MESES .......................69

TABELA 16. TESTES DE EFEITOS FIXOS PARA A VARIÁVEL T $\mathrm{T}_{4}$ L AO LONGO DE 48 MESES...................... 70

TABELA 17. VALORES MÉDIOS DAS VARIÁVEIS LABORATORIAIS AVALIADAS NOS PARTICIPANTES AO

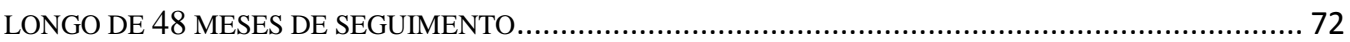

TABELA 18. NÚMERO DE SINTOMAS REFERIDOS PELOS GRUPOS AO LONGO DO SEGUIMENTO DE 4 ANOS, DURANTE 17 AVALIAÇÕES. 74

TABELA 19. TESTES DE EFEITOS FIXOS PARA A VARIÁVEL NÚMERO DE SINTOMAS AO LONGO DE 48 MESES.

TABELA 20. TESTES DE EFEITOS FIXOS PARA A VARIÁVEL NÚMERO DE SINTOMAS DEPENDENTE DAS QUEIXAS DE MEMÓRIA E DEPRESSÃO AO LONGO DE 48 MESES ................................................ 76

TABELA 21. SINTOMAS MAIS COMUNS REFERIDOS PELOS PACIENTES ATRAVÉS DO QUESTIONÁRIO UKU AO LONGO DE 48 MESES

TABELA 22. INTERFERÊNCIA DOS EFEITOS COLATERAIS NAS ATIVIDADES DE VIDA DIÁRIA ENTRE OS PACIENTES SEGUNDO A PERCEPÇÃO DO PACIENTE AO LONGO DE 48 MESES

TABELA 23. INTERFERÊNCIA DOS EFEITOS COLATERAIS NAS ATIVIDADES DE VIDA DIÁRIA ENTRE OS PACIENTES SEGUNDO A PERCEPÇÃO DO MÉDICO AO LONGO DE 48 MESES.

TABELA 24. CORRELAÇÃO ENTRE AS INTERFERÊNCIAS DOS EFEITOS COLATERAIS OBSERVADOS PELOS PARTICIPANTES E PELO MÉDICO AVALIADOR DURANTE O SEGUIMENTO DE 4 ANOS...... 80

TABELA 25. CONSEQUÊNCIA DA CONDUTA MÉDICA EM RAZÃO DOS EFEITOS COLATERAIS OBSERVADOS PELO MÉDICO AO LONGO DE 48 MESES. 


\section{RESUMO}

Aprahamian I. Análise da função renal em idosos com comprometimento cognitivo leve usuários de lítio em baixa dosagem: um estudo randomizado, duplo cego, placebo-controlado [tese]. São Paulo: Universidade de São Paulo, Faculdade de Medicina; 2013.

Introdução: segundo a literatura, sais de lítio podem produzir redução da função renal. A magnitude dessa informação é debatível, uma vez que não há estudo clínico randomizado e controlado entre usuários de lítio, em sua maioria pacientes com depressão ou transtorno bipolar. A possibilidade do uso do lítio para o tratamento da demência de Alzheimer prodrômica reforça a necessidade de maior investigação de efeitos adversos atribuídos ao lítio, especialmente com relação à função renal. Objetivos: avaliar a segurança da utilização do lítio em baixa dosagem com relação à função renal de pacientes idosos. Como objetivos secundários serão avaliadas: a segurança clínica através de exame e questionário específico, as funções tireoidiana, imunológica e o metabolismo glicêmico. Métodos: estudo randomizado e placebo controlado de 2 anos, seguido de fase aberta por mais 2 anos. Foram avaliados 59 idosos com comprometimento cognitivo leve com seguimento mínimo de dois anos (fase controlada). A função renal foi estimada através das fórmulas aMDRD e CKDEPI, a partir de exames laboratoriais e dados clínicos coletados durante o estudo. As funções tireoidiana, imunológica e glicêmica foram avaliadas respectivamente através de $\mathrm{TSH}, \mathrm{T}_{4}$ livre, leucócitos total, neutrófilos, linfócitos, glicemia e insulinemia de jejum, e HOMA-IR. A segurança clínica foi avaliada através de entrevista sistemática realizada a cada 3 meses, utilizando exame físico e a escala UKU para efeitos adversos. Resultados: não houve piora da função renal com o uso do lítio (litemia entre $0,25-0,5 \mathrm{mmol} / \mathrm{l})$ tanto pela aMDRD $(p=0,453)$ como pela CKD-EPI $(p=0,181)$. Houve aumento significativo de neutrófilos $(p=0,038)$ e do TSH $(p=0,034)$. O grupo lítio apresentou incidência significativamente maior de diabetes mellitus $(p=0,037)$ e arritmias $(p=0,028)$, maior ganho de peso $(p=0,015)$, mais sintomas na escala UKU $(p=0,045)$, e maior interferência dos efeitos adversos do lítio em atividades diárias $(p<0,001)$. Houve correlação entre a opinião de médico e do paciente nas interferências das atividades diárias atribuídas aos sintomas adversos $(p<0,001)$. Conclusões: o uso de lítio em baixa dose não alterou a função renal, produziu alterações no sistema imunológico e tireoidiano sem impacto clínico, e foi seguro clinicamente. As razões do aumento de incidência de diabetes e arritmias merecem investigação posterior.

Descritores: Lítio/sangue; Lítio/efeitos adversos; Tolerância a medicamentos; Gerenciamento de segurança; Insuficiência renal/diagnóstico; Lesão renal aguda/diagnóstico; Idoso; Compometimento cognitivo leve; Doença de Alzheimer. 


\begin{abstract}
Aprahamian I. Analysis of the renal function in elderly with mild cognitive impairment using lithium in low dose: a randomized, double-blind, placebocontrolled study [tese]. São Paulo: Universidade de São Paulo, Faculdade de Medicina; 2013.

Introduction: according to the literature, lithium salts may produce a reduction in kidney function. The magnitude of this information is debatable because there is no randomized and controlled clinical trial among lithium users, being mostly patients with depression or bipolar disorder. The possibility of using lithium for the treatment of prodromal Alzheimer's disease dementia increases the need for further investigation of adverse effects attributed to lithium, especially regarding to renal function. Objectives: To evaluate the safety of using low-dose lithium with respect to renal function in elderly patients. Secondary objectives were the evaluation of the clinical safety through specific questionnaire and clinical assessment, and to assess thyroid, immunological and glycemic function. Methods: a randomized and placebo controlled study for 2 years, followed by an open label follow-up of 2 years. We evaluated 59 elderly patients with mild cognitive impairment with accomplishment of at least two years of the controlled phase. Renal function was estimated by the aMDRD and CKD-EPI equation, and by laboratory and clinical data collected during the trial. The thyroid, immunological and glycemic functions were respectively evaluated by $\mathrm{TSH}$, free $\mathrm{T}_{4}$, leukocyte count, neutrophil count, lymphocyte count, fasting plasma glucose and insulin, and the HOMA-IR. The clinical safety was evaluated through systematic examination performed every 3 months, with physical examination, clinical interview and UKU scale for adverse effects. Results: There was no decline of renal function with the use of lithium (litemia between 0.25-0.5 $\mathrm{mmol} / \mathrm{l})$ both in the aMDRD $(p=0.453)$ and CKD-EPI $(p=0.181)$ equations. A significant increase of neutrophils $(p=0.038)$ and TSH $(p=0.034)$ were observed. The lithium group showed significantly higher incidence of diabetes mellitus $(p=0.037)$, arrhythmias $(p=0.028)$, weight gain $(p=0.015)$, more symptoms of UKU scale $(p=0.045)$, and greater interference from the adverse effects of lithium during daily activities $(p<0.001)$. There was an observed correlation between the opinion of the attending physician and the patient in respect to the interference in daily activities secondary to the adverse symptoms $(p<0.001)$. Conclusions: The use of lithium in low doses did not result in renal function impairment, produced subtle changes in the immunological system and thyroid function, and was clinically safe for adverse effects. The reasons for the increased incidence of arrhythmias and diabetes mellitus deserve further investigation.
\end{abstract}

Descriports: Litium/blood; Lithium/adverse effects; Drug tolerance; Safety management; Renal insuffiency/diagnosis; Acute kidney injury/diagnosis; Aged; Mild cognitive impairment; Alzheimer disease. 


\section{INTRODUÇÃO}

\subsection{Por que estudar a segurança do tratamento com sais de lítio?}

Os sais de lítio representam uma opção terapêutica relevante na psiquiatria clínica, sendo eficazes no tratamento agudo e de longo prazo do transtorno afetivo bipolar e reduzindo a incidência de suicídio e mortalidade nos transtornos do humor de forma geral (Geddes et al., 2004; Cipriani et al., 2005; Ohgami et al., 2009). Mais recentemente, novas propriedades biológicas do lítio têm sido descobertas, dando suporte ao medicamento como um candidato para seu uso como droga modificadora de doenças neurodegenerativas, especialmente da demência da doença de Alzheimer (DA). Em um recente estudo realizado em nosso grupo, o tratamento crônico com lítio para pacientes com comprometimento cognitivo leve (CCL) foi associado com estabilização cognitiva e funcional, além da modificação de biomarcadores patológicos da DA (Forlenza et al., 2011).

Embora a maioria das diretrizes recomendem a prescrição de lítio como uma droga de primeira linha para o tratamento do transtorno afetivo bipolar, seu uso tem diminuído, principalmente por razões acerca de sua segurança clínica (Young et al., 2007). Na verdade existem diversas preocupações relacionadas com a própria prescrição do medicamento, tais como uma janela terapêutica estreita, a exigência de coletas frequentes para verificação dos níveis séricos, a avaliação da incidência de efeitos adversos potencialmente incapacitante (ex. sede, alteração gustativa, tremor, poliúria, ganho de peso), o risco de teratogenicidade, e a possibilidade de surgimento de lesões orgânicas (ex. insuficiência renal, disfunção tubular renal, hipotireoidismo, hiperparatireoidismo) particularmente com o uso a longo prazo. Neste contexto, a disfunção renal tem sido apontada como uma das principais, senão a principal, 
preocupações dos médicos que prescrevem derivados de lítio, devido ao seu potencial para o desenvolvimento de disfunção renal grave (Young et al., 2007; Grandjean et al., 2007).

Infelizmente, alguns pontos são desfavoráveis ao melhor estudo da segurança clínica com o uso do lítio. Primeiramente, o desenho de um ensaio clínico randomizado e controlado, de longo prazo (e no caso do lítio, consideraríamos vários anos para se avaliar a totalidade da perda de função renal, por exemplo), é extremamente oneroso e com alta taxa de desistências em razão da população estudada (especialmente pacientes com transtornos depressivos graves ou transtorno afetivo bipolar) e da ocorrência de efeitos colaterais sintomáticos decorrentes da medicação. Segundo, o carbonato de lítio (sal de lítio mais comum e comercializado em nosso meio) é uma medicação barata, o que dificultaria o retorno financeiro de um estudo patrocinado pela própria indústria farmacêutica. Somando-se a isto, ao contrário de outras drogas, o lítio possui alternativas à sua prescrição, ainda que mais onerosas, como os derivados do ácido valpróico. Estas medicações têm ações benéficas muito próximas ao lítio no tratamento de pacientes com transtornos de humor.

Com relação específica à função renal, metanálises de alguns estudos com pacientes com transtornos de humor (em sua maioria com doença bipolar) apontam para uma tendência à diminuição da filtração glomerular, mas sem diferença significativamente expressiva quando comparado aos não usuários (McKnight et al., 2012). Em dois estudos com pacientes idosos com CCL em tratamento com o lítio, não houve uma avaliação sistemática da segurança clínica (McDonald et al., 2008; Hampel et al., 2009). Nenhum dos estudos de boa qualidade técnica avaliados até 
aqui possuem um grau de evidência forte o suficiente para chegarmos a uma conclusão final da ação do lítio sobre a função renal, especialmente levando-se em consideração algumas questões tais como: o tempo de exposição, qual a extensão desta lesão, e o impacto sobre a população mais frágil, ou seja, os idosos. Estas questões importantes ainda não foram respondidas, com relação ao tempo de exposição ou à litemia. 


\subsection{Princípios da farmacologia do lítio}

Apesar do conhecimento e de sua utilização ao longo de muitos anos, o lítio continua sendo uma sólida opção terapêutica para diversos transtornos do humor (Geddes et al., 2004; Cipriani et al., 2005). Contudo, estudos apontam para a falta de conhecimento sobre evidências e princípios farmacológicos do composto entre médicos, especialmente nas gerações mais jovens (Young e Hammond, 2007; Grandjean e Aubry, 2009a). Em razão da potencial toxicidade da droga, uma revisão de seus princípios farmacocinéticos é fundamental.

Os resultados dos estudos farmacocinéticos com lítio apresentam resultados variáveis em razão da multiplicidade de esquemas terapêuticos: diversos sais disponíveis, uma ampla dose terapêutica (600-1000mg), uso de intervalos variados de administração (8-24h) e diferentes formas de administração (liberação imediata ou prolongada). O sal de lítio é formulado muito frequentemente como comprimido de liberação prolongada a fim de evitar picos plasmáticos elevados, associados com maior chance de intoxicação (Keck et al., 2000).

A maioria dos estudos farmacocinéticos iniciais sobre sais de lítio foram executados dentro de um período curto de observação (Grandjean e Aubry, 2009a). Isto resultou num viés da análise da porção extrapolada da área sob a curva da concentração plasmática em razão do tempo (AUC). Hoje, recomenda-se que esta porção deve ter no máximo $20 \%$. Quando a dose administrada de sal de lítio é plotada dentro da AUC, percebe-se que as formulações de liberação sustentada produzem pouca alteração na curva e implicam em discretas alterações na concentração máxima da droga $\left(\mathrm{C}_{\max }\right)$ (Castrogiovanni, 2002). 
O comportamento cinético do lítio após múltiplas doses é altamente variável (Hunter, 1988). Um estudo avaliou o padrão cinético da droga em formulações de liberação prolongada, estabelecendo o tempo até o pico de $\mathrm{C}_{\max }$ era de 4,5 horas, com um estado de equilíbrio semelhante ao da formulação de liberação imediata, mas sem uma brusca $\mathrm{C}_{\max }$ (Cooper et al., 1978). Por outro lado, a comparação entre as duas formulações terapêuticas para a concentração plasmática mais baixa $\left(\mathrm{C}_{\text {trough }}\right)$ não foi realizada (Grandjean e Aubry, 2009a).

O sal de lítio possui biodisponibilidade de $80-100 \%$, dentro de um volume de distribuição (Vd) entre 0,7 e 1,0 L/Kg. Sua depuração é renal entre 10 e 40 mL/min, com um tempo de meia-vida $\left(\mathrm{t}_{1 / 2}\right)$ entre 18 e 36 horas (Ward et al., 1994).

A absorção dos sais de lítio é variável, dependendo do composto. Sais hidrossolúveis, como cloreto e sulfato, são mais rapidamente absorvíveis no trato gastrointestinal alto (sem conhecimento exato do local), enquanto sais menos solúveis apresentam absorção mais lenta, tal como o carbonato de lítio (Grandjean e Aubry, 2009a). Um único estudo se dedicou à avaliação do tempo de meia-vida de absorção do carbonato de lítio, encontrando valores de 0,78 e 3,73 horas para a liberação imediata e prolongada, respectivamente (Thornhill, 1978). A ingestão concomitante de alimento pode aumentar esse tempo (Gai et al., 2000). A distribuição orgânica subsequente do lítio no corpo humano não foi bem estuda diretamente, sendo a maioria dos estudos dedicados à transposição da barreira hemato-encefálica. Apesar da pobre correlação entre as concentrações plasmática e cerebral, geralmente as cerebrais são metade das plasmáticas, podendo atingir 75 a 80\% (Soares et al., 2000). Apesar das variações na concentração cerebral do lítio nas primeiras 48 horas, o íon desaparece após 10 dias da sua interrupção (Soares et al., 
2000). Um estudo de autópsia demonstra correlação entre os achados de concentração cerebral em ratos, primatas e humanos (Birch et al., 1976; Spirtes, 1976; Moore et al., 2002). Apesar disso, a compreensão da distribuição cerebral do lítio continua em debate, tendo seus dados baseados em poucos estudos.

A ligação protéica do lítio é de aproximadamente $15 \%$, em níveis fisiológicos, a valores irrisórios em nível terapêutico (Clarke et al., 1998). Ao contrário, sua ligação ao tecido ósseo é expressiva, levando meses para o término de sua eliminação (Birch et al., 1976; Spirtes, 1976). Evidências apontam para um efeito protetor contra fraturas associado com essa forte ligação (Vestergaad et al., 2005; Wilting et al., 2007). Há grande concentração do lítio igualmente na bile, variando entre as ordens de 2 (administração aguda) a 10 (uso crônico) vezes a dos níveis plasmáticos (Birch et al., 1976; Terhaag et al., 1978).

O lítio não sofre transformação metabólica e é totalmente excretado pelos rins em sua forma iônica, cruzando a membrana glomerular livremente. No entanto, $80 \%$ do lítio filtrado presente no túbulo proximal é reabsorvido. A depuração renal varia entre 0,6 a 2,4 L/h, dependendo intimamente da depuração da creatinina e do peso corporal do sujeito (Sproule et al., 2000). A $t_{1 / 2}$ plasmática é influenciada pela depuração renal além do Vd e do tempo de tratamento. Há também eliminação do lítio via biliar concomitantemente, mas sua importância não é conhecida (Sproule et al., 2000).

As propriedades farmacocinéticas são influenciadas por idade, gênero, raça, doença renal ou cardiovascular, obesidade, gestação e lactação. O fator idade será abordado com detalhe mais a frente quando discutirmos sobre a população idosa. Embora evidência aponte para uma diferença entre gêneros e raças, nossas 
evidências são escassas. Nenhum estudo de exploração farmacológica foi realizado entre mulheres (Freeman e Gelenberg, 2005), ou mesmo com diversas raças, fora caucasianos. Somente um estudo foi realizado com uma população asiática, com potencial viés devido a comparação dessa população com caucasianos (Lee et al., 1998).

Com relação a doenças clínicas, a terapia com lítio é contra-indicada para pacientes com doença renal em razão do aumento de sua concentração plasmática e do seu potencial risco de intoxicação, principalmente naqueles com dieta pobre em sódio (Using lithium safely, 1999). Pacientes com doença cardíaca de maior gravidade (hipertensão arterial grave de difícil controle, arritmias complexas, insuficiência cardíaca congestiva) constituem potenciais candidatos à disfunção renal, necessitando de cuidados especiais na monitorização do lítio. Nos pacientes obesos, observa-se maior depuração do lítio assim como menor Vd no estado de equilíbrio (Reiss et al., 1994). Inicialmente, recomenda-se a administração de doses menores do sal, próximas ao peso ideal dos pacientes com obesidade, seguido por doses progressivamente maiores na fase de manutenção, mais próximas de seu peso atual. A gestação consiste em outra situação importante para a terapia com lítio, uma vez que o íon atravessa a barreira placentária (Schou, 1990). O lítio tem potencial teratogênico durante a gestação numa incidência de até 12\% (Viguera et al., 2002). No último trimestre, a depuração renal de lítio aumenta em 30-50\%, necessitando ajuste terapêutico (Schou, 1990). Na lactação, a concentração de lítio passada à criança é aproximadamente um quarto da presente na mãe (Viguera et al., 2007).

Um outro relevante tópico em farmacocinético e farmacodinâmica é o perfil de interação medicamentosa do lítio. Na grande maioria dos casos, há aumento da 
litemia por redução da excreção e consequente maior risco para intoxicação (Grandjean e Aubry, 2009a). Grande parte dessa evidência vem de estudos de série de casos, experiência clínica e estudos com voluntários (Grandjean e Aubry, 2009a). Dentre as drogas com potencial interação com o lítio destaca-se os diuréticos excretores de sódio, os inibidores da enzima conversora de angiotensina (IECA) e os antiinflamatórios não-esteroidais (AINEs), com possível exceção para a aspirina (Harvey e Merriman, 1994).

Os diuréticos tiazídicos agem no túbulo renal proximal e têm grande impacto na redução da depuração renal de lítio em razão da maior excreção de sódio. Recomenda-se reduzir inicialmente a dose do sal de lítio em $40-50 \%$, caso o uso desse diurético seja indispensável, até que novos controles de função renal e litemia possam ser estabelecidos (Grandjean e Aubry, 2009a). Entretanto, um estudo casocontrole de 10 anos de observação com uma amostra de idosos, não apontou essa alteração consequente do uso de tiazídicos, mas sim, com a utilização de diuréticos de alça como a furosemida (Juurlink et al., 2004). Diuréticos poupadores de potássio, como a amilorida, são preferencialmente prescritos em conjunto com o lítio. Contudo, a espironolactona, pertencente a esta mesma classe, pode aumentar a litemia. A amilorida é também utilizada no tratamento do diabetes insipidus induzido pelo próprio sal de lítio (Kosten e Forrest, 1986; Stone, 1999). Dessa forma, diuréticos devem ser prescritos com cautela, sendo a amilorida o mais seguro.

Apesar do mecanismo ainda não totalmente conhecido, vasodilatadores como os IECA, antagonistas do receptor de angiotensina e bloqueadores de canal de cálcio podem induzir retenção de lítio (Harvey e Merriman, 1994; Finley et al., 1995). Os beta-bloqueadores consistem em uma classe terapêutica mais segura para pacientes 
hipertensos, apesar do propranolol reduzir a depuração renal de lítio em 20\% (Schou e Vestergaard, 1987). Os antagonistas do receptor de angiotensina II e bloqueadores de canal de cálcio são mais seguros do que os IECA, mas requerem avaliação mais cautelosa. No caso dos AINEs, esse incremento da concentração de lítio pode chegar entre 15 a 30\%, podendo incluir inibidores da COX-2 (Türck et al., 2000). A utilização de AINEs de forma constante requer uma redução de $20 \%$ na dose de lítio (Granjean e Aubry, 2009a). Alguns agentes antimicrobianos também podem produzir ação semelhante, tais como: trimetoprim, metronidazol, tetraciclinas, espectinomicina e levofloxacino (Grandjean e Aubry, 2009a). Contrariamente, as xantinas (teofilina, cafeína, por exemplo) diminuem em $20-25 \%$ a concentração do lítio plasmático (Cook et al., 1985).

Com relação à interação de medicações atuantes no sistema nervosos central, diversos efeitos adversos foram relatados com a administração conjunta do lítio. Os inibidores seletivos de serotonina podem promover efeitos adversos expressivos no sistema nervoso central quando associados ao lítio, tais como confusão mental, tontura, disartria, tremor, perda de coordenação, convulsões, mioclonia e sinais cerebelares de forma infrequente (Granjean e Aubry, 2009a). A síndrome serotoninérgica já foi descrita através da associação do lítio com antagonistas do receptor 5-HT 1 (triptanos), inibidores seletivos de recaptação de serotonina (IRSS) e de noradrenalina (IRNS), assim como de antidepressivos tricíclicos (Jaunay e Guelfi, 2001). O lítio pode potencialmente afetar a biodisponibilidade de neurolépticos. A neurotoxicidade reversível entre lítio e neurolépticos também pode ocorrer, com exceção da risperidona. O uso do valproato juntamente com o lítio é recomendado, embora possa estar associado ao aumento de frequência urinária e maior gravidade 
de sintomas colaterias (National Institute for Health and Clinical Excellence, 2006). A carbamazepina coadministrada com lítio pode apresentar potencialização de seus efeitos adversos tais como confusão, tremor intenso e sinais de disfunção cerebelar (Harvey e Merriman, 1994). O efeito do tabaco, álcool ou outras substâncias de abuso não foram devidamente avaliadas conjuntamente com o lítio (Granjean e Aubry, 2009b). Apesar das interações referidas, os potenciais efeitos tóxicos sobre o sistema nervoso central parecem envolver sobretudo o aumento da concentração plasmática do lítio.

Há também interações positivas entre o lítio e outras drogas, tais como a redução da leucopenia causada pela carbamazepina e a potencialização dos antitireoidianos e da ação da levodopa (Granjean e Aubry, 2009a).

A resposta terapêutica ao lítio demonstra alguma influência genética como nos casos de maior resposta entre os parentes de primeiro grau de pacientes com transtorno bipolar respondedores ao lítio e naqueles possuidores do antígeno $\mathrm{M}$, pertencente ao grupo sanguíneo MNS (Serretti e Artioli, 2003). Diversos polimorfismos também já foram avaliados, destacando-se os dos genes SERT-PR e TPH e sua correlação com pior resposta ao uso lítio (Serretti e Artioli, 2003). 


\subsection{Manejo clínico dos sais de lítio}

O lítio é um dos medicamentos mais eficazes para o tratamento a longo prazo dos transtornos afetivos, como confirmado em uma revisão de ensaios clínicos randomizados (Smith et al., 2007). A prevalência de tratamento com lítio em países ocidentais é relatada entre 0,8:1000 e 2,5:1000 pessoas (Walker, 1993; Castells et al., 2006; Bendz et al., 2010). Como somente uma proporção destes pacientes irá usá-lo durante muitos anos, 1:1000 é provavelmente a relação mais próxima da verdadeira prevalência.

Desde o início de sua utilização como medicamento, a monitorização dos níveis séricos foi recomendada em razão de sua estreita margem terapêutica. Os intervalos de verificação da litemia são discutíveis, variando de 6-12 semanas a 6 meses (Mitchell, 2000). Recomenda-se que seja sempre avaliado nas seguintes condições: após o início do tratamento, mudança da dose, intercorrência clínica e alteração de prescrição envolvendo outra droga receitada concomitantemente (Grandjean e Aubry, 2009a). O período ideal da coleta da litemia é dentro de 7 dias, quando o nível sérico atingiu o estado de equilíbrio farmacocinético (Grandjean e Aubry, 2009a).

A resposta terapêutica ao lítio normalmente é dose dependente, e da mesma forma, a litemia depende diretamente da dose administrada. Apesar de controverso, o limite terapêutico estabelecido fica entre $0,6 \mathrm{mmol} / \mathrm{L}$ e $1,0 \mathrm{mmol} / \mathrm{L}$ (Grandjean e Aubry, 2009a). Em idosos, evidências favorecem a utilização de níveis terapêuticos ao redor de 0,6 mmol/L (Eastham et al., 1998; Sproule et al., 2000). A coleta da litemia deve ser realizada após 12 horas da última administração da dose. Recomenda-se o início do tratamento com a dose de 450-900 mg. Doses até 50\% 
menores são recomendáveis para pacientes idosos (Sproule et al., 2000). A distribuição das doses administradas varia entre 2 a 3 vezes ao dia a fim de atingir a posologia segundo a idade: 925-1300 mg para menores de 40 anos; 740-925 mg para os entre 40-60 anos; e 550- 740 mg para maiores de 60 anos (Schou, 1988). A utilização de formulações de liberação prolongada pode diminuir a incidência de lesões orgânicas, tais como a incidência de poliúria e disfunção tubular proximal (Grandjean e Aubry, 2009a). Em razão do maior tempo para o incremento dos níveis plasmáticos e menor $\mathrm{C}_{\max }$ nessas formulações, outros efeitos adversos sintomáticos podem ser minimizados, tais como: tremor, dores epigástricas e náusea, eritemas, lentificação neuromuscular e frequência urinária (Bowden, 1998). O único efeito adverso que pode piorar com esta formulação é o surgimento de diarréia (Grandjean e Aubry, 2009a). 


\subsection{Efeitos adversos do lítio}

Diversos efeitos adversos sintomáticos são associados ao uso do lítio, sendo os mais comuns: desconforto abdominal, diarréia, tremor, poliúria, noctúria, ganho de peso, edema e diversas formas de eritemas (Grandjean e Aubry, 2009b). Anorexia, náuseas, vômitos, dores abdominais e diarréia são além de comuns, particularmente transitórios, ocorrendo mais frequentemente no início do tratamento (Rybalowski et al., 2006). As formulações de liberação prolongada estão menos associados aos sintomas adversos como já citado anteriormente.

$\mathrm{Na}$ prática clínica, os efeitos mais pronunciados e com maior repercussão para o paciente são a sede, a poliúria, a xerostomia, o ganho de peso, alterações cognitivas e a fadiga (Grandjean e Aubry, 2009b). Geralmente, os sintomas gastrointestinais e do sistema nervoso central, apesar de incômodos, têm pouco impacto prognóstico, ou seja, influenciam pouco na suspensão da droga (Grandjean e Aubry, 2009b). Ao todo, 15-20\% dos pacientes abandonam o tratamento em razão dos efeitos adversos, dentro de ambientes de ensaios clínicos controlados (Kleindienst et al., 2002; Calabrese et al., 2005). Contudo, a adesão pode ser melhorada com o fornecimento de informações precisas acerca da droga, supervisão terapêutica constante e apoio psicológico (Schou, 1997). A prevalência desses efeitos adversos é maior do que $20 \%$ durante o tratamento de longa duração, diretamente relacionados com a quantidade e frequência do sal de lítio administrado (Grandjean e Aubry, 2009b).

O ganho de peso entre 4-10 quilos é encontrado em $30 \%$ dos pacientes aproximadamente (Grandjean e Aubry, 2009b). Contudo, em alguns estudos, um ganho acima de 20 quilos não é raro (Rybakowski e Suwalska, 2006). De forma 
geral, o aumento de peso parece estar relacionado ao excesso de alimentação e ingesta de bebidas de alto teor calórico. Nenhum estudo explorou o efeito do lítio entre seus usuários comparado com pacientes controles para avaliar possíveis efeitos específicos no primeiro grupo com relação ao ganho de peso. Em estudo experimental com ratos recebendo litemia baixa, observou-se aumento dos níveis de uréia e glicose, elevação da peroxidade lipídica e redução da glutationa sanguíneas, indicando estresse oxidativo (Ahmad et al., 2011). Neste estudo, na avaliação histopatológica dos tecidos do fígado e dos rins, diversas deformidades estruturais e alterações histológicas foram observadas nos ratos tratados com lítio. Uma possibilidade é a elevação da glicose refletir uma alteração do metabolismo pancreático (insuficiência insulínica). Estudos experimentais com intoxicação por lítio já observaram redução de glicogênio hepático e renal juntamente com elevação da glicemia. Outra possível explicação seria a interferência do lítio no tempo do metabolismo de carboidratos durante a gliconeogênese e a glicogenólise, resultando em elevação glicêmica. Contudo, em outro estudo experimental com desenho e achados histopatológicos semelhantes ao citado anteriormente, as alterações do metabolismo glicêmico não foram encontradas (Sharma \& Iqbal, 2005).

No sistema nervoso, o sinal mais frequente é o tremor postural fino ou de ação, presente entre 4 a 20\% dos casos (Pogarell et al., 2006). O tremor é mais incidente e intenso quando associado ao uso de cafeína, antidepressivos e neurolépticos, e mais atenuado pelo uso concomitante de beta-bloqueadores (Pogarell et al., 2006). A grande maioria dos estudos envolvendo o sistema nervoso central recrutou voluntários saudáveis na avaliação dos efeitos cognitivos do lítio (Grandjean e Aubry, 2009a). A administração prolongada do lítio pode produzir 
efeitos negativos discretos no aprendizado, na vigilância, no alerta e na memória de curto-prazo (Honig et al., 1999; Stip et al., 2000). Em outra revisão sobre esse tópico, pacientes relataram lentificação mental e psicomotora após o uso da medicação (Pachet e Wisniewski, 2003). Num estudo placebo-controlado envolvendo ressonância magnética funcional foi demonstrado que o lítio produziu pequena mas significante redução de sinais cerebrais oxigênio-dependentes durante tarefas cognitivas (Bell et al., 2005). Geralmente, na prática clínica, os efeitos negativos na cognição são frequentes em memória, vigilância e tempo de reação (Honig et al., 1999). Todos os efeitos cognitivos relatados normalmente são leves. Excepcionalmente, alterações eletroencefalográficas, incluindo estado epiléptico não-convulsivo, e alterações cerebelares e extra-piramidais podem estar presentes (Granjean e Aubry, 2009b). Não há recomendação específica para o uso do lítio entre pacientes com epilepsia (Mula et al., 2004).

Algumas formas de exantema podem surgir durante a terapia com lítio. A droga pode exacerbar a psoríase. Uma dermatopatia de maior gravidade, a queratose folicular ou doença de Darier, uma genodermatose rara, pode ser muito agravada através do lítio, consistindo em uma contra-indicação absoluta à prescrição da droga (Granjean e Aubry, 2009b).

Laboratorialmente, o lítio pode reduzir o nível sérico de prolactina, diferentemente da maioria de outros psicotrópicos (Bastürk et al., 2001; El Khoury et al., 2003). No hemograma pode se observar aumento de leucócitos às custas de neutrófilos, em cerca de 1,5 vezes mais o limite superior do paciente (Inayat e Gallicchio, 2006). Alguma alteração no metabolismo glicêmico já foi descrita, incluindo o aparecimento de diabetes mellitus, contudo sem exploração da 
causalidade (Vendsborg e Prytz, 1976; Kuruvilla et al., 2001). A maioria de estudos controlados não associa o lítio diretamente à intolerância glicêmica ou diabetes, mas sim, o ganho de peso secundário ao uso da medicação (Granjean e Aubry, 2009b). Alterações inespecíficas de repolarização ventricular no eletrocardiograma, sem repercussão clínica, foram descritas concomitantes ao uso do lítio, perfazendo um total de 13 a 100\% dos pacientes, dependendo do estudo (Bierbrauer et al., 2006).

A disfunção tireoidiana é um dos efeitos adversos mais frequentemente observados durante a terapia com lítio, especialmente entre o sexo feminino (Baptista et al., 1997; Baptista et al., 2000; Livingstone e Rampes, 2006). A alteração do hormônio estimulante da tireóide ou tireotrofina (TSH) é o efeito mais comumente observado (Grandjean e Aubry, 2009a). Inicialmente não se acreditava que o lítio poderia provocar alterações tireoidianas. No entanto, atualmente reconhece-se que o tratamento pode inibir a produção de hormônios tireoidianos e induzir quadros clínicos de hipotireoidismo ou hipertireoidismo, até mesmo o aparecimento de bócio. Em revisão da literatura, tanto o hipotireoidismo clínico como o sub-clínico demonstraram maior prevalência entre os usuários de lítio (Kleiner et al., 1999). Em um estudo com 20 anos de seguimento a incidência de hipotireoidismo foi de 25/1000 sobreviventes-ano (Lazarus et al., 2006). A prevalência do hipotireoidismo clínico variou entre 8 e 19\% entre usuários de lítio quando comparada entre 0,5 a 1\% na população geral (Kleiner et al., 1999). Para os casos sub-clínicos, 23\% contra 10,3\%, respectivamente (Kleiner et al., 1999). Em estudo prospectivo, aproximadamente $40 \%$ dos pacientes desenvolveram hipotireoidismo, sendo mais precoce $(3,7$ contra 8,6 anos de lítio) naqueles que possuíam parentes de primeiro grau com a doença (Kusalic e Engelsmann, 1999). Em um grande estudo 
retrospectivo com 718 sujeitos, o hipotireoidismo apresentou prevalência de 10\%, com maior risco para usuários da droga do sexo feminino (14\% versus $4,5 \%$ ) (Johnston e Eagles, 1999). Um estudo randomizado e prospectivo sugeriu que o hipotireoidismo está associado a uma menor resposta ao uso do lítio (Frye et al., 1999).

A incidência de bócio tireoidiano esteve presente em $51 \%$ dos 150 pacientes ambulatoriais avaliados em um estudo clínico (Bocchetta et al., 1991). Neste estudo, $19 \%$ dos sujeitos apresentaram hipotireoidismo sub-clínico e 53\% se tornaram positivos para a presença de anticorpos antitireoidianos, apesar da ausência de casos de hipotireoidismo clínico. Os anticorpos, mais presentes em mulheres, foram positivamente correlacionados com a idade e o tempo do tratamento com o lítio. $\mathrm{O}$ declínio da função tireoidiana pode estar associado ou não com a presença de anticorpos antitireoperoxidase (Lazarus, 1998). A presença dos anticorpos pode ser ocasionada através de mecanismos imunomoduladores do lítio, induzindo elevação de seus títulos nos pacientes que já possuem esses anticorpos, sem evidência de indução primária dos mesmos (Lazarus, 1998). Na prática clínica, a dosagem de anticorpos tem valor questionável (Kleiner et al., 1999). Além disso, o lítio provavelmente atua no eixo hipotálamo-hipofisário resultando numa resposta exagerada do TSH à liberação do hormônio liberador de tireotropina, conforme encontrado em mais de 50\% dos pacientes em estudo prévio (Lazarus, 1999).

Recomenda-se que a função tireoidiana seja avaliada através de exames laboratoriais antes do início, após 3 meses e a cada 6 a 12 meses durante da terapia com lítio (Livingstone e Rampes, 2006). Caso o TSH esteja entre 5 a 10 mU/L, dosagens devem ser mais próximas, entre 1 a 3 meses. Se o TSH alcançar níveis 
acima de $10 \mathrm{mU} / \mathrm{L}$, recomenda-se introdução de levotiroxina independente da presença de sintomas, com a intenção de continuar com o tratamento com lítio (Kleiner et al., 1999).

Apesar de menos prevalente, o hipertireodismo também pode ocorrer na vigência de tratamento com lítio (Barclay et al., 1994). Foi sugerido que a disfunção fosse provocada pela indução de uma tireoidite autoimune (como na doença de Graves) ou simplesmente através da exacerbação de uma tireoidite silenciosa (Miller e Daniels, 2001). Em estudo retrospectivo de pacientes com hipertireodismo, a exposição ao lítio foi associada a um risco de 4,7 vezes maior para o desenvolvimento de tireoidite silenciosa (Miller e Daniels, 2001).

A utilização de lítio a longo prazo está associado com hiperparatireoidismo e hipercalcemia persistentes (Groleau, 1994). Mesmo com níveis normais ou baixos de fosfato, 10 a $42 \%$ dos pacientes desenvolvem algum grau de hipercalcemia sérica, sendo que $29 \%$ estão associados com elevação de hormônio paratireoidiano (PTH) (Grandjean e Aubry, 2009b). Em um estudo epidemiológico, pacientes tratados com lítio por mais de 15 anos apresentaram 3 a 6 vezes mais hipercalcemia quando comparado com a população geral (Bendz et al., 1996). Em outro estudo, prospectivo de 2 anos, pacientes que nunca tinham usado lítio anteriormente apresentaram elevação de PTH e aumento na reabsorção de cálcio juntamente com redução da excreção de cálcio, diferentemente do observado com o hiperparatireoidismo primário (Mak et al., 1998). Múltiplos relatos de caso associam o uso de lítio e o hiperparatireoidismo com adenomas únicos ou múltiplos das glândulas paratireóideas (Szalat et al., 2009). A hipermagnesemia é também frequentemente associada ao uso de lítio, chegando à 30\% dos casos (Groleau, 1994). Os sintomas de hipercalcemia 
demandam suspensão da terapia com lítio imediatamente. 


\subsection{Comprometimento renal}

Segundo a literatura, aproximadamente 20 anos de utilização de lítio seria o tempo para que um usuário pudesse desenvolver insuficiência renal grave. Dessa forma, pode-se calcular que não mais de 1:100 pacientes irão desenvolver esta complicação (ver o cálculo da prevalência anteriormente descrita, no item 1.3). Este cálculo é praticamente idêntico ao da prevalência de $1,2 \%$ de insuficiência renal relatado previamente por Bendz e colaboradores (2010) em estudo populacional.

A perda da função renal, assim como sua magnitude, permanecem controversos se avaliarmos as evidências apresentadas na maioria dos estudos clínicos (Paul et al., 2010; McKinight et al., 2012). Uma revisão de 14 estudos publicados antes de 1987 estimou uma prevalência para a redução na taxa de filtração glomerular (TFG) de 15\% (Boton et al., 1987). Contudo, diversos estudos realizados nas décadas de 1980 e 1990 não apresentaram mudanças significativas na TFG ou apenas uma ligeira deterioração funcional com o uso de lítio a longo prazo (Johnson et al., 1984; Jensen e Rickers, 1984; Jorgensen et al., 1984; Lokkegaard et al., 1985; Waller, 1988; Schou e Vestergaard, 1988; Povlsen et al., 1992; Kallner e Petterson, 1995). Cinco estudos mais recentes reportaram que entre 21 e $55 \%$ dos pacientes tratados com lítio apresentaram uma TFG estimada menor do que 60 $\mathrm{ml} / \mathrm{min} / 1.73 \mathrm{~m}^{2}$, correspondente ao ponto de corte para a fase 3 da lesão renal (Bendz et al., 1994; Bendz et al., 2001; Bassilios et al., 2008; McCann et al., 2008; Janowsky et al., 2009). Uma recente revisão sistemática selecionou 23 estudos que investigaram o efeito do uso do lítio sobre a função renal, dividindo-os em três categorias: estudos caso-controle transversais, estudos com observação pré e póstratamento com lítio, e observacionais de longo-prazo (Paul et al., 2010). Em todas 
as três categorias avaliadas houve aumento da creatinina em favor dos usuários de lítio, sendo somente significativo dentro da primeira e terceira categoria. O maior aumento da creatinina foi observado no terceiro grupo, com uma média de nível plasmático de aumento de 0,018 mg/dL/ano (Paul et al., 2010). A discussão acerca da perda de função renal é controversa quando revista a magnitude da evidência disponível na literatura, especialmente por existirem poucos estudos bem desenhados, como os randomizados e placebo-controlados e longa duração (McKnight et al., 2012).

O envolvimento glomerular é o terceiro comprometimento patológico renal possível em ordem cronológica entre usuários de lítio, apesar das evidências ainda produzirem maior controvérsia neste tópico quando comparada às alterações renais mais precoces como a redução da capacidade de concentração urinária máxima e o diabetes insipidus (Grünfeld e Rossier, 2009). A disfunção glomerular se traduz pela perda da capacidade de filtração renal, o que culmina em perda funcional e doença renal crônica. É aceito que o uso do lítio dentro da faixa terapêutica remete a uma perda da filtração glomerular em torno de $20 \%$ entre os usuários de longo-prazo (Grandjean e Aubry, 2009b). Em um estudo, pacientes em uso de lítio por mais de 15 anos foram recrutados entre 1986 e 1989 a partir de 149 sujeitos em seguimento ambulatorial (Bendz et al., 1996). Somente 13 sujeitos usuários de lítio (média de 10 anos em lítio; litemia média de 0,66 mmol/l) e 13 controles puderam ser incluídos no estudo. O primeiro grupo foi avaliado durante o tratamento na quinta e nona semana após a interrupção da droga. Apesar de não haver diferença significativa na TFG entre os grupos, após a suspensão da droga houve melhora da TFG entre os usuários. A capacidade de concentração urinária máxima não aumentou após a suspensão do 
lítio, permanecendo mais baixa no grupo recebendo lítio (Bendz et al., 1996). Num estudo retrospectivo da função renal dessa mesma coorte após 8-12 anos de seguimento clínico, observou-se que tanto a capacidade de concentração urinária e a TFG não estiveram mais reduzidos quando comparados com aqueles falecidos ou que interromperam o uso do lítio (Bendz et al., 2001). Dessa amostra, 21 pacientes faleceram, sendo um deles atribuído a quadro urêmico grave decorrente ao uso de lítio, e 42 sujeitos interromperam o uso da droga. Nos 63 pacientes restantes da amostra, a concentração urinária foi reavaliada, assim como a TFG em 29 sujeitos. Desta amostra, a redução da capacidade de concentração e da TFG foi significativa quando comparado à avaliação inicial. A redução da TFG foi associada à duração do tratamento e à idade, ao passo que a concentração urinária somente foi associada com o tempo de uso do lítio.

Estudo anterior envolvendo 207 pacientes tratados entre 1 a 30 anos com lítio, mantendo litemia média entre 0,6 e 0,8 mmol/L, observou níveis aumentados de creatinina sérica entre aqueles usuários por mais de 15 anos, sem ajuste com a idade do paciente (Kallner e Petterson, 1995). Em outro estudo, retrospectivo e comparativo, $21 \%$ dos pacientes em regime com lítio desenvolveram aumento de creatinina (Lepkifker et al., 2004). Tanto a duração do tratamento quanto a litemia não influenciaram no desenvolvimento de insuficiência renal. Em outro estudo clínico com 61 pacientes recebendo lítio por aproximadamente 15 anos, a sua função renal foi avaliada ao final de 11,5 anos de seguimento, e comparada com a de um grupo composto por 53 pacientes submetidos a eletroconvulsoterapia e 9 pacientes sob tratamento com outro estabilizador de humor (Tredget et al., 2010). Nos sujeitos usando lítio foi observada menor TFG (66,1 versus 75,0 $\left.\mathrm{mL} / \mathrm{min} / 1,73 \mathrm{~m}^{2}\right)$, com 
34,4\% apresentando níveis menores que $60 \mathrm{~mL} / \mathrm{min}$ contra 13,1\% dos controles e um paciente do primeiro grupo evoluindo com insuficiência renal dialítica após 6 anos de acompanhamento. A correlação entre o tempo de exposição ao lítio e a perda de função renal também não foi significativa neste estudo, em concordância com o estudo de Lepkifker e colaboradores (2004). Contudo, diferentemente dos dois estudos anteriores, McCann e colaboradores (2008), num estudo transversal e retrospectivo, encontraram correlação positiva entre o tempo de exposição ao lítio e a deterioração da função renal.

Poucos artigos publicaram casos de insuficiência renal progressiva e dialítica após o uso do lítio (Chugh et al., 1997). Uma razão óbvia é inerente ao princípio terapêutico da utilização da droga, no qual é altamente recomendado o controle da litemia e da função renal, conseguindo-se identificar precocemente tanto intoxicações quanto disfunções renais mais leves. Contudo, através de estudos com biópsias e ensaios imunohistoquímicos de casos em terapia com lítio, a incidência de lesões glomerulares focais é maior do que imaginado anteriormente (Markowitz et al., 2000). Presne e colaboradores (2003) acompanharam 74 usuários de lítio, dos quais 29 realizaram biópsia renal, entre 1970 e 2001. A perda anual da TFG foi de 2,29 $\mathrm{mL} / \mathrm{min}$ e 12 desses pacientes tiveram doença renal terminal ao atingirem a terceira idade. O grau de fibrose intersticial foi diretamente proporcional ao tempo de exposição ao lítio.

Um estudo recente publicou que 5\% dos sujeitos avaliados entre 40 e 69 anos, tratados com lítio, evoluíram com doença renal em estágio 4 (insuficiência renal dialítica) (Bassilios et al., 2008). Markowitz e colaboradores (2000) relataram oito pacientes que desenvolveram doença renal dialítica após 13,6 anos em tratamento 
com lítio. Um estudo sueco sobre a prevalência de insuficiência renal analisou os dados de pacientes em diálise ou transplante renal a partir de uma população de 2,7 milhões de pessoas. Um total de 18 pacientes de 3.369 tratados com lítio receberam o diagnóstico de doença renal dialítica, conferindo um risco 6 vezes maior para a doença do que o da população geral. A prevalência de doença renal crônica foi de 1,2\% e o risco para diálise foi 2,5 vezes maior entre os usuários de longa duração (maior que 15 anos) comparado com a população total de usuários de lítio (Bendz et al., 2010). Este estudo também observou que, mesmo com a interrupção da droga, caso o nível de creatinina estivesse acima de $2,5 \mathrm{mg} / \mathrm{dL}$, a disfunção renal continuava progressivamente (Bendz et a., 2010). Em estudo que avaliou pacientes em diálise em toda a França, o lítio foi associado como causa da insuficiência renal em 2 a cada 1000 sujeitos (Presne et al., 2003).

Um efeito adverso mais comum e mais precoce do que a insuficiência renal consequente da lesão glomerular é a redução da capacidade de concentração urinária causada pelo lítio (Grandjean e Aubry, 2009b). Cerca de 50\% dos pacientes em uso de lítio apresentam queda da concentração urinária. O mecanismo associado envolve quatro ações do lítio no rim, segundo modelos animais: 1) interferência na capacidade de gerar adenosina monofosfato cíclica (AMP) em resposta ao estímulo do hormônio antidiurético pela porção cortical das células do túbulo coletor (Grandjean e Aubry, 2009b); 2) inibição das adenosinas trifosfatases (Eiam-Ong et al., 1993); 3) supressão (downregulation) da síntese de aquaporinas (Marples et al., 1995); e 4) interferência na produção de prostaglandinas (Kotnik et al., 2005). O resultado clínico é a poliúria com consequente sede referida pelo paciente. Estudos de longa duração relatam em torno de $15 \%$ a incidência de diminuição da capacidade 
de concentração urinária de forma irreversível em usuários de lítio (Presne et al., 2003; Schou et al., 2006). Esse efeito pode ser mais frequente com a administração do lítio duas vezes ao dia quando comparado com uma única administração de liberação estendida (Kusalic e Engelsmann, 1996; Singh et al., 2011). Estudo utilizando outros marcadores de lesão renal, como a $\beta_{2}$-microglobulina (associado com lesão tubular proximal) e o glucosaminoglicano (componente da membrana basal glomerular) em 107 usuários de lítio entre 1-15 anos por doença bipolar, foram comparados com 29 controles com outros transtornos psiquiátricos (Coşkunol et al., 1997). O volume urinário de 24 horas e os marcadores utilizados no estudo estiveram elevados, enquanto a osmolaridade urinária esteve diminuída no grupo utilizando lítio. A excreção de $\beta_{2}$-microglobulina foi significativamente maior tanto nos pacientes com poliúria quanto naqueles com maiores comprometimentos da capacidade de concentração urinária. Contudo, não houve correlação entre a TFG e a duração da doença, o tratamento com lítio e as dosagens utilizadas da droga. O tempo de duração do tratamento com lítio também não foi relacionado com a alteração da capacidade de concentração urinária.

O quadro de disfunção tubular pode ser ainda mais complexo, passando de poliúria referida pelo paciente para o aparecimento de diabetes insipidus nefrogênico, definido por poliúria mensurada acima de 3 litros e urina hipotônica (razão da osmolalidade urinária pela plasmática menor do que 1) (Grandjean e Aubry, 2009b; Grünfeld e Rossier, 2009). Normalmente essa alteração é reversível até o tratamento a médio-prazo (em torno de 6 anos), passando a irreversível após um longo período de prescrição do lítio (em torno de 15 anos ou mais). Contudo, há relato de $27 \%$ de incidência de diabetes insipidus em curto seguimento (4 meses), 
associado de forma significativa ao uso conjunto de antidepressivos serotoninérgicos (Movig et al., 2003). Em outro estudo, pacientes com transtorno bipolar foram avaliados tanto para disfunção renal como para alteração da capacidade de concentração urinária, divididos em três grupos: 10 sem uso prévio de lítio, 10 com uso por curto-prazo e 10 com uso por longo-prazo (Turana et al., 2002). A depuração da creatinina nos pacientes com regime de longo prazo foi significativamente menor do que a dos outros dois grupos. Depois de 8 horas de privação de água e também após injeção de desmopressina, não foi encontrada diferença entre os grupos em termos de osmolalidade urinária. No entanto, quando cada paciente foi avaliado individualmente em termos de sua capacidade de concentração renal, observou-se diabetes insipidus nefrogênico parcial em quatro pacientes em longo prazo e em dois pacientes em tratamento de curto prazo. É interessante notar a presença de diabetes insipidus hipotalâmico diagnosticado em outros dois pacientes em tratamento a longo prazo (Turana et al., 2002). A indução de diabetes insipidus central já havia sido proposto experimentalmente em ratos (Martines-Maldonado et al., 1977).

Nos usuários de lítio, observa-se também alterações estruturais nos rins além das alterações funcionais já descritas. Achados anatomopatológicos em sujeitos tratados com lítio evidenciam nefropatia tubulointersticial crônica incluindo atrofia tubular e fibrose intersticial entremeadas por dilatações e cistos tubulares (Farres et al., 2003; Tuazon et al., 2008). As formações microcísticas, geralmente múltiplas, são vistas entre 33 e 62,5\% dos pacientes em exames de ressonância magnética, tanto em córtex como em medula, especialmente em regiões com atrofia e fibrose extensas (Farres et al., 2003; Tuazon et al., 2008). Normalmente, o acometimento é bilateral e esparso, sem exceder 1-2mm em diâmetro (Farres et al., 2003; Tuazon et al., 2008). 
Os cistos podem ultrapassar $3 \mathrm{~mm}$ e não se correlacionam com a presença de disfunção renal (Roque et al., 2012).

Como recomendação geral, deve-se evitar a prescrição de lítio para pacientes com insuficiência renal grave (Granjean e Aubry, 2009b). A síndrome nefrótica também constitui uma contra-indicação terapêutica (Schou, 1988). Em situações de diminuição de função renal, a dose obrigatoriamente deve ser ajustada. Tem sido proposto que após uma estimativa de filtração glomerular abaixo de $60 \mathrm{~mL} / \mathrm{min}$ ou um aumento da creatinina sérica em três ou mais ocasiões, realize-se uma avaliação complementar com avaliação de proteinúria, glicosúria, hematúria, além da verificação da pressão arterial (Morriss et al., 2008). De acordo com recomendações recentes, os pacientes com TFG menores que $60 \mathrm{ml} / \mathrm{min} / 1,73 \mathrm{~m}^{2}$ exigem um acompanhamento mais intensivo (Morriss e Benjamin, 2008; Kripalani et al., 2009). A interrupção precoce de lítio poderia prevenir a doença renal terminal. Lepkifker e colaboradores (2004) relataram que em 24 pacientes com creatinina sérica de 1,5 $\mathrm{mg} / \mathrm{dl}$ cujo lítio foi retirado ou reduzido, 15 pacientes tiveram os níveis de creatinina estabilizado, e em nove deles houve piora. De acordo com Markowitz e colaboradores (2000) poderia ser tarde demais para evitar a diálise caso o lítio fosse interrompido após se atingirem níveis de creatinina de $2,5 \mathrm{mg} / \mathrm{dl}$ ou mais. Presne e colegas (2003) relataram que com uma TFG maior que $40 \mathrm{ml} / \mathrm{min}$ a função renal apresentou melhora entre cinco de sete pacientes após a interrupção do lítio. Quando a TFG foi menor que $25 \mathrm{ml} / \mathrm{min}$, a deterioração da função renal continuou em todos os pacientes. Janowsky e colaboradores (2011) avaliaram 16 pacientes usuários de lítio com deficiência intelectual e insuficiência renal (pico de creatinina em 1,5 mg/dL) em estudo caso-controle entre 1980 e 2010. O tempo médio até o nível da 
creatinina atingir $1,5 \mathrm{mg} / \mathrm{dL}$ foi de 7,9 anos. Após a interrupção do lítio não houve alteração da função renal. O fator preditivo identificado para atingir uma creatinina de $1,5 \mathrm{mg}$ foi um valor anterior de $1,3 \mathrm{mg} / \mathrm{dL}$. Outros fatores como idade na qual o lítio foi iniciado, creatinina de base, tempo de uso do lítio, gênero ou raça não diferenciaram aqueles que evoluíram com insuficiência renal (Janowsky et al., 2011). 


\subsection{Segurança clínica para grupos especiais sob lítio}

\subsubsection{Gênero}

O sexo feminino parece ter maior sensibilidade aos efeitos adversos do lítio, especialmente relacionado à função renal, hipotireoidismo e ganho ponderal (Granjean e Aubry, 2009b).

\subsubsection{Idade}

Em pacientes idosos, os níveis terapêuticos devem ser menores (isto é, entre 0,5 e 0,8 mmol/L), reduzindo-se a dose prescrita em 25-50\% (Granjean e Aubry, 2009b). Os efeitos adversos podem ser mais frequentes em razão de doença renal subjacente e demência, além do uso de medicações que favorecem a intoxicação pelo lítio, tais como tiazídicos, IECA, AINEs (Eastham et al., 1998). Alguns efeitos adversos, em especial o tremor, ataxia, poliúria, sede, náusea, diarréia, hipotireoidismo e psoríase, são menos tolerados pelos idosos (Head \& Dening, 1998; Shulman \& Herrmann, 1999).

Em 2002, o primeiro estudo placebo controlado a relatar efeitos colaterais da terapia com lítio em idosos, não encontrou diferença significativa destes entre os grupos (Wilkinson et al., 2002). Os sintomas descritos foram: fome, poliúria, sede, gosto metálico, insônia, dificuldade em memória, tremor e distúrbios gastrointestinais. A conclusão dos autores foi que a ausência da diferença entre os grupos foi resultado do baixo nível terapêutico utilizado $(0,43 \mathrm{mmol} / \mathrm{L})$. 
Contudo, grupos de especialistas não recomendam o uso rotineiro de lítio para idosos em razão do risco de intoxicação e potenciais efeitos colaterais na memória (Caer-Frouard et al., 2006).

\subsubsection{Doença cardiovascular}

Pacientes com doença cardiovascular requerem cautela na prescrição de lítio. Naqueles com hipertensão arterial sistêmica, insuficiência cardíaca ou doença coronária, o uso de diuréticos, IECA e dieta pobre em sódio é frequente (Guedi et al., 1996). Apesar de raro, o lítio é associado ao aparecimento de arritmias cardíacas. Além desses fatores, a filtração glomerular costuma ser menor nos portadores de insuficiência cardíaca assim como o fluxo arterial renal nos hipertensos, o que potencialmente contribui com uma maior chance de intoxicação pelo lítio. Nos casos de surgimento de evento coronariano agudo ou subagudo, é recomendado que o lítio seja evitado (Guedi et al., 1996). 


\subsection{Particularidades na prescrição de lítio em idosos}

A prevalência de usuários de lítio idosos foi avaliado no estudo Cambridge Mental Health Services, representando 0,27\% da população local (Head \& Dening, 1998). Este estudo apontou para uma prevalência maior do que a descrita em estudos com populações adultas. Quase a metade desses pacientes não passaram em consulta com um psiquiatra nos últimos 12 meses e apenas um terço apresentava controle de litemia conforme orientações de consenso local. Na população avaliada, $32 \%$ estavam em uso de hormônio tireoidiano ou tinham seu TSH alterado.

Ainda existem divergências quanto à litemia ideal para o tratamento do transtorno bipolar em idosos. Na prática clínica, com a monitorização dos níveis plasmáticos da droga, observa-se que os indivíduos acima dos 65 anos necessitam menores doses para atingirem a concentração plasmática do estado de equilíbrio. Alguns estudos demonstram boas respostas abaixo do limite inferior, enquanto outros mostram que as litemias devem seguir os valores preconizados para os adultos, estando entre 0,8mEq/L e 1,2mEq/L (Eastham et al., 1998). Há pouco mais de 30 anos, notou-se que os pacientes idosos necessitavam de menores doses de lítio para atingirem litemia semelhante em adultos mais jovens. Hewick e colaboradores avaliaram a dose de lítio necessária para atingir uma litemia de $1 \mathrm{mmol} / \mathrm{L} \mathrm{em}$ pacientes entre 70 e 79 anos e encontraram uma dose $31 \%$ menor do que a dos adultos menores de 50 anos (Hewick et al., 1977). Uma correlação entre idade e quantidade de lítio administrada foi também encontrada em outros estudos (Slater et al., 1984; Vestergaard \& Shou, 1984). Em um desses estudos, além da relação inversamente proporcional entre idade e dose terapêutica, a redução desta foi semelhante ao estudo de Hewick e colaboradores, sendo $34 \%$ menor para os idosos 
(Vestergaard \& Shou, 1984). Um estudo comparou pacientes idosos com dois grupos etários mais jovens, com médias etárias em 34,9 e 53 anos. Com relação ao primeiro grupo, os idosos necessitaram doses $36 \%$ menores, enquanto que para o segundo, $20 \%$ menores (Greil et al., 1985).

A redução da dose para a população idosa varia entre 25-35\% (Sproule et al., 2000). Apesar das alterações gastrointestinais fisiológicas nessa faixa etária, como aumento do pH gástrico e redução do fluxo sanguíneo local, a absorção do lítio não parece estar alterada em idosos. A biodisponibilidade, da mesma forma, não se altera, uma vez que não existe efeito de primeira passagem do lítio. No entanto, o Vd é diminuído por alterações fisiológicas do envelhecimento (por exemplo: aumento da composição de gordura, diminuição da água corporal). O Vd do lítio é influenciado principalmente pelo compartimento de água corporal total, uma vez que a droga não se liga a proteínas ou tecidos. No envelhecimento, há diminuição da água corporal em detrimento de aumento da gordura. Consequentemente, uma vez que os idosos possuem menos água para a distribuição do medicamento, há concentração do lítio tende a subir.

A depuração renal também diminui graças ao envelhecimento desse órgão. Estudos demonstram uma queda de filtração glomerular em torno de $10 \mathrm{~mL} / \mathrm{min}$ por década após os 30 anos de idade (Rowe et al., 1976; Lindeman et al., 1985). Um estudo transversal (van Melick et al., 2008) tentou avaliar o impacto do uso do lítio na filtração glomerular renal e na capacidade de concentração renal máxima (Umax) em idosos. O estudo envolveu 48 idosos (idade média de 74,8 anos) em litioterapia por mais de seis meses (média de 9,2 anos) com avaliação da filtração glomerular através da fórmula de Cockroft-Gault e da Umax (urina de 3 a 5 horas após 40mcg 
de desmopressina intranasal). Não houve correlação em relação ao tempo de litioterapia e filtração glomerular. Houve correlação negativa entre Umax e tempo de utilização de lítio. Entre os participantes do estudo, 73\% apresentaram defeito moderado a grave de concentração renal. Não houve outros fatores de risco associados a alteração renal observada. A Umax reduzida foi associada à poliúria (>2500 mL em 24 horas) em 33\% dos sujeitos.

A tolerância de idosos ao lítio foi avaliada em alguns estudos. Num estudo piloto, $76 \%$ dos pacientes foram intolerantes aos efeitos adversos, com litemia média de 0,63 (Stoudemire et al., 1988). Os efeitos mais comuns foram: tremores, náuseas, vômitos, declínio cognitivo, sedação ou fadiga. Em outro estudo, com litemias entre 0,3 e $0,5 \mathrm{mmol} / \mathrm{L}$, os efeitos adversos relatados não foram significantes (Hardy et al., 1997). O tremor é o efeito adverso mais comum do lítio em idosos, variando de 17,4\% em pacientes ambulatoriais (Holroyd \& Rabins, 1994) a $40 \%$ naqueles internados (Smith \& Helms, 1982). Seu aparecimento independe da litemia e é progressivamente pior com o avançar da idade (Murray et al., 1983). O efeito do lítio na tireóide de idosos foi estudado em 148 idosos recebendo lítio, com 32\% evoluindo com reposição hormonal ou TSH muito elevados (Head \& Dening, 1998). Um estudo clássico com 344 idosos apresentou 6\% de elevação relevante no TSH e 14\% de aumento discreto (Sawin et al., 1979). Outro estudo transversal avaliou a tolerância e os efeitos adversos do lítio em 20 pacientes octagenários (Fahy \& Lawlor, 2001). As funções renal e tireoidiana, assim como impacto de efeitos adversos, foram estudados a partir da revisão de prontuários durante 53,7 meses de tratamento com lítio, mantendo litemia média de $0,42 \mathrm{mmol} / \mathrm{L}$. Apesar do lítio não ter sido descontinuado, a função renal demonstrou alterações transitórias. Um paciente 
desenvolveu diabetes insipidus no período, enquanto uma idosa apresentou hipotireoidismo.

Um estudo populacional canadense avaliou a admissão hospitalar por intoxicação de lítio e uso de diuréticos, inibidores da enzima de conversão de angiotensina e AINEs (Juurlink et al., 2004). Foram identificados 10.615 idosos recebendo lítio entre 1992 e 2001. Desses, 3,9\% foram internados por intoxicação pela droga. Um aumento do risco para o evento foi identificado nos pacientes que iniciaram o primeiro mês de uso de um diurético de alça ou IECA. Tanto diuréticos tiazídicos como AINEs não foram associados ao risco.

Recomenda-se a dose entre 150 e $300 \mathrm{mg} /$ dia para idosos acima de 80 anos ou com critérios de fragilidade. Obviamente a variação entre indivíduos e o julgamento clínico são primordiais nessa decisão. 


\subsection{Intoxicação por lítio}

A intoxicação por lítio pode ser classificada em aguda, quando o paciente não recebia lítio previamente; aguda sobre o uso crônico, quando o usuário recebe uma dose aumentada sobre seu regime; e crônica, a qual é definida no usuário sem alteração de seu esquema terapêutico (Bailey e McGuigan, 2000). A cada ano, centros de referência em intoxicação relatam aproximadamente 5.000 casos atribuídos ao uso de lítio, mas com baixa mortalidade, sem atingir 10 casos (Litovitz et al., 1999; Watson et al., 2005). O quadro agudo é dominado por sintomas do sistema nervoso central e gastrointestinal, tais como confusão mental, sinais cerebelares, náuseas e vômitos. Poliúria, polidipsia e até diabetes insipidus podem estar presentes também. Sinais e sintomas menos comuns são: sinais extrapiramidais e neuromusculares (fasciculações e mioclonia), polineuropatias, arritmias, hipotensão, insuficiência respiratória e distúrbios de termorregulação. Normalmente os episódios agudos são rapidamente identificados, não se correlacionam com a litemia e trazem menor risco ao paciente (Jaeger et al., 1993). Em casos de litemia alta, o lítio induz um processo de auto-inibição de excreção renal, resultando em acúmulo do mesmo e deterioração clínica. O maior grupo de intoxicações consiste nos casos agudos sobre usuários crônicos e são subestimados. Mesmo casos de litemia moderadamente alta são associados a quadros graves e muito sintomáticos. Usualmente a eliminação da droga está prolongada, semelhantemente aos casos crônicos. Estes, possuem ainda melhor correlação entre litemia, sintomas e prognóstico, ocasionados por mudança na dose diária, doses mais altas usadas cronicamente, mudança dos níveis de sódio ou água corporal, doença renal, interação medicamentosa, infecção concomitante ou cirurgia (Hansen e Amdisen, 1978; 
Granjean e Aubry, 2009b).

A conduta na intoxicação consiste no suporte clínico para pacientes graves, com o incremento de lavagem estomacal quando há tempo hábil, hidratação endovenosa, correção de sódio quando necessário e suporte dialítico em casos extremos. O carvão ativado não produz efeito em substâncias carregadas eletricamente, caso dos sais de lítio. O regime dialítico, quando necessário, é mais eficaz através da hemodiálise, com capacidade de depuração de $50 \mathrm{~mL} / \mathrm{min}$, quando comparado a peritoneal (15 mL/min) (Simard et al., 1985; Dawson e Whyte, 1999). Dentre os critérios utilizados para a diálise, destacam-se: litema acima de 3,5-4,0 mmol/L, sintomas de gravidade (coma, convulsões, insuficiência respiratória, deterioração rapidamente progressiva) e considerações farmacocinéticas relevantes ao caso (Simard et al., 1985; Dawson e Whyte, 1999). Em razão do lento equilíbrio compartimental do lítio entre o plasma e tecíduos, a hemodiálise normalmente é repetida ou realizada novamente caso a litemia persista acima de 1,0 mmol/L (Dawson e Whyte, 1999). Em caso de retorno do lítio, as doses devem ser menores em razão da possível liberação de estoques ósseos da droga (Granjean e Aubry, 2009a).

$\mathrm{Na}$ tentativa de se evitar a intoxicação, algumas medidas podem ser realizadas, tais como: dosar a creatinina e o cálcio sérico a cada 6-12 meses; avaliar o estado tireoidiano a cada 6 meses nos 3 primeiros anos e anualmente após esse prazo; monitorar hidratação, possíveis infecções, ingesta de sódio e uso de drogas prescritas concomitantemente (Granjean e Aubry, 2009b). 


\section{OBJETIVOS}

\subsection{Objetivo principal}

O objetivo principal é avaliar a evolução da função renal, através da creatinina sérica e de medidas de estimativa padronizadas para o cálculo da depuração de creatinina em 24 horas, em idosos usuários de lítio em baixa dosagem seguidos ao longo de 4 anos.

\subsection{Objetivo secundário}

Como objetivos secundários, pretende-se avaliar a evolução dos seguintes parâmetros em nossa amostra de pacientes idosos ao longo de 4 anos:

2.2.1. a segurança clínica do paciente usuário de lítio, através de questionário específico para reações adversas (UKU) e avaliação clínica geral.

2.2.2. a função tireoidiana através dos hormônios $\mathrm{TSH}_{\mathrm{H}} \mathrm{T} \mathrm{T}_{4}$ livre.

2.2.3. a contagem leucocitária total, neutrofílica e linfocitária.

2.2.4. a evolução do metabolismo glicêmico através da glicemia e insulina de jejum e do cálculo da resistência insulínica (HOMA-IR) concomitantemente. 


\section{HIPÓTESES}

O uso do sal de lítio para tratamento de pacientes idosos pode ser seguro, inclusive contra disfunções orgânicas graves como a insuficiência renal.

A utilização de litemia baixa, mais adequada aos idosos, assim como um seguimento clínico frequente possivelmente poderão evitar maiores reações adversas e lesões orgânicas.

Dessa forma, um estudo randomizado e controlado poderá avaliar mais adequadamente estas hipóteses ao contrário de estudos de coorte e caso-controle evidentes até o momento. 


\section{JUSTIFICATIVA}

Esta tese justifica-se sobre dois pilares:

1) $\mathrm{O}$ tratamento baseado em sais de lítio é referência em doenças psiquiátricas muito relevantes e prevalentes como o transtorno afetivo bipolar e a depressão unipolar. Dessa forma, a melhor exploração da segurança na utilização dos sais de lítio é mandatória.

2) Não há forte evidência científica baseada em ensaio clínico, randomizado, duplo cego, placebo-controlado, que explore a evolução da função renal, principalmente, assim como outras possíveis reações adversas nos usuários de lítio, especialmente dentro do grupamento geriátrico, que possui alto risco potencial de complicações secundárias deste tratamento. 


\section{MÉTODOS}

O atual estudo deriva do Projeto Temático "Lítio, neuroproteção e memória: das bases moleculares à aplicação clínica”. Este ensaio clínico randomizado, duplocego, placebo-controlado, foi desenhado para a avaliação do lítio como terapia modificadora da doença para pacientes idosos com CCL, assim como para avaliar a segurança do uso do lítio nestes pacientes idosos. O Projeto Temático foi dividido didaticamente em três módulos: o Módulo 1 compreendeu os estudos de orientação clínica (avaliação dos efeitos do lítio sobre parâmetros cognitivos em pacientes portadores de CCL); o Módulo 2 compreendeu os estudos de interface clínicolaboratorial (marcadores biológicos e eletrofisiológicos); e o Módulo 3 incluiu os estudos laboratoriais propriamente ditos (modelos animais e celulares). O projeto desta tese (dentro do Módulo 2) consistiu em um dos dois braços clínicos principais deste temático: a avaliação da segurança clínica dos usuários de lítio, com foco principalmente sobre a função renal dos participantes do ensaio. $\mathrm{O}$ outro braço clínico do projeto constituiu na avaliação de parâmetros cognitivos e neurobiológicos dos pacientes submetidos ao tratamento com lítio (Forlenza et al., 2011). O presente estudo possuiu uma fase randomizada e placebo controlada de 2 (dois) anos, seguida de uma fase aberta com seguimento de mais 2 (dois) anos.

Dois médicos clínicos (Ivan Aprahamian e Franklin Santana Santos) foram responsáveis pela avaliação da segurança e seguimento trimestral dos pacientes envolvidos no estudo. 


\subsection{Amostra}

Cinquenta e nove pacientes com CCL pareados pelo nível de escolaridade foram incluídos neste estudo de segurança durante os 4 anos de acompanhamento. A Figura 1 esquematiza o recrutamento de sujeitos segundo sua distribuição em cada ano de seguimento. Durante os 4 anos de seguimento, 35 participantes descontinuaram antes do final do estudo. Quatro pacientes abandonaram o primeiro ano em razão de falecimento por broncopneumonia (1), acidente vascular encefálico isquêmico (1) e perda de contato (2). No segundo ano, mais 4 participantes descontinuaram por tratamento de câncer (1), complicações clínicas diversas (2) e intolerância ao lítio (1). Após a fase duplo-cego, 7 pacientes desistiram de participar do estudo, 6 foram afastados por complicações clínicas, 3 para tratar câncer, 1 por acidente vascular encefálico isquêmico e 1 por sofrer cirurgia de grande porte. No último ano, 2 pacientes desistiram de continuar o estudo, 2 foram afastados após sofrerem cirurgias de grande porte, 2 após acidente vascular encefálico isquêmico e 2 por complicações clínicas, e finalmente 1 para tratamento oncológico.

Todos os participantes eram idosos de ambos os sexos com idade maior ou igual a 60 anos e com escolaridade mínima de 4 anos. Para atender aos objetivos dos Módulos 1 e 2 foram recrutados pacientes com CCL que frequentavam o ambulatório de Psiquiatria Geriátrica do Laboratório de Neurociências (LIM-27) do Instituto de Psiquiatria do Hospital das Clínicas da Faculdade de Medicina da Universidade de São Paulo (HCFMUSP). Os pacientes tiveram seguimento mínimo de dois anos na fase controlada até o término do projeto em quatro anos. 
Figure 1. Distribuição dos sujeitos avaliados no estudo segundo o grupo de tratamento e o ano de avaliação.

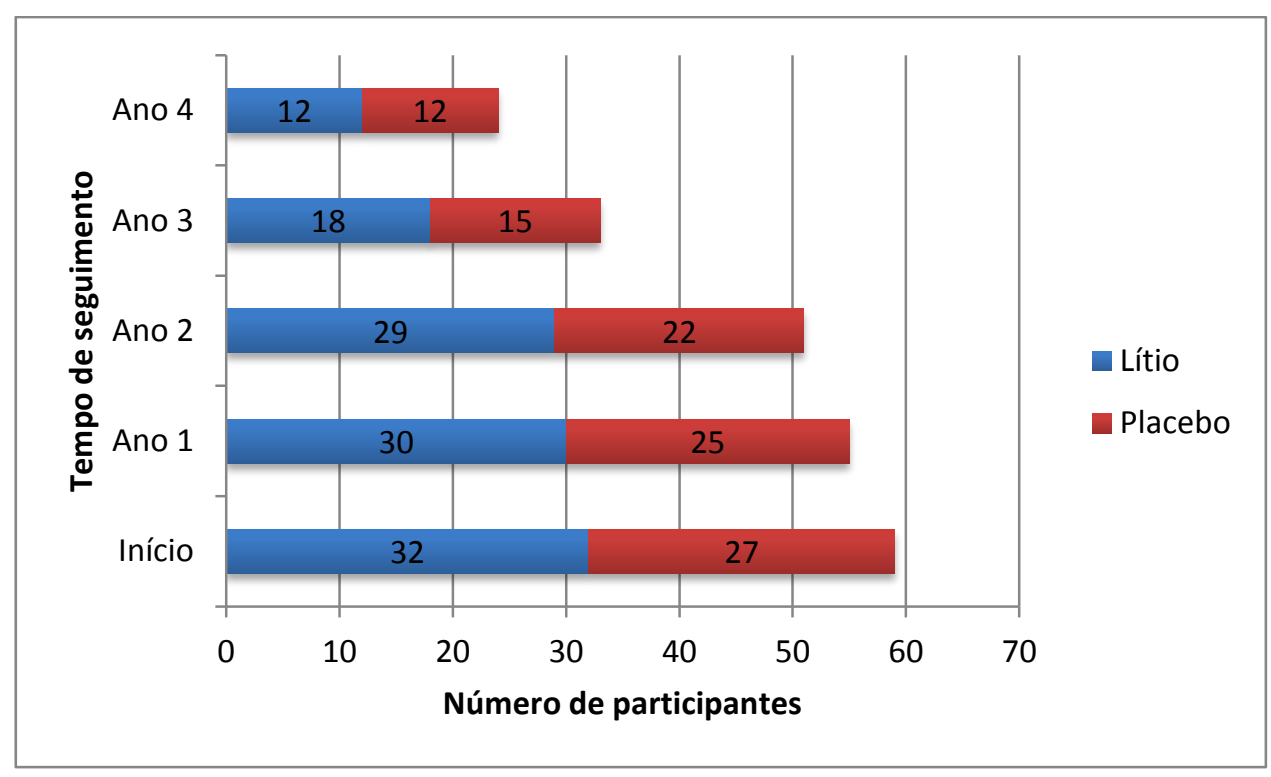

Foram excluídos da amostra os pacientes que apresentaram síndromes demenciais, deficiências visuais ou auditivas disfuncionais, condições gerais de saúde gravemente alteradas que inviabilizassem o uso do lítio devido a potenciais interações medicamentosas graves, contra-indicação absoluta ao lítio, incapacidade para a execução de testes neuropsicológicos ou para realizar exames complementares subsidiários. Também foram excluídos os indivíduos com antecedentes de uso prévio do lítio ou que fossem portadores de doenças ou condições clínicas que possam se agravar pelo uso do lítio. Os sujeitos receberam tratamento com carbonato de lítio, randomicamente, em doses suficientes para perfazerem a inibição da enzima GSK-3 $\beta$ (baixa dosagem de litemia). As doses de lítio para inibição enzimática foram testadas e avaliadas tanto experimentalmente quanto clinicamente dentro de nosso laboratório.

Os critérios diagnósticos utilizados para os participantes do estudo foram: 
1) Comprometimento Cognitivo Leve (CCL): O diagnóstico de CCL obedece aos critérios estabelecidos pela Classificação Internacional das Doenças (CID-10) para Comprometimento Cognitivo Leve (F06.7), corroborado, sempre que possível, pelos critérios de Petersen para a condição descrita como Mild Cognitive Impairment (Petersen et al., 1999), isto é: (1) queixa de perda de memória feita pelo paciente e/ou corroborada pelo acompanhante; (2) déficit de memória comprovado por meio de exame neuropsicológico (adiante), capaz de caracterizar desempenho de memória inferior à normalidade ( $\leq 1,5 \mathrm{DP})$, levando-se em conta as normas estabelecidas para a respectiva faixa etária e nível educacional; (3) ausência de comprometimento de outras funções cognitivas; (4) capacidade de desempenhar atividades da vida diária preservada; (5) ausência de demência.

2) Demência da doença de Alzheimer (DA): diagnóstico de DA provável ou possível, segundo os critérios diagnósticos NINCDS-ADRDA (McKhann et al., 1984). 


\subsection{Instrumentos de avaliação clínica}

Para a avaliação dos parâmetros cognitivos, os pacientes foram avaliados através do instrumento Alzheimer's Disease Assessment Scale - cognitive subscale (ADAS-Cog) e pelo Clinical Dementia Rating (CDR) nas versões brasileiras. Todos os participantes coletaram amostras de sangue periférico e líquido cefalorraquiano para a determinação, respectivamente, de polimorfismos genéticos e marcadores biológicos para a DA, assim como parâmetros clínicos e laboratoriais gerais relevantes para usuários de lítio. Os participantes foram avaliados a cada três meses para a realização do exame clínico, o controle das litemias e o rastreio de eventos adversos, utilizando a escala padronizada UKU para reações adversas, e semestralmente para a determinação do estado cognitivo. Em ambos os casos, os avaliadores não tinham conhecimento dos grupos terapêuticos a que pertenciam os pacientes. A UKU (Ugvalg for Kliniske Undersgelser) é uma escala detalhada para avaliação de efeitos colaterais medicamentosos compreendendo os seguintes 4 grupos de efeitos colaterais: psíquicos, neurológicos, autonômicos e outros. Cada item é avaliado numa escala de zero (ausente) a 3 (grave). Para cada item é assinalada a relação causal com a medicação em uso (improvável, possível e provável). Há também um item de avaliação global da interferência dos efeitos colaterais no desempenho das atividades diárias do paciente $(0=$ sem efeitos colaterais a 3=efeitos colaterais interferindo marcadamente no desempenho das atividades), julgado tanto pelo paciente como pelo médico; outro item avalia a consequência da interferência: de 0, nenhuma ação, a 3, descontinuação da medicação. A folha de avaliação clínica assim como a tabela UKU encontram-se no Anexo I. 


\subsection{Exames complementares}

O diagnóstico diferencial da síndrome demencial foi estabelecido com o auxílio de exames laboratoriais e de imagem cerebral, realizados no Complexo HCFMUSP através da rotina de atendimento ambulatorial. Segundo o protocolo do estudo, foram solicitados de rotina os seguintes exames: hemograma, glicemia e insulina de jejum, hemossedimentação, testes de lesão hepática (transaminases TGO e TGP) e função renal (uréia e creatinina), níveis séricos de principais eletrólitos (sódio, potássio, magnésio, cálcio e fósforo), provas de função tireoidiana (hormônio tireoestimulante, TSH, e tiroxina livre, $\mathrm{T}_{4} \mathrm{~L}$ ), níveis séricos de vitaminas (B12 e ácido fólico), sorologia para sífilis (VDRL), eletrocardiograma e neuroimagem estrutural. Outros exames laboratoriais ou de neuroimagem eram solicitados segundo indicação clínica (por exemplo, ultra-som doppler de carótidas ou SPECT e PET cerebral). 


\subsection{Administração dos tratamentos: randomização}

Pacientes portadores do CCL foram randomizados a uma razão de 2:1 para receberem tratamento com lítio ou placebo. Os pacientes do grupo "lítio" (32 sujeitos) receberam alternativamente cápsulas de carbonato de lítio, formuladas magistralmente nas doses de 150mg, 300mg, 450mg ou 600mg, e prescritas suficientemente para atingirem e manterem litemias de $0,25 \mathrm{mEq} / \mathrm{L}$ a $0,5 \mathrm{mEq} / \mathrm{L}$. Os indivíduos do grupo controle (27 sujeitos) receberam cápsulas destituídas de princípio ativo (placebo). Todas as cápsulas foram visualmente idênticas, e eram administradas em duas tomadas diárias, sendo uma a duas cápsulas pela manhã e à noite, conforme a prescrição para perfazerem os níveis terapêuticos desejados, e para que a dose da medicação possa ser ajustada sem diferenciar os grupos pelo número de comprimidos ingeridos em cada horário.

O estudo foi conduzido segundo o modelo duplo-cego. Os médicos e psicólogos encarregados do seguimento dos pacientes não foram informados do grupo em que cada paciente se encontrava. A administração dos tratamentos foi feita por um médico assistente de pesquisa (no caso o investigador principal, Orestes Vicente Forlenza), que não terá acesso aos dados clínicos e neuropsicológicos, mas poderá ser informado, pelos médicos responsáveis pelos atendimentos para avaliação de segurança clínica, da necessidade de interrupção da medicação ou redução de sua dose, na vigência de eventos adversos ou intolerância. Foram confeccionados envelopes datados, que contém a medicação para cada dia de uso, e foram dispensados pelo assistente de pesquisa, tendo como base o conhecimento dos grupos experimentais e respectivas litemias-alvo. 
Com o objetivo de se definirem as menores doses de carbonato de lítio (e respectivas litemias) necessárias para modificar a expressão e a atividade da GSK$3 \beta$, foram realizados, antes do início dos tratamentos, experimentos in vitro e in vivo, além de ensaio em voluntários normais. Os dados obtidos nestes experimentos preliminares dentro de nosso laboratório orientaram uma redução das doses utilizadas nos grupos tratados com carbonato de lítio. 


\subsection{Avaliação da função renal}

A função renal foi avaliada com base nos exames laboratoriais realizados pelos participantes do projeto ao longo dos quatro anos do estudo. Utilizou-se a creatinina sérica como marcador da função renal, respeitando a apresentação clínica do paciente para situações que poderiam falsear a real função renal, tais como descompensações diabéticas ou hipertensivas, estados de desidratação ou infecção, tratamento farmacológicos, e comprometimento obstrutivo dos rins e vias urinárias. Quando necessário a dosagem era repetida no momento clinicamente mais adequado. Em razão da limitação na utilização isolada da creatinina como expressão da função renal, utilizamos duas fórmulas padronizadas internacionalmente para a estimativa da taxa de filtração glomerular: a MDRD abreviada (aMDRD) e a CKD-EPI (Fliser, 2008; Earley et al. 2012).

A taxa de filtração glomerular (TFG) corresponde ao volume filtrado através dos capilares glomerulares para dentro da cápsula de Bowman por unidade de tempo. A TFG pode ser calculada através da avaliação de qualquer substância presente no sangue que seja excretada livremente pelo rim, sem reabsorção ou secreção pelos rins. É normalmente referida em volume por tempo (como por exemplo, $\mathrm{ml} / \mathrm{min}$ ). Há diversas formas para se calcular ou estimar a GFR. O cálculo padrão-ouro utiliza a coleta de urina de 24 horas, o que é difícil para a aderência em grupos especiais como o dos idosos. Frequentemente, utiliza-se fórmulas para estimar a função renal. Estas fórmulas, mais simples e diretas, possuem boa correlação com a depuração de creatinina de 24 horas (Fliser, 2008). Os valores normais de TFG, ajustados pela área de superfície corporal, são semelhantes entre homens e mulheres, variando entre 
100-130 ml/min/1.73m². Após 40 anos, a TFG diminui progressivamente com a idade por volta de $0.4-1.2 \mathrm{ml} / \mathrm{min} / \mathrm{ano}$.

Na prática clínica, as estimativas de TFG se concentram na utilização da creatinina sérica. A creatinina é produzida naturalmente no músculo através da quebra do fosfato de creatina, sendo então originada em decorrência do balanço entre o catabolismo muscular e sua excreção renal. Os níveis de creatinina teoricamente são estáveis em pessoas saudáveis. Nos indivíduos com função renal normal, a creatinina sérica varia entre 0,8 a 1,3 em homens e 0,6 a $1,0 \mathrm{mg} / \mathrm{dL}$ em mulheres (Fliser, 2008). É livremente filtrada no glomérulo, mas ativamente secretada em pequenas quantidades por capilares peritubulares, provocando uma superestimativa da TFG em 10-20\%. Esta margem é aceitável em razão da praticidade do uso da creatinina, ao contrário da inulina, por exemplo, na qual se faz necessária sua infusão para se realizar a medida da TFG. Todas as fórmulas utilizam a creatinina, dependente da condição muscular do paciente nas últimas 24 horas.

As fórmulas são a maneira mais comum de se realizar a estimativa da função renal, sendo as mais utilizadas e validadas, a fórmula de Cockroft-Gault e a Modification of Diet in Renal Disease (MDRD) (Fliser, 2008). A primeira superestima a GFR em pessoas normais ou com disfunção leve, especialmente em idosos (especialmente em muito idosos). Apesar disso, é bem aceita como estimativa de função nessa população. A MDRD com seis variáveis e a versão abreviada são melhores em idosos do que a fórmula de Cockroft-Gault (Verhave et al., 2005). O único problema é a estimativa da superfície corporal utilizada na MDRD original, com menor praticidade clínica. A fórmula MDRD mais utilizada é a versão abreviada (aMDRD) com quatro variáveis (creatinina sérica, idade, raça e gênero), 
excluindo o cálculo da superfície corporal e que não requer a utilização de albumina ou de uréia séricas, que foi desenvolvida para simplificação do seu uso no cotidiano clínico (Kallner et al., 2008). Estudos recentes observaram que a aMDRD fornece valores de função renal muito próximos da realidade (Froissart et al., 2005; Poge et al., 2007). As fórmulas MDRD foram validadas em pacientes com doença renal crônica. Contudo, todas as versões subestimam a TFG em adultos saudáveis com mais de $60 \mathrm{ml} / \mathrm{min} / 1.73 \mathrm{~m}^{2}$ (Rule et al., 2004). Uma vez que essas fórmulas não são ajustadas por peso, elas subestimam TFG para obesos e superestimam para pessoas com baixo peso. Em razão da MDRD atingir melhor acurácia em TFG mais baixas, utilizamos a equação CKD-EPI que, juntamente com a MDRD, formam as duas fórmulas mais validadas na atualidade para a estimativa da função renal, e que apresenta melhor acurácia com TFG mais altas (Early et al., 2012). Dessa forma, a utilização das duas fórmulas diminuiria a possibilidade de erros na avaliação dos pacientes do estudo.

Particularmente nos idosos o uso isolado da creatinina para avaliação da função renal não é recomendado em razão da redução da massa muscular. Como descrito acima, a depuração da creatinina pode ser estimada através de equações que levam em consideração a idade, raça, creatinina, peso, entre outros fatores, já estudados e validados tanto para a população geral como para os idosos. É importante lembrar que alguns fatores podem acelerar o declínio da filtração glomerular em idosos, tais como: aterosclerose, hipertensão arterial, insuficiência cardíaca, intolerância glicêmica ou diabetes mellitus, obesidade, doença renal subjacente, tabagismo e doenças incapacitantes graves (Fliser, 2008). A quantidade 
de proteína ingerida pelo paciente idoso também pode influenciar na evolução da função renal.

Nos idosos, como há menor produção muscular, os valores laboratoriais normais já podem estar associados com declínio funcional dos rins. Dessa forma, a creatinina isolada não é um parâmetro suficientemente seguro para estimar a filtração glomerular. Uma limitação intrínseca é a chamada área cega da curva de creatinina, ponto no qual, após a elevação da creatinina acima dos níveis normais, os pacientes jovens já perderam $40 \%$ da função renal (Fliser, 2008). Em estudo clínico, $40 \%$ dos sujeitos com creatinina dentro dos valores referenciais apresentaram diminuição da filtração glomerular (Levey et al., 1999). Estima-se que a área cega seja ainda maior em idosos. O consenso do Kidney Disease Outcomes Quality Initiative (K/DOQI) recomenda que a creatinina isoladamente não seja usada na estimativa da função renal (Levey et al., 2007). Alternativamente, diversos métodos são disponíveis para mensuração da função renal. Métodos como avaliação através da inulina, 51CrEDTA, Tc99m DTPA, 125I-iotalamato, apesar de considerados padrão-ouro, são invasivos, caros, demandam horas para a avaliação, diversas amostras sanguíneas e muitas vezes são radioativos. A dosagem da cistatina $\mathrm{C}$, muito mais onerosa do que a creatinina, e o cálculo da depuração da creatinina urinária de 24 horas, apesar de menos invasivos, dependem de local específico para execução ou coleta urinária por longo período, o que pode ser um problema para pacientes idosos. Estes exames, especialmente para idosos, podem ainda superestimar a função renal. 


\subsection{Consentimento informado}

Todos os procedimentos clínicos e exames laboratoriais de interesse a projetos de pesquisa foram informados aos sujeitos e, quando necessário, ao seu acompanhante, sendo então obtida a assinatura de Termo de Consentimento Livre e Esclarecido, devidamente aprovado pelo Comitê de Ética do HCFMUSP. O Projeto "Lítio, neuroproteção e memória: das bases moleculares à aplicação clínica" foi aprovado pela Comissão de Ética para Análise de Projetos de Pesquisa do HCFMUSP (CAPPesq). O estudo desta tese especificamente também foi aprovado individualmente tanto pelo Departamento de Psiquiatria como pelo CAPPesq com número de projeto $0553 / 10$. 


\subsection{Análise estatística}

A análise estatística foi realizada através do programa Statistical Package for Social Sciences (SPSS) versão 18. Para avaliar a evolução das funções renais (através das variações em creatinina, aMDRD e CKD-EPI), tireoidianas (através da variação de TSH e $\mathrm{T}_{4}$ livre), do metabolismo glicêmico (através das variações de glicemia e insulina de jejum e do HOMA-IR), e da contagem leucocitária total e linfocitária foi utilizado um método de regressão longitudinal através de um modelo linear de efeitos mistos. Utilizou-se gráficos de interação para a expressão gráfica da evolução destas variáveis de interesse. Para a comparação de novos diagnósticos clínicos novos ao longo do tempo de estudo foi utilizado o teste exato de Fisher. Para a análise da intensidade dos sintomas presentes na escala UKU e a avaliação dos pacientes e do médico, assim como entre a associação dos sintomas com o uso de lítio e avaliação dos pacientes e do médico foi utilizado o método de correlação policórica. O teste de qui-quadrado foi optado para a análise dos sintomas predominantes dentro do grupo lítio comparado ao grupo placebo, assim como para a intensidade de sintomas e a conduta clínica segundo o uso de medicação (lítio versus placebo). A concordância das avaliações de pacientes e médico foi feito através de coeficiente kappa de Cohen. 


\subsection{Orçamento do estudo}

O custo orçamentário para execução desse projeto foi de $\mathrm{R} \$ 25.296,00$. O ônus do projeto acabou não acarretado gastos diretos ao Instituto de Psiquiatria ou mesmo ao HCFMUSP, uma vez que o Projeto Temático teve subsídio tanto do CNPq quanto da Alzheimer's Association. Os gastos orçamentados foram para cobertura de material de insumo $(\mathrm{R} \$ 496,00)$ e kits laboratoriais $(\mathrm{R} \$ 24.800,00)$ já contemplados dentro do Projeto Temático. 


\section{RESULTADOS}

Foram avaliados 32 pacientes do grupo lítio e 27 pacientes do grupo placebo durante 4 anos de acompanhamento. As características sociodemográficas dos participantes encontram-se na Tabela 1 . O grupo lítio apresentou menor idade média quando comparado ao grupo placebo de forma significante $(p=0,034)$, enquanto as demais características não apresentaram diferença significativa. Esta diferença significativa desapareceu ao longo do primeiro ano do estudo.

As morbidades mais prevalentes em ambos os grupos no início do estudo estão apresentadas na Tabela 1. Dentre as doenças mais frequentes e com maior impacto sobre o objetivo principal do estudo, ou seja, o comprometimento da função renal, não se observou diferença significativa entre os grupos (Tabela 1). 
Tabela 1. Características sociodemográficas dos participantes no início do estudo

\begin{tabular}{lllll}
\hline \multicolumn{5}{c}{ Média (DP) } \\
& Lítio $(\mathrm{n}=32)$ & $\begin{array}{l}\text { Placebo } \\
(\mathrm{n}=27)\end{array}$ & $\mathrm{t}(\mathrm{df})^{*}$ & $p$ \\
\hline Idade, anos & $71,6 \pm 5,07$ & $74,8 \pm 6,32$ & $-2,170(57)^{\mathrm{a}}$ & 0,034 \\
\hline Educação, anos & $9,47 \pm 5,29$ & $9,04 \pm 4,74$ & $0,327(57)^{\mathrm{a}}$ & 0,744 \\
\hline Sexo feminino & 23 & 19 & $0,016(1)^{\mathrm{b}}$ & 0,898 \\
\hline Raça & & & $\mathrm{NA}^{\mathrm{c}}$ & 0,665 \\
\hline Caucasiana & 27 & 23 & & \\
\hline Negra & 1 & 3 & & \\
\hline Asiática & 4 & 1 & & \\
\hline
\end{tabular}

Comorbidades

\begin{tabular}{|c|c|c|c|c|}
\hline Hipertensão & 24 & 18 & $0,172(1)^{b}$ & 0,677 \\
\hline Osteoartrose & 13 & 14 & $0,743(1)^{b}$ & 0,388 \\
\hline Depressão & 10 & 8 & $0,018(1)^{b}$ & 0,892 \\
\hline Dislipidemia & 8 & 11 & $1,661(1)^{b}$ & 0,197 \\
\hline Hipotireoidismo & 8 & 7 & $0,006(1)^{b}$ & 0,935 \\
\hline Diabetes & 7 & 4 & $0,481(1)^{\mathrm{b}}$ & 0,487 \\
\hline
\end{tabular}

Após 48 meses de observação, foram diagnosticadas diversas novas doenças em ambos os grupos. No grupo placebo, as morbidades mais frequentes foram: dislipidemia (20\%), demência de Alzheimer (12\%), hiperplasia prostática benigna (8\%) e gastrite aguda (8\%). No grupo lítio, as morbidades mais frequentes foram: dislipidemia (40\%), diabetes mellitus (28\%), arritmias (20\%) e gastrite aguda (20\%). 
Dentre estes novos diagnósticos, houve diferença significativa somente na incidência de diabetes mellitus $(\mathrm{p}=0,037)$ e arritmias $(\mathrm{p}=0,028)$ entre os pacientes usuários de lítio.

$\mathrm{Na}$ Tabelas 2 observa-se o número de medicações utilizadas por ambos os grupos no início e ao longo dos 48 meses do estudo, respectivamente. Somente as medicações hipoglicemiantes foram significativamente maiores no grupo lítio após 48 meses de observação em razão do maior número de casos de diabetes mellitus.

\begin{tabular}{|c|c|c|c|c|c|c|c|c|c|c|}
\hline \multirow[t]{2}{*}{ Medicações } & \multicolumn{2}{|c|}{$\begin{array}{l}\text { Placebo } \\
\text { (Inicial) }\end{array}$} & \multicolumn{2}{|c|}{ Lítio (Inicial) } & \multirow[t]{2}{*}{$p^{*}$} & \multicolumn{2}{|c|}{ Placebo $(48 m)$} & \multicolumn{2}{|c|}{ Lítio (48m) } & \multirow[t]{2}{*}{$p^{*}$} \\
\hline & $\mathrm{N}$ & $\%$ & $\mathrm{~N}$ & $\%$ & & $\mathrm{~N}$ & $\%$ & $\mathrm{~N}$ & $\%$ & \\
\hline Antagonista de AT1 & 4 & 16 & 5 & 20 & 1,000 & 3 & 12 & 4 & 16 & 1,000 \\
\hline Aspirina & 7 & 28 & 7 & 28 & 1,000 & 0 & 0 & 0 & 0 & NA \\
\hline Benzodiazepínico ou agonista & 3 & 12 & 1 & 4 & 0,602 & 0 & 0 & 0 & 0 & NA \\
\hline Beta-bloqueador & 9 & 36 & 3 & 12 & 0,097 & 0 & 0 & 4 & 16 & 0,118 \\
\hline Bisfosfonado & 2 & 8 & 4 & 16 & 0,663 & 2 & 8 & 0 & 0 & 0,470 \\
\hline Bloqueador de bomba $\mathrm{H}+$ & 8 & 32 & 4 & 16 & 0,320 & 0 & 0 & 4 & 16 & 0,118 \\
\hline Bloqueador de canal de $\mathrm{Ca}^{2+}$ & 4 & 16 & 3 & 12 & 1,000 & 4 & 16 & 0 & 0 & 0,118 \\
\hline Cálcio com vitamina D & 4 & 16 & 9 & 36 & 0,197 & 0 & 0 & 0 & 0 & NA \\
\hline Diurético & 11 & 44 & 6 & 24 & 0,232 & 2 & 8 & 3 & 12 & 1,000 \\
\hline Estatinas & 9 & 36 & 6 & 24 & 0,537 & 2 & 8 & 8 & 32 & 0,077 \\
\hline IECA & 13 & 52 & 6 & 24 & 0,080 & 0 & 0 & 4 & 16 & 0,118 \\
\hline Hipoglicemiante oral & 8 & 32 & 4 & 16 & 0,320 & 0 & 0 & 8 & 32 & 0,006 \\
\hline Inibidor de AChE & 2 & 8 & 4 & 16 & 0,663 & 3 & 12 & 0 & 0 & 0,233 \\
\hline IRSS & 8 & 32 & 10 & 40 & 0,768 & 0 & 0 & 3 & 12 & 0,233 \\
\hline Levotiroxina & 7 & 28 & 8 & 32 & 1,000 & 0 & 0 & 0 & 0 & NA \\
\hline
\end{tabular}

Nota: *Qui-quadrado; 48m=48 meses; AT1=angiotensina 1; $\mathrm{Ca}^{2+}=$ cálcio; $\mathrm{H}^{+}=$próton de hidrogênio; IECA=inibidor da enzima de conversão da angiotensina; $\mathrm{AChE}=$ anticolinesterase; IRSS=inibidor de recaptação seletiva de serotonina.

No grupo lítio observou-se ganho ponderal significativo $(p=0,005)$ quando comparado ao grupo placebo (Tabela 3). Os incrementos no peso, medidos em quilogramas, entre os oito sujeitos do grupo lítio variaram entre 2 a 14 quilogramas $(\mathrm{Kg})$, sendo que neste último houve interrupção do tabagismo conjuntamente com o 
ganho ponderal e uso de lítio por 18 meses previamente sem alteração do peso (mediana de 5,5 kg).

\begin{tabular}{lcccc}
\hline $\begin{array}{l}\text { Tabela 3. Ganho ponderal observado nos grupos ao final do } \\
\text { estudo }\end{array}$ \\
\hline \multicolumn{4}{c}{ Ganho de peso } \\
\hline \\
Grupos & Não & Sim & Total \\
& Placebo & 27 & 0 & 27 \\
\hline & $100 \%$ & $0 \%$ & $100 \%$ \\
\hline & Lítio & 24 & 8 & 32 \\
\hline & $75 \%$ & $25 \%$ & $100 \%$ \\
\hline & 51 & 8 & 59 \\
\hline & $86,40 \%$ & $13,60 \%$ & $100 \%$ \\
\hline
\end{tabular}

$\mathrm{Na}$ avaliação da função renal, a creatinina sérica média esteve mais elevada de forma não significativa no grupo placebo ao longo dos 48 meses de seguimento (Gráfico 1; Tabela 4).

Gráfico 1. Evolução da creatinina sérica nos grupos ao longo de 48 meses

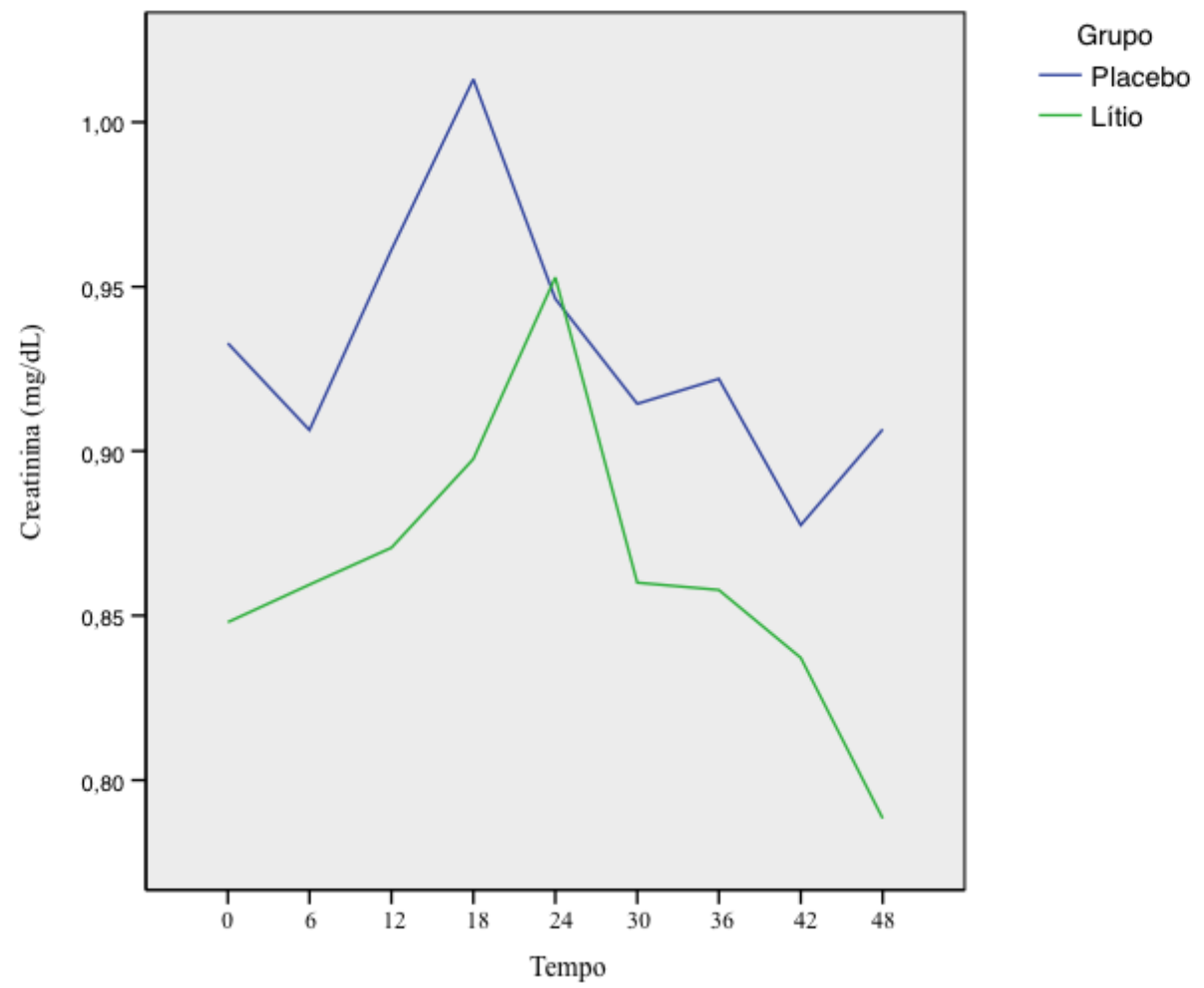




$\begin{aligned} & \text { Tabela 4. Testes de efeitos fixos para a variável creatinina ao longo de } \\
& \text { meses }\end{aligned}$
\begin{tabular}{lcccc}
\hline Fonte & Numerador df & Denominador df & F & $p$ \\
\hline Grupo & 1 & 53,87 & 1,19 & 0,279 \\
Tempo & 8 & 162,48 & 1,55 & 0,301 \\
\hline Grupo * Tempo & 8 & 162,48 & 1,14 & 0,333 \\
\hline Nota: df=grau de liberdade; F=valor do teste & & & \\
\hline
\end{tabular}

A estimativa da função renal utilizando a equação aMDRD também não evidenciou diferença significativa entre os grupos (Tabela 5) ao longo de 4 anos (Gráfico 2). Em razão da maior acurácia para detecção de alterações da função renal em pacientes idosos com a fórmula aMDRD, avaliou-se a potencial influência da presença das variáveis hipertensão arterial e diabetes mellitus, principais morbidades de risco para perda de função renal, sobre o resultado obtido através desta fórmula. Não houve diferença significativa sobre a função renal nos pacientes com hipertensão ou diabetes entre os grupos ou ao longo do tempo de seguimento (Tabela 6). 
Gráfico 2. Evolução da aMDRD calculada nos grupos ao longo de 48 meses

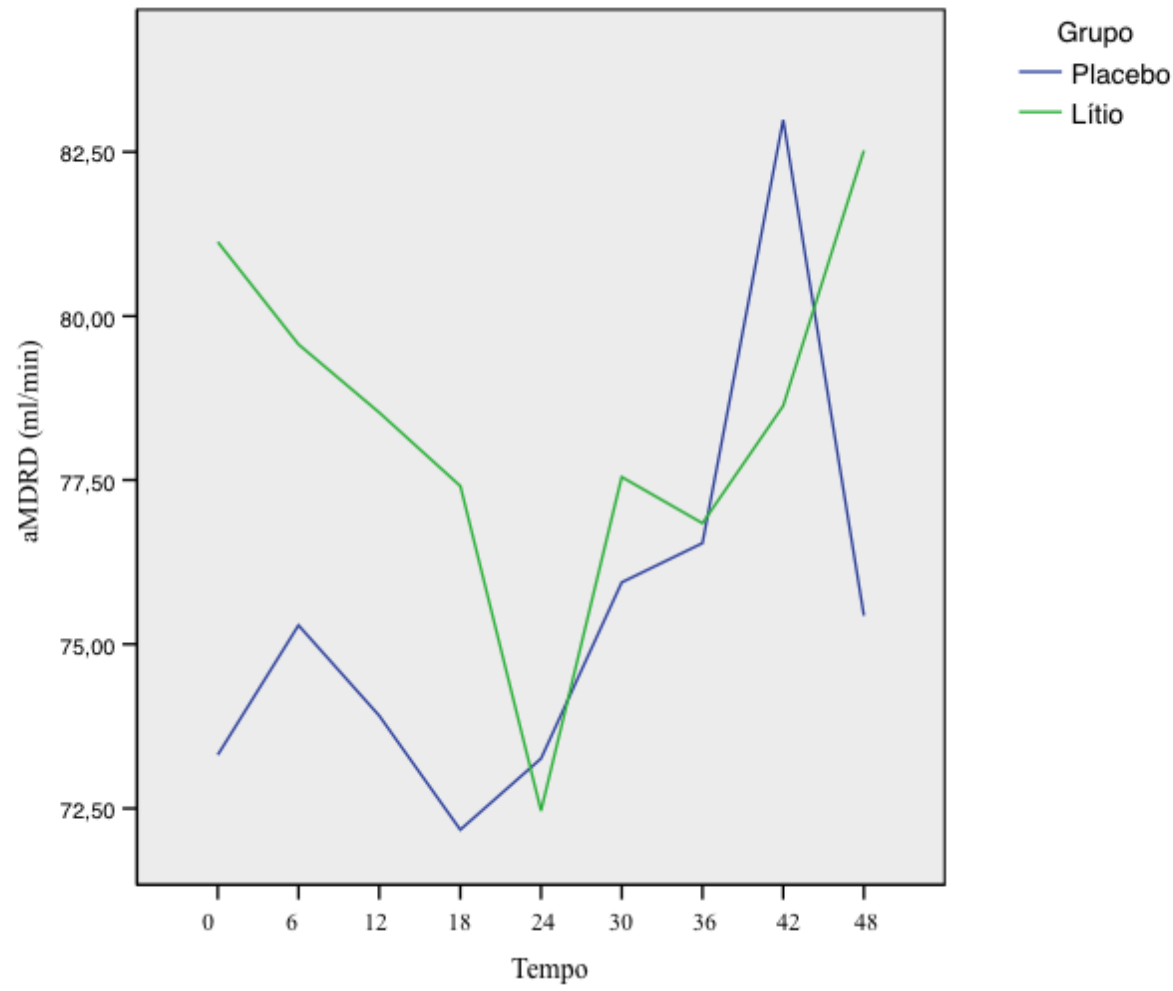

Tabela 5. Testes de efeitos fixos para a variável aMDRD ao longo de 48 meses

\begin{tabular}{lcccc}
\hline Fonte & Numerador df & Denominador $\mathrm{df}$ & $\mathrm{F}$ & $p$ \\
Grupo & 1 & 57,97 & 0,73 & 0,395 \\
Tempo & 8 & 124,42 & 1,55 & 0,145 \\
Grupo * Tempo & 8 & 124,42 & 0,98 & 0,453 \\
\hline Nota: df=grau de liberdade; F=valor do teste & & & \\
\hline
\end{tabular}


Tabela 6. Testes de efeitos fixos para a variável aMDRD segundo a presença de hipertensão e diabetes ao longo de 48 meses

\begin{tabular}{lcccc}
\hline Fonte & Numerador $\mathrm{df}$ & Denominador $\mathrm{df}$ & $\mathrm{F}$ & $p$ \\
Grupo & 1 & 58,07 & 0,49 & 0,487 \\
Tempo & 8 & 125,25 & 1,53 & 0,152 \\
Hipertensão & 1 & 128,67 & 0,62 & 0,432 \\
Diabetes & 1 & 272,62 & 0,63 & 0,426 \\
Grupo * Tempo & 8 & 124,58 & 0,92 & 0,497 \\
Nota: df=grau de liberdade; F=valor do teste. & & & \\
\hline
\end{tabular}

Apesar dos achados com a fórmula aMDRD, a equação CKD-EPI evidenciou maior queda da função renal entre os sujeitos do grupo placebo até 2 anos de seguimento ( $p=0,011$; Tabela 7). Após esse período, não houve variação significativa da função renal estimada (Gráfico 3). Não houve alteração significativa da função renal quando os grupos foram comparados ou na interação entre as médias dos grupos e o tempo de acompanhamento (Tabela 7). Quando a idade é utilizada como variável dependente para creatinina, aMDRD e CKD-EPI os valores corrigidos de $p$ passam para $0,117,0,453$ e 0,181 , respectivamente. Dessa forma, mantém-se a ausência de diferença significativa na interação grupo versus tempo para as variáveis de função renal. 
Gráfico 3. Evolução da CKD-EPI estimada nos grupos ao longo de 48 meses

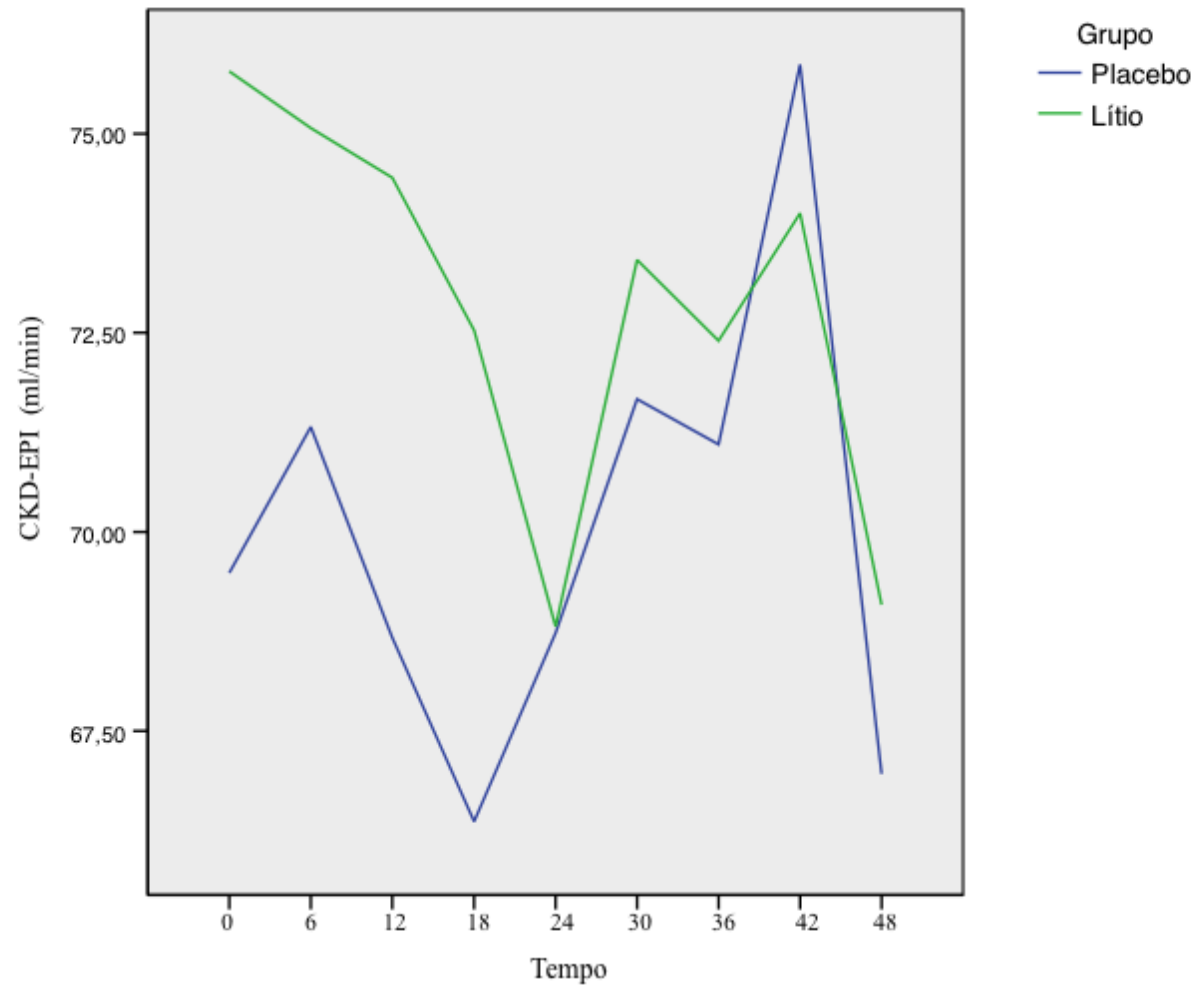

Tabela 7. Testes de efeitos fixos para a variável CKD-EPI ao longo de 48 meses

\begin{tabular}{lcccc}
\hline Fonte & Numerador df & Denominador df & F & $p$ \\
Grupo & 1 & 57,04 & 0,71 & 0,401 \\
Tempo & 8 & 119,04 & 2,63 & $\mathbf{0 , 0 1 1}$ \\
Grupo * Tempo & 8 & 119,04 & 1,37 & 0,213 \\
\hline Nota: df=grau de liberdade; F=valor do teste. & & & \\
\hline
\end{tabular}

Na Tabela 8 pode-se observar as médias das depurações de creatinina obtidos através das fórmulas aMDRD e CKD-EPI em cada grupo ao longo de 4 anos de seguimento. 
Tabela 8. Médias dos valores das equações aMDRD e CKD-EPI em cada grupo

\begin{tabular}{|ccccc}
\hline & \multicolumn{2}{c}{ Placebo } & \multicolumn{2}{c}{ Lítio } \\
Tempo (meses) & aMDRD & CKD-EPI & aMDRD & CKD-EPI \\
\hline 0 & $73,31 \pm 18,84$ & $69,48 \pm 17,83$ & $81,12 \pm 18,74$ & $75,78 \pm 14,92$ \\
\hline 6 & $75,29 \pm 19,30$ & $71,31 \pm 17,48$ & $79,56 \pm 17,69$ & $75,07 \pm 14,46$ \\
\hline 12 & $73,91 \pm 22,72$ & $68,67 \pm 19,76$ & $78,53 \pm 16,64$ & $74,44 \pm 14,67$ \\
\hline 18 & $72,17 \pm 25,88$ & $66,36 \pm 21,03$ & $77,41 \pm 20,07$ & $72,53 \pm 16,39$ \\
\hline 24 & $73,25 \pm 19,40$ & $68,73 \pm 17,89$ & $72,46 \pm 19,53$ & $68,81 \pm 17,85$ \\
\hline 30 & $75,94 \pm 17,79$ & $71,66 \pm 16,26$ & $77,54 \pm 18,85$ & $73,41 \pm 16,15$ \\
\hline 36 & $76,54 \pm 19,51$ & $71,10 \pm 17,36$ & $76,84 \pm 18,67$ & $72,40 \pm 15,41$ \\
\hline 42 & $82,98 \pm 19,41$ & $75,86 \pm 16,55$ & $78,63 \pm 18,24$ & $74,00 \pm 15,03$ \\
48 & $75,43 \pm 32,67$ & $66,96 \pm 26,53$ & $82,51 \pm 18,42$ & $69,08 \pm 18,68$ \\
\hline
\end{tabular}

O metabolismo glicêmico não apresentou alteração significativa entre os grupos ao longo de 4 anos, tanto na glicemia e insulina de jejum como para o cálculo de resistência insulínica através da fórmula HOMA-IR (Tabelas 9 a 11 e Gráficos 4 a 6, respectivamente). No entanto, nota-se um incremento não significativo da insulina e HOMA-IR entre o segundo ano e a metade do terceiro ano, contudo sem alteração na glicemia de jejum.

Tabela 9. Testes de efeitos fixos para a variável glicemia ao longo de $\mathbf{4 8}$ meses

\begin{tabular}{lcccc}
\hline Fonte & Numerador df & Denominador df & F & $p$ \\
Grupo & 1 & 60,74 & 0,53 & 0,469 \\
Tempo & 8 & 91,47 & 0,48 & 0,862 \\
Grupo * Tempo & 8 & 91,47 & 0,91 & 0,511 \\
\hline Nota: df=grau de liberdade; F=valor do teste. & & & \\
\hline
\end{tabular}


Tabela 10. Testes de efeitos fixos para a variável insulinemia ao longo de 48 meses

\begin{tabular}{lcccc}
\hline Fonte & Numerador $\mathrm{df}$ & Denominador $\mathrm{df}$ & $\mathrm{F}$ & $p$ \\
Grupo & 1 & 55,71 & 1,27 & 0,263 \\
\hline Tempo & 8 & 98,24 & 1,68 & 0,111 \\
\hline Grupo * Tempo & 8 & 98,24 & 1,32 & 0,241 \\
\hline Nota: df=grau de liberdade; F=valor do teste. & & & \\
\hline
\end{tabular}

Tabela 11. Testes de efeitos fixos para a variável HOMA-IR ao longo de 48 meses

\begin{tabular}{lcccc}
\hline Fonte & Numerador df & Denominador df & F & $p$ \\
Grupo & 1 & 45,31 & 0,83 & 0,365 \\
Tempo & 8 & 77,63 & 0,63 & 0,750 \\
Grupo * Tempo & 8 & 77,63 & 1,14 & 0,344 \\
Nota: df=grau de liberdade; F=valor do teste. & & & \\
\hline
\end{tabular}

Gráfico 4. Evolução da glicemia nos grupos ao longo de 48 meses

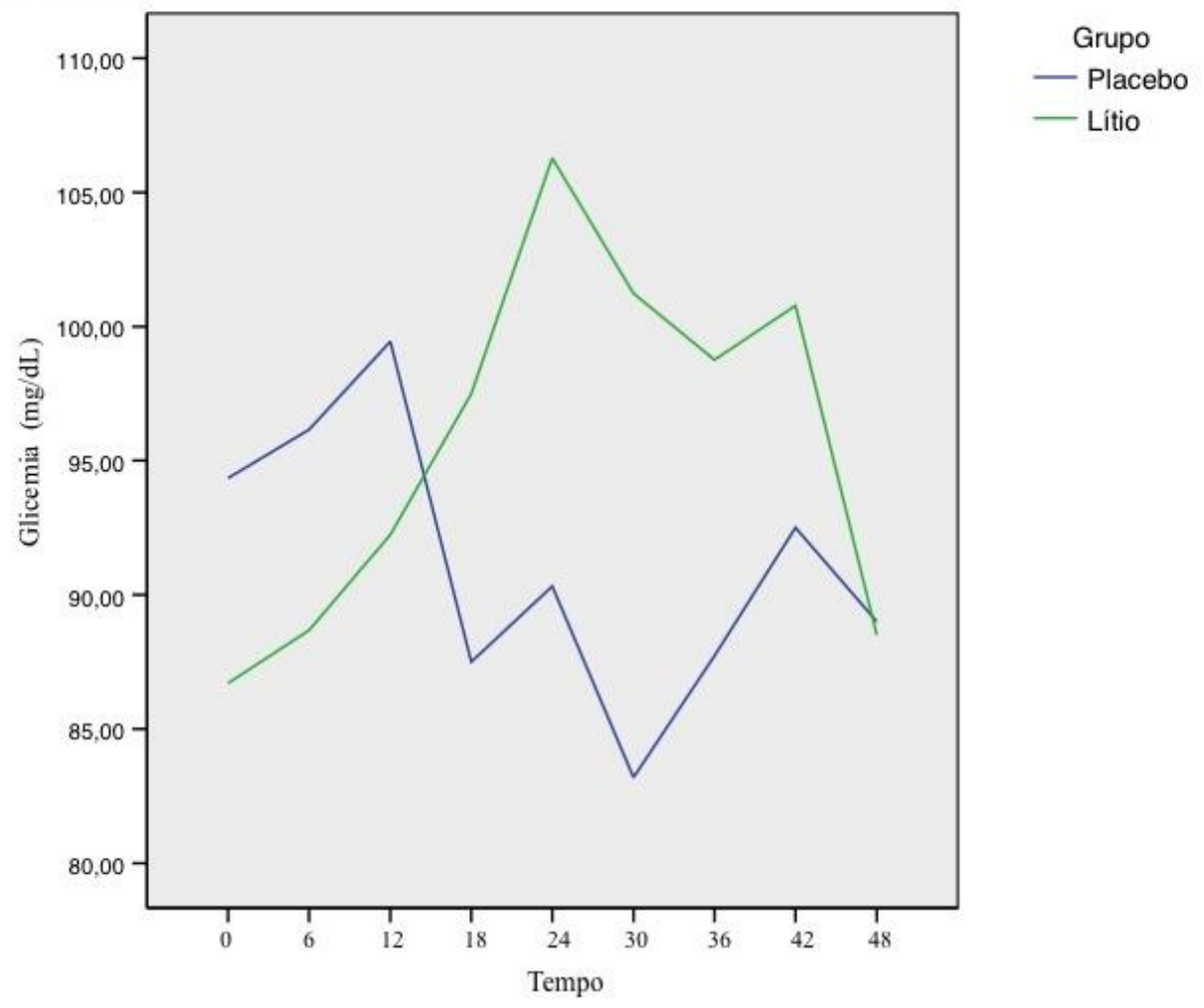


Gráfico 5. Evolução da insulinemia nos grupos ao longo de 48 meses

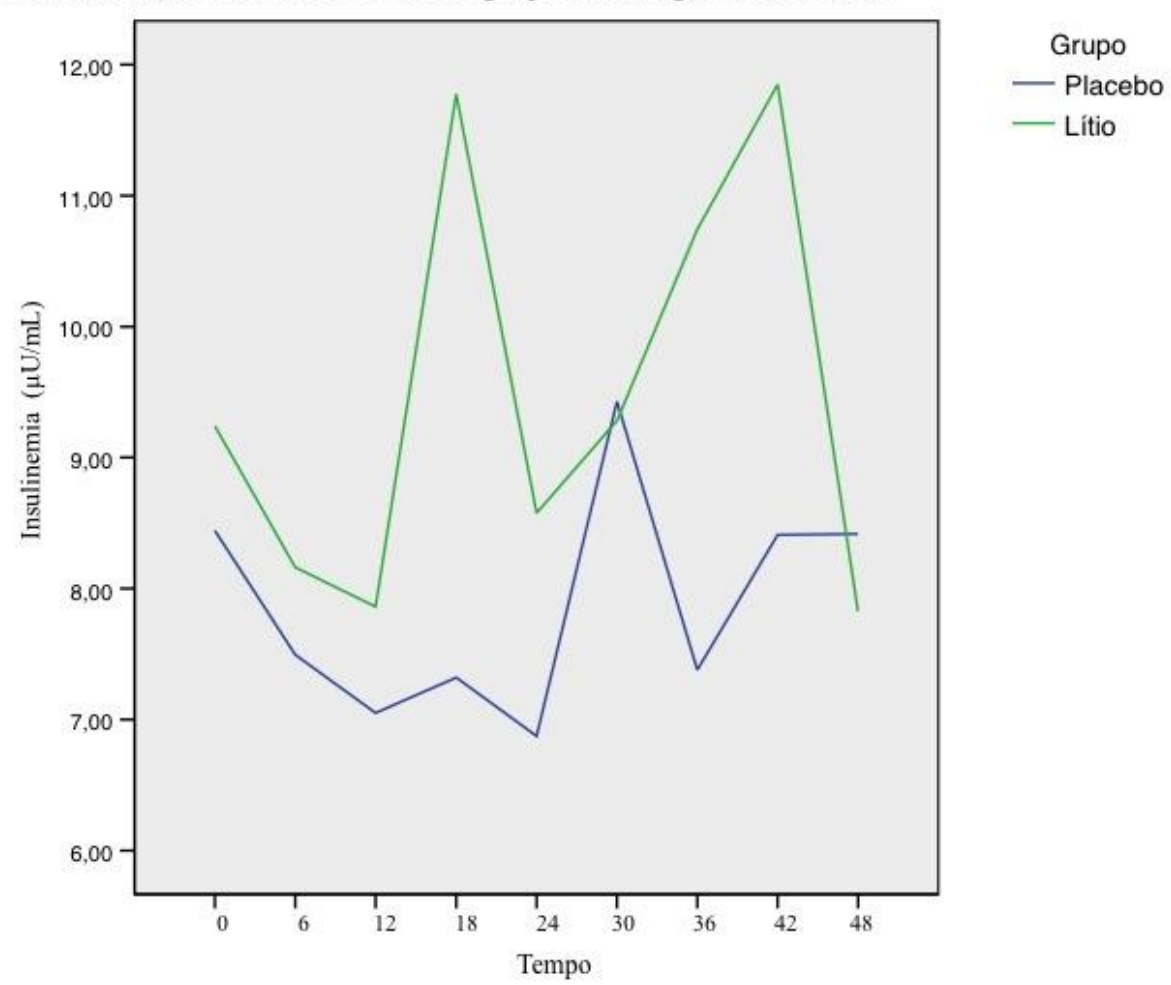

Gráfico 6. Evolução da resistência insulínica nos grupos ao longo de 48 meses

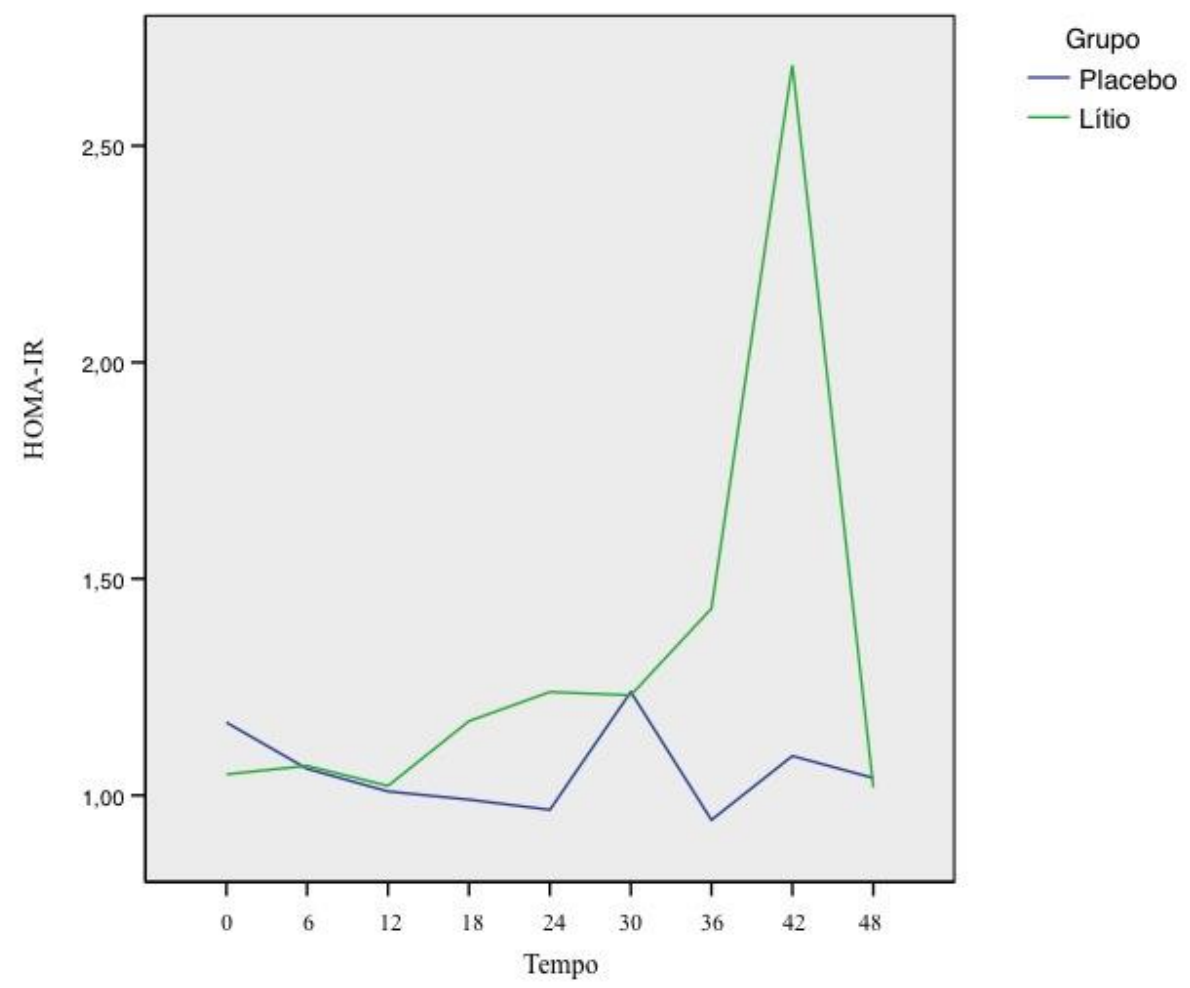


O número de leucócitos totais elevou-se significativamente nos participantes do grupo lítio ( $p=0,026$; Tabela 12 ) ao longo do tempo, especialmente nos primeiros dois anos e meio de observação (Gráfico 7).

Tabela 12. Testes de efeitos fixos para a variável leucócitos ao longo de 48 meses

\begin{tabular}{lcccc}
\hline Fonte & Numerador df & Denominador df & $\mathrm{F}$ & $p$ \\
Grupo & 1 & 71,50 & 1,74 & 0,190 \\
Tempo & 8 & 105,30 & 1,10 & 0,366 \\
Grupo * Tempo & 8 & 105,30 & 2,29 & $\mathbf{0 , 0 2 6}$ \\
Nota: df=grau de liberdade; F=valor do teste. & & & \\
\hline
\end{tabular}

Gráfico 7. Evolução do número de leucócitos nos grupos ao longo de 48 meses

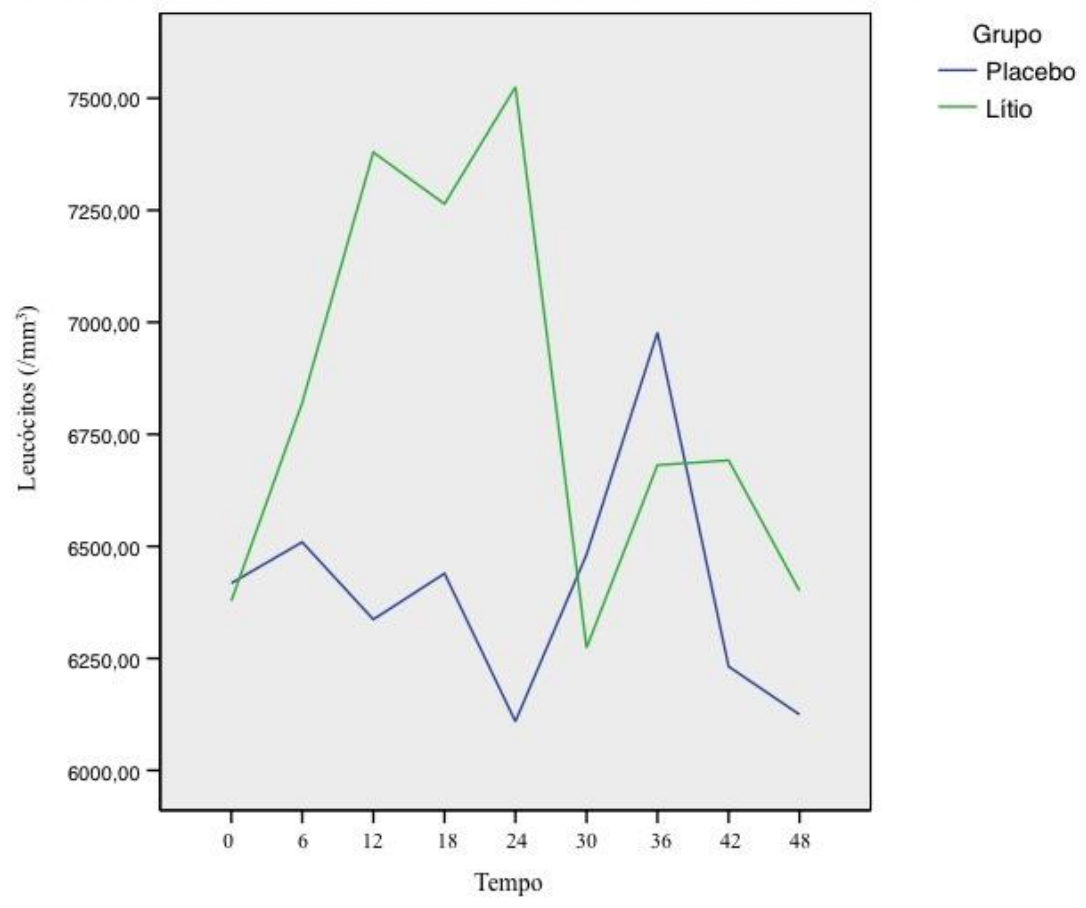

$\mathrm{Na}$ avaliação de grupos específicos de leucócitos, observou-se queda progressiva mas não significativa do número de linfócitos em ambos os grupos (Tabela 13; Gráfico 8). Ao contrário deste, verificou-se incremento do número de neutrófilos nos usuários de lítio de forma significativa ( $p=0,038$; Tabela 14), observando-se distribuição semelhante ao do número total de leucócitos ao longo dos 4 anos de observação (Gráfico 9). 
Tabela 13. Testes de efeitos fixos para a variável linfócitos ao longo de 48 meses

\begin{tabular}{lcccc}
\hline Fonte & Numerador df & Denominador df & F & $p$ \\
Grupo & 1 & 63,46 & 0,21 & 0,886 \\
Tempo & 8 & 158,1 & 1,25 & 0,269 \\
Grupo * Tempo & 8 & 158,1 & 1,25 & 0,270 \\
Nota: df=grau de liberdade; F=valor do teste. & & & \\
\hline
\end{tabular}


Gráfico 8. Evolução do número de linfócitos nos grupos ao longo de 48 meses

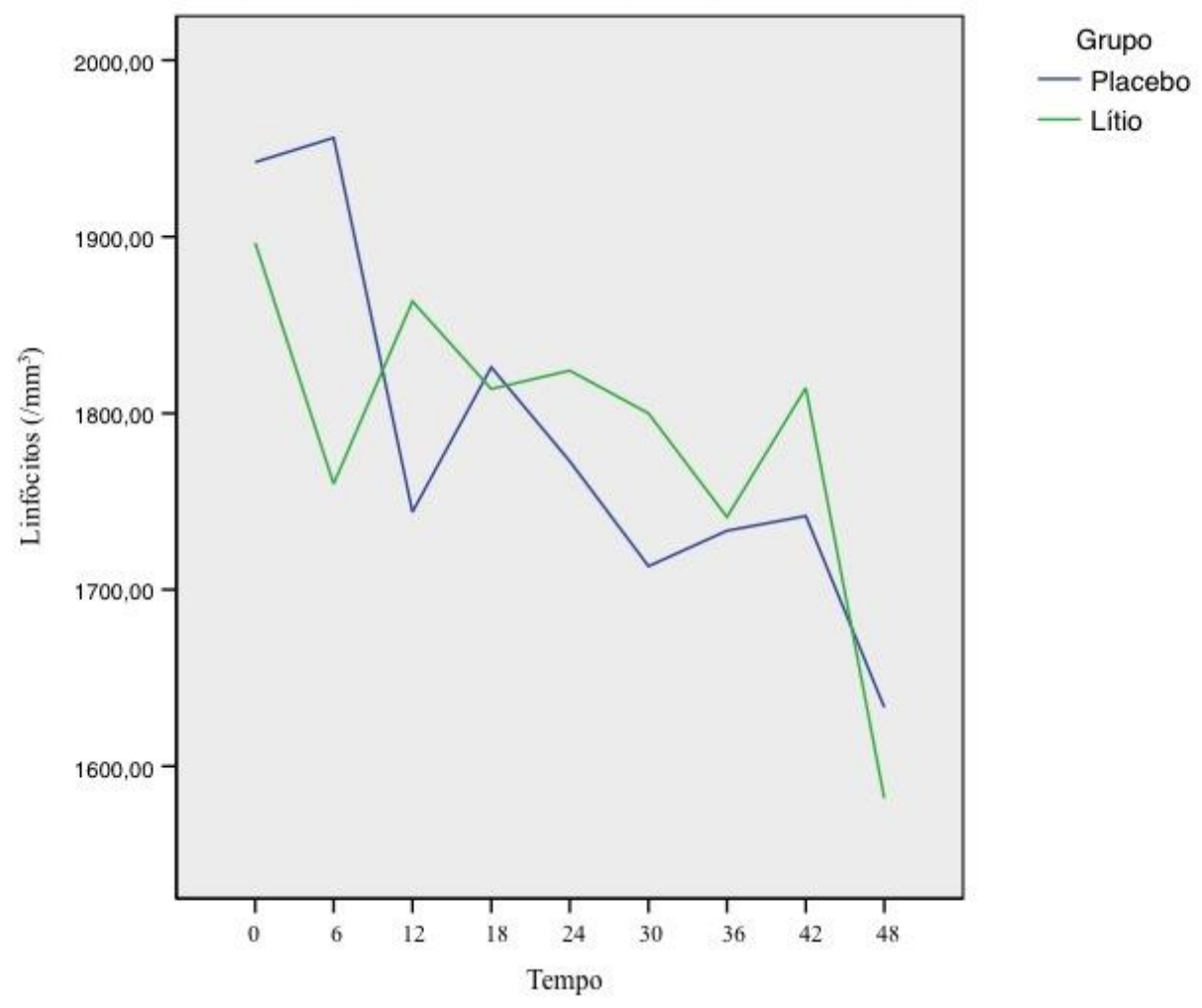

Tabela 14. Testes de efeitos fixos para a variável neutrófilos ao longo de $\mathbf{4 8}$ meses

\begin{tabular}{lcccc}
\hline Fonte & Numerador df & Denominador df & $\mathrm{F}$ & $p$ \\
Grupo & 1 & 75,76 & 2,93 & 0,91 \\
Tempo & 8 & 98,02 & 1,48 & 0,173 \\
Grupo * Tempo & 8 & 98,02 & 2,14 & $\mathbf{0 , 0 3 8}$ \\
Nota: df=grau de liberdade; F=valor do teste. & & & \\
\hline
\end{tabular}


Gráfico 9. Evolução do número de neutrófilos nos grupos ao longo de 48 meses

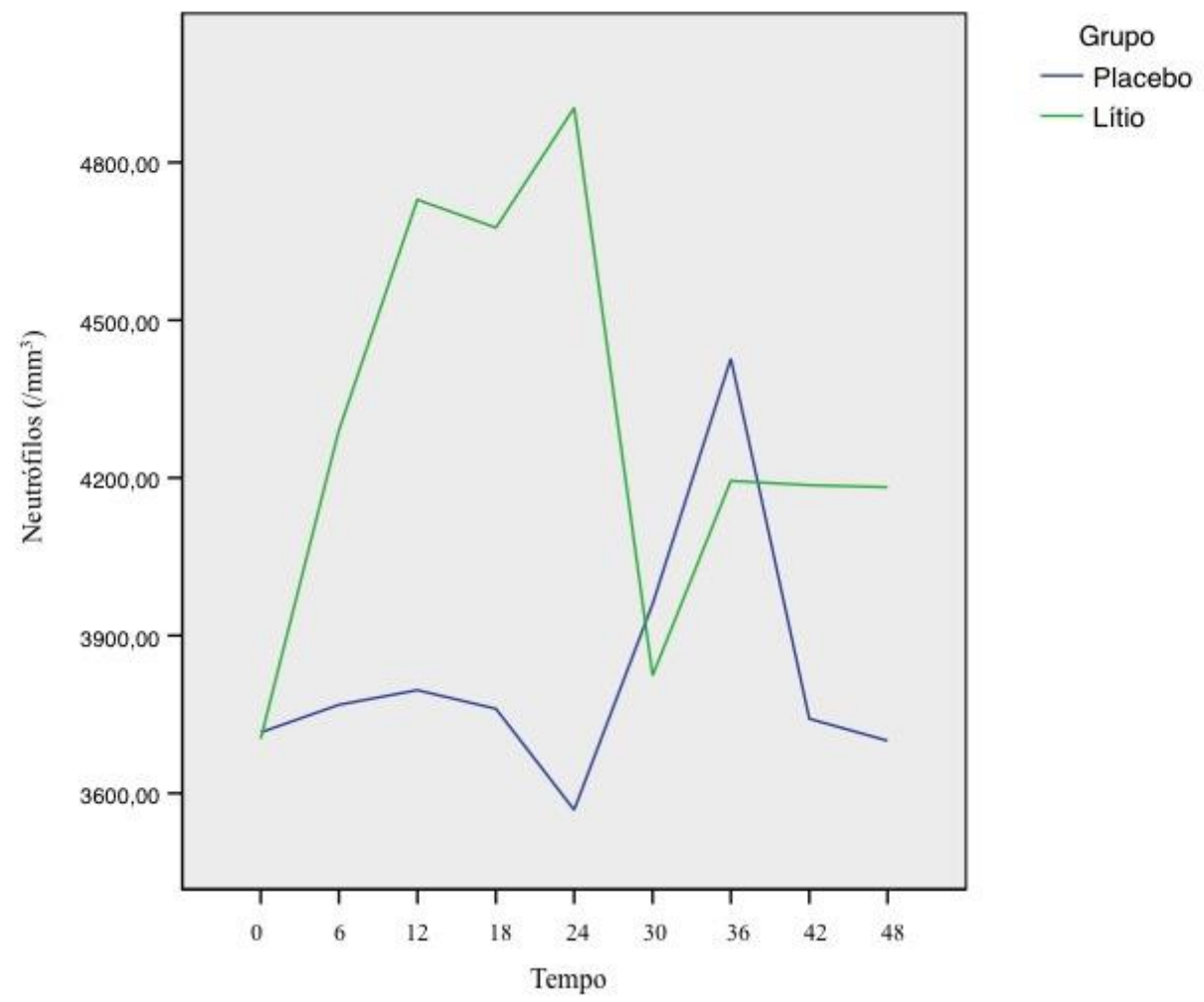

$\mathrm{Na}$ avaliação da função tireoidiana, observou-se elevação significativa do TSH no grupo lítio quando comparado ao grupo placebo ( $p=0,034$; Tabela 15$)$. Contudo, o aumento dos níveis de TSH não foi significativo levando-se em consideração a interação entre os grupos ao longo dos 48 meses de observação (Gráfico 10). As médias dos níveis de tiroxina livre apresentaram-se diminuídos nos usuários de lítio, mas sem diferença significativa entre os grupos ou durante o tempo de seguimento (Tabela 16; Gráfico 11).

Tabela 15. Testes de efeitos fixos para a variável TSH ao longo de 48 meses

\begin{tabular}{lcccc}
\hline Fonte & Numerador $\mathrm{df}$ & Denominador $\mathrm{df}$ & $\mathrm{F}$ & $p$ \\
Grupo & 1 & 53,53 & 4,7 & $\mathbf{0 , 0 3 4}$ \\
Tempo & 8 & 105,04 & 1,17 & 0,321 \\
Grupo * Tempo & 8 & 105,04 & 0,96 & 0,471 \\
\hline Nota: df=grau de liberdade; F=valor do teste. & & & \\
\hline
\end{tabular}


Gráfico 10. Evolução do TSH nos grupos ao longo de 48 meses

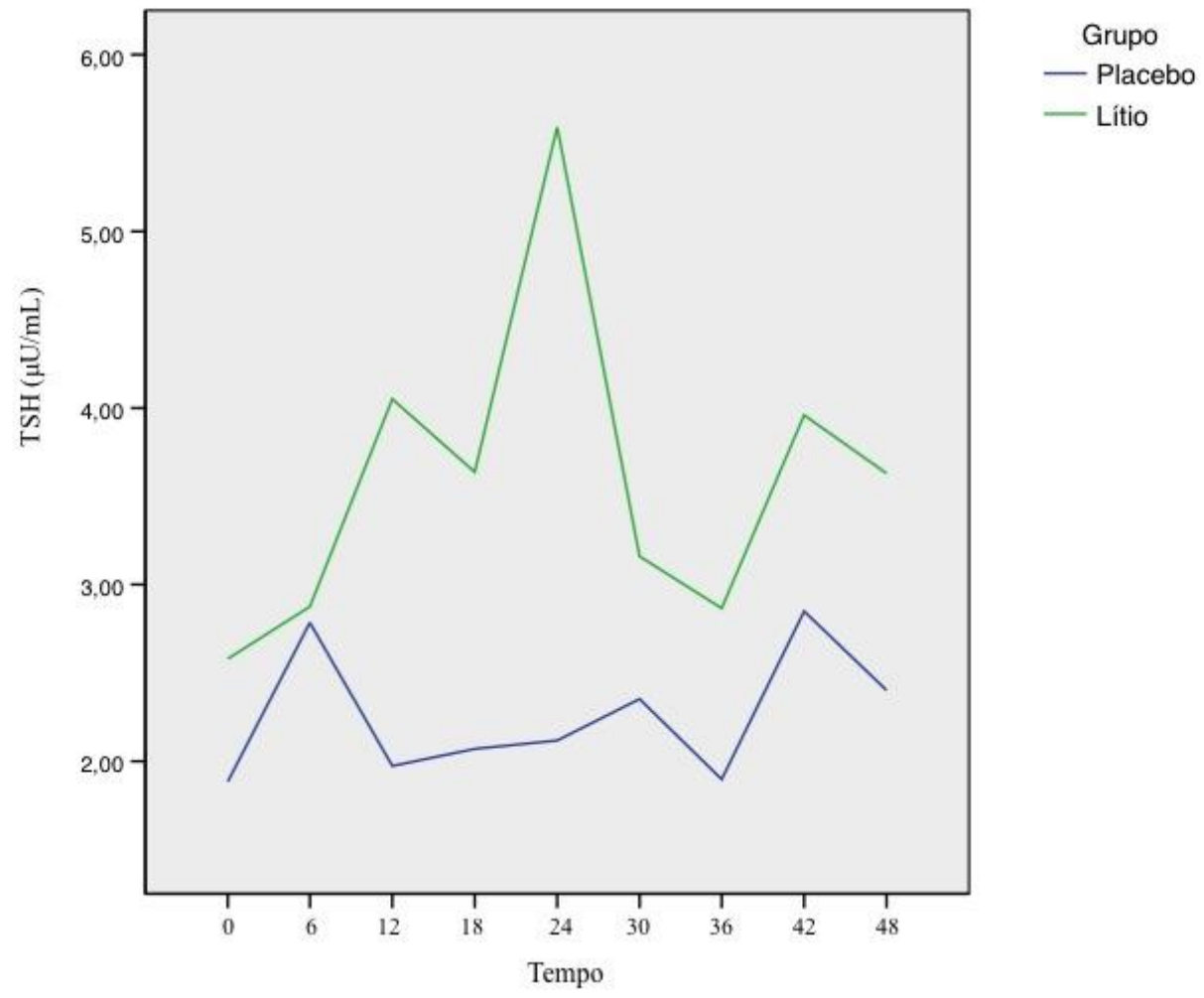

Tabela 16. Testes de efeitos fixos para a variável $T_{4} L$ ao longo de 48 meses

\begin{tabular}{lcccc}
\hline Fonte & Numerador df & Denominador $\mathrm{df}$ & $\mathrm{F}$ & $p$ \\
Grupo & 1 & 74,26 & 2,23 & 0,139 \\
Tempo & 8 & 116,95 & 1,02 & 0,418 \\
Grupo * Tempo & 8 & 116,95 & 0,34 & 0,945 \\
\hline Nota: df=grau de liberdade; F=valor do teste. & & & \\
\hline
\end{tabular}


Gráfico 11. Evolução do $\mathrm{T}_{4}$ livre nos grupos ao longo de 48 meses

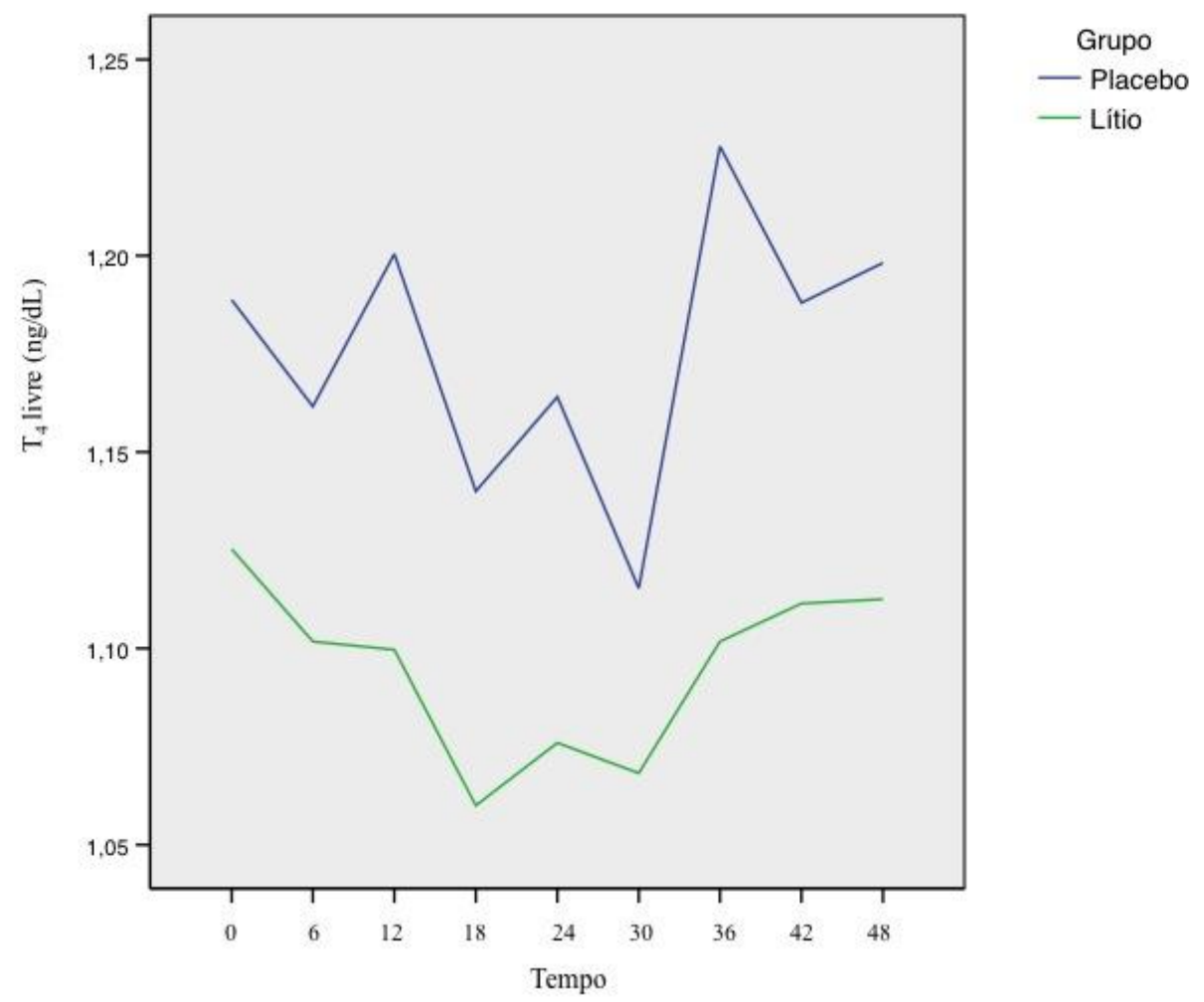

Os valores médios das variáveis laboratoriais englobando a função renal, metabolismo glicêmico, perfil leucocitário e função tireoidiana dos grupos placebo e lítio ao longo de 4 anos de seguimento encontram-se nas Tabela 17. 
Tabela 17. Valores médios das variáveis laboratoriais avaliadas nos participantes ao longo de 48 meses de seguimento

\begin{tabular}{|c|c|c|c|c|c|c|c|c|c|c|}
\hline Tempo (meses) & Grupos & Creatinina $^{*}$ & Glicemia $^{*}$ & Insulina $^{+}$ & HOMA-IR & Leucócitos ${ }^{* *}$ & Neutrófilos ${ }^{* *}$ & Linfócitos $^{* *}$ & $\mathrm{~T}_{4} \mathrm{~L}^{++}$ & $\mathrm{TSH}^{*}$ \\
\hline \multirow[t]{2}{*}{$\mathbf{0}$} & Placebo & $0,93 \pm 0,27$ & $94,34 \pm 40,96$ & $8,44 \pm 6,70$ & $1,16 \pm 0,97$ & $6417,30 \pm 1466,37$ & $3715,38 \pm 1138,31$ & $1942,30 \pm 602,77$ & $1,18 \pm 0,27$ & $1,88 \pm 1,59$ \\
\hline & Lítio & $0,84 \pm 0,20$ & $86,70 \pm 15,88$ & $9,24 \pm 5,74$ & $1,04 \pm 0,51$ & $6378,00 \pm 1568,99$ & $3703,33 \pm 1288,80$ & $1896,66 \pm 556,76$ & $1,12 \pm 0,28$ & $2,58 \pm 2,06$ \\
\hline \multirow[t]{2}{*}{6} & Placebo & $0,90 \pm 0,28$ & $96,16 \pm 29,48$ & $7,49 \pm 4,78$ & $1,06 \pm 0,62$ & $6509,20 \pm 1422,41$ & $3768,00 \pm 1110,82$ & $1956,00 \pm 597,27$ & $1,16 \pm 0,31$ & $2,78 \pm 4,12$ \\
\hline & Lítio & $0,85 \pm 0,20$ & $88,67 \pm 15,78$ & $8,16 \pm 5,33$ & $1,06 \pm 0,67$ & $6819,66 \pm 1417,58$ & $4290,00 \pm 1214,66$ & $1760,00 \pm 481,80$ & $1,10 \pm 0,32$ & $2,87 \pm 2,20$ \\
\hline \multirow[t]{2}{*}{12} & Placebo & $0,96 \pm 0,33$ & $99,44 \pm 43,15$ & $7,05 \pm 3,64$ & $1,00 \pm 5,17$ & $6336,80 \pm 1792,49$ & $3796,00 \pm 1377,64$ & $1744,00 \pm 571,33$ & $1,20 \pm 0,47$ & $1,97 \pm 2,28$ \\
\hline & Lítio & $0,87 \pm 0,21$ & $92,23 \pm 19,84$ & $7,86 \pm 4,94$ & $1,02 \pm 0,62$ & $7379,33 \pm 1943,47$ & $4729,33 \pm 1693,36$ & $1863,33 \pm 590,43$ & $1,09 \pm 0,37$ & $4,05 \pm 5,51$ \\
\hline \multirow[t]{2}{*}{18} & Placebo & $1,01 \pm 0,42$ & $87,50 \pm 11,55$ & $7,32 \pm 4,25$ & $0,99 \pm 0,55$ & $6439,13 \pm 1683,76$ & $3760,86 \pm 1345,94$ & $1826,08 \pm 730,63$ & $1,14 \pm 0,17$ & $2,07 \pm 1,67$ \\
\hline & Lítio & $0,89 \pm 0,23$ & $97,50 \pm 23,54$ & $11,77 \pm 15,59$ & $1,17 \pm 0,55$ & $7263,79 \pm 1828,72$ & $4675,86 \pm 1620,77$ & $1813,79 \pm 544,92$ & $1,06 \pm 0,22$ & $3,63 \pm 3,80$ \\
\hline \multirow[t]{2}{*}{24} & Placebo & $0,94 \pm 0,29$ & $90,31 \pm 27,04$ & $6,87 \pm 3,20$ & $0,96 \pm 0,50$ & $6109,09 \pm 1562,21$ & $3568,18 \pm 1258,26$ & $1772,72 \pm 625,01$ & $1,16 \pm 0,18$ & $2,11 \pm 1,50$ \\
\hline & Lítio & $0,95 \pm 0,31$ & $106,27 \pm 63,74$ & $8,57 \pm 4,76$ & $1,23 \pm 0,80$ & $7524,82 \pm 1970,71$ & $4903,44 \pm 1701,99$ & $1824,13 \pm 490,37$ & $1,07 \pm 2,60$ & $5,58 \pm 7,93$ \\
\hline \multirow[t]{2}{*}{30} & Placebo & $0,91 \pm 0,24$ & $83,18 \pm 16,40$ & $9,42 \pm 5,74$ & $1,23 \pm 0,69$ & $6482,00 \pm 1725,04$ & $3960,00 \pm 1486,99$ & $1713,33 \pm 632,3$ & $1,11 \pm 0,21$ & $2,35 \pm 2,57$ \\
\hline & Lítio & $0,86 \pm 0,23$ & $101,23 \pm 21,56$ & $9,28 \pm 6,08$ & $1,23 \pm 0,83$ & $6273,52 \pm 2410,46$ & $3823,52 \pm 2044,05$ & $1800,00 \pm 590,55$ & $1,06 \pm 0,24$ & $3,16 \pm 1,83$ \\
\hline \multirow[t]{2}{*}{36} & Placebo & $0,92 \pm 0,27$ & $87,73 \pm 13,69$ & $7,37 \pm 4,41$ & $0,94 \pm 0,58$ & $6976,66 \pm 2262,18$ & $4426,66 \pm 1766,13$ & $1733,33 \pm 512,23$ & $1,22 \pm 0,25$ & $1,89 \pm 1,09$ \\
\hline & Lítio & $0,85 \pm 0,21$ & $98,76 \pm 20,31$ & $10,74 \pm 10,62$ & $1,43 \pm 1,38$ & $6681,17 \pm 2203,61$ & $4194,11 \pm 1893,23$ & $1741,17 \pm 605,24$ & $1,10 \pm 0,22$ & $2,86 \pm 1,40$ \\
\hline \multirow[t]{2}{*}{42} & Placebo & $0,87 \pm 0,25$ & $92,50 \pm 26,81$ & $8,40 \pm 3,55$ & $1,09 \pm 0,43$ & $6231,66 \pm 1653,56$ & $3741,66 \pm 1572,75$ & $1741,66 \pm 614,16$ & $1,18 \pm 0,21$ & $2,84 \pm 3,03$ \\
\hline & Lítio & $0,83 \pm 0,23$ & $100,78 \pm 34,09$ & $11,85 \pm 11,99$ & $2,68 \pm 4,46$ & $6691,42 \pm 2084,63$ & $4185,71 \pm 1896,09$ & $1814,28 \pm 599,81$ & $1,11 \pm 0,21$ & $3,95 \pm 2,55$ \\
\hline \multirow[t]{2}{*}{48} & Placebo & $0,9 \pm 0,25$ & $89 \pm 26,43$ & $8,41 \pm 2,91$ & $1,04 \pm 0,36$ & $6124,16 \pm 1831,74$ & $3700,00 \pm 1280,62$ & $1633,33 \pm 521,07$ & $1,19 \pm 0,19$ & $2,401 \pm 1,54$ \\
\hline & Lítio & $0,78 \pm 0,13$ & $88,50 \pm 14,29$ & $7,82 \pm 3,40$ & $1,01 \pm 0,44$ & $6400,90 \pm 2447,96$ & $4181,81 \pm 2084,13$ & $158181 \pm 601,36$ & $1,11 \pm 0,17$ & $3,62 \pm 1,92$ \\
\hline
\end{tabular}

Nota: $\mathrm{mg} / \mathrm{dL} ;{ }^{+} \mu \mathrm{U} / \mathrm{mL} ;{ }^{* *}$ unidades $/ \mathrm{mm}^{3} ;{ }^{++} \mathrm{ng} / \mathrm{mL} ;{ }^{\#} \mu \mathrm{U} / \mathrm{mL}$ 
Através do questionário UKU foram avaliados a presença de 58 diferentes sintomas entre os participantes de ambos os grupos de estudo. Os participantes do grupo placebo referiram 4,07 sintomas em média ao longo de 48 meses, enquanto os sujeitos presentes no grupo lítio apresentaram 4,98 (Tabela 18). O número de sintomas referidos pelos participantes do estudo foi maior entre os usuários de lítio e apresentou queda em ambos os grupos ao longo dos 4 anos de seguimento (Gráfico 12). A diferença no número total de sintomas apresentados foi significativamente diferente entre os grupos $(p=0,045)$ e segundo o tempo $(p=0,005)$ de acompanhamento (Tabela 19). Contudo, não houve diferença quando analisada a interação entre estes fatores $(p=0,833 ;$ Tabela 19). 
Tabela 18. Número de sintomas referidos pelos grupos ao longo do seguimento de 4 anos, durante 17 avaliações.

\begin{tabular}{|c|c|c|c|c|c|c|c|c|c|c|c|c|c|c|c|c|c|c|c|}
\hline \multirow[b]{2}{*}{ Medicação } & & \multicolumn{18}{|c|}{ Tempo das avaliações } \\
\hline & & 0 & 1 & 2 & 3 & 4 & 5 & 6 & 7 & 8 & 9 & 10 & 11 & 12 & 13 & 14 & 15 & 16 & Total \\
\hline Placebo & Média & 5,24 & $\begin{array}{c}6,3 \\
6\end{array}$ & 5,54 & 4,85 & 3,92 & 3,13 & 3,74 & 2,87 & 3,67 & 3,50 & 3,25 & 3,00 & 3,21 & 3,69 & 2,64 & 2,70 & 3,50 & 4,07 \\
\hline & DP & 4,04 & $\begin{array}{c}4,2 \\
7\end{array}$ & 3,16 & 3,94 & 3,17 & 2,56 & 2,70 & 2,11 & 2,98 & 2,63 & 2,46 & 1,96 & 2,51 & 2,59 & 2,11 & 3,16 & 3,17 & 3,24 \\
\hline Lítio & Média & 6,19 & $\begin{array}{c}5,5 \\
2\end{array}$ & 6,10 & 4,97 & 4,77 & 4,23 & 5,43 & 4,30 & 4,96 & 5,58 & 4,84 & 3,84 & 3,78 & 4,81 & 4,20 & 4,86 & 4,83 & 4,98 \\
\hline & DP & 4,06 & $\begin{array}{c}3,5 \\
3\end{array}$ & 3,57 & 3,47 & 3,54 & 2,99 & 3,57 & 3,72 & 3,66 & 2,77 & 3,04 & 3,38 & 3,37 & 3,50 & 2,62 & 3,37 & 3,35 & 3,46 \\
\hline
\end{tabular}


Gráfico 12. Número de sintomas apresentados pelos pacientes ao longo de 48 meses

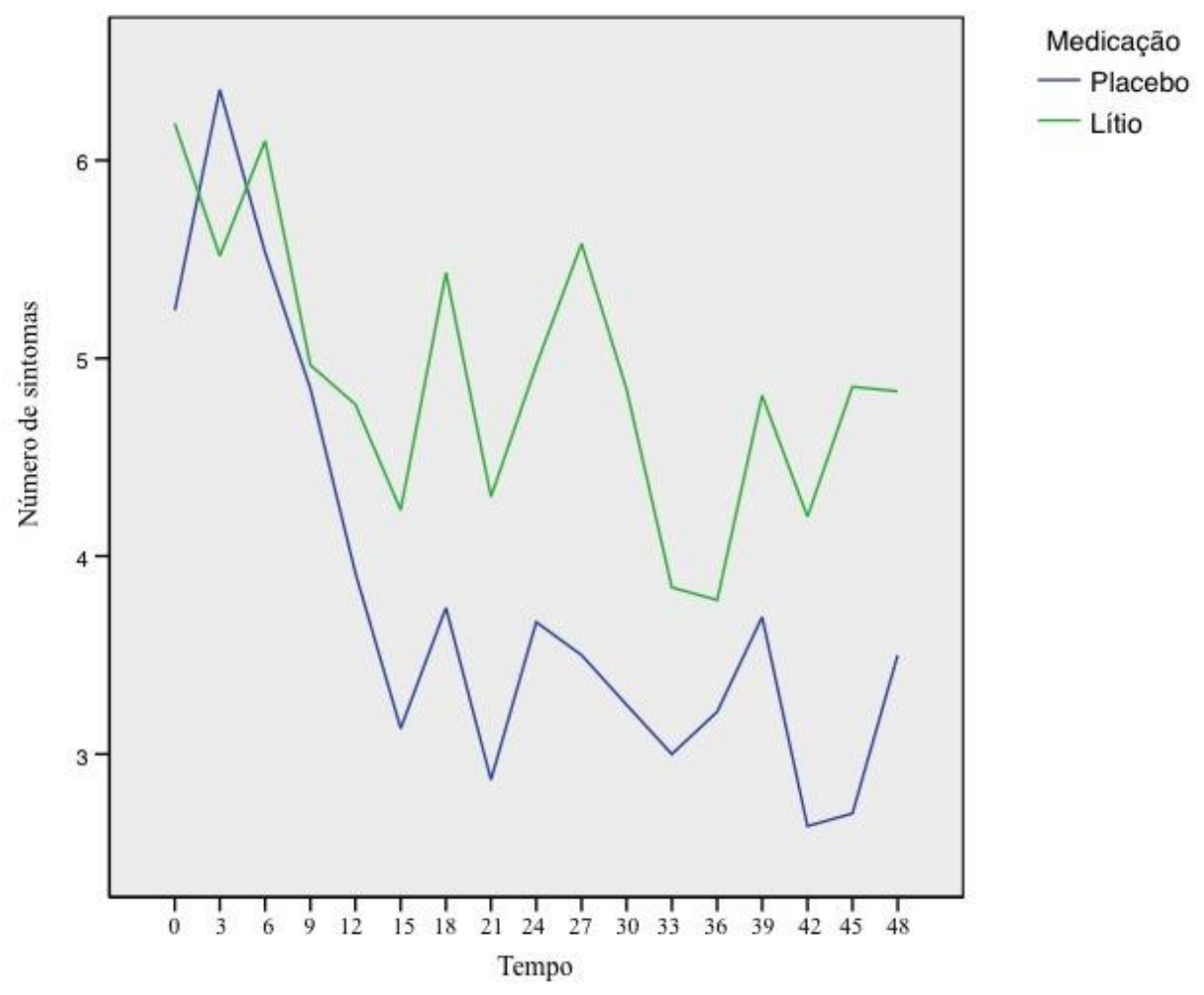

Tabela 19. Testes de efeitos fixos para a variável número de sintomas ao longo de 48 meses

\begin{tabular}{|c|c|c|c|c|}
\hline Fonte & Numerador df & Denominador df & $\mathrm{F}$ & $p$ \\
\hline Grupo & 1 & 106,28 & 4,1 & 0,045 \\
\hline Tempo & 16 & 453,98 & 2,19 & 0,005 \\
\hline Grupo * Tempo & 16 & 453,98 & 0,66 & 0,833 \\
\hline
\end{tabular}

Uma vez que os sintomas foram relatados por pacientes idosos com distúrbios cognitivos e, em alguns casos, depressão ou sintomas sub-sindrômicos da doença, optou-se por reavaliar a variável "número de sintomas" através da dependência de dificuldades em memória e sintomatologia depressiva referidos pelos pacientes (Tabela 20). Observou-se, novamente, diferença significativa entre os grupos $(p<0,001)$ e o tempo de observação $(p=0,013)$, contudo, sem significância na 
interação desses elementos $(p=0,846)$. A presença de queixas de dificuldade de memória e sintomas de depressão exerceu diferença significante no número de sintomas apresentados entre os grupos $(p<0,001)$.

Tabela 20. Testes de efeitos fixos para a variável número de sintomas dependente das queixas de memória e depressão ao longo de 48 meses

\begin{tabular}{lcccc}
\hline \multicolumn{1}{c}{ Fonte } & $\begin{array}{c}\text { Numerador } \\
\text { df }\end{array}$ & $\begin{array}{c}\text { Denominador } \\
\text { df }\end{array}$ & F & $p$ \\
Grupo & 1 & 112,52 & 13,96 & $<\mathbf{0 , 0 0 1}$ \\
Tempo & 16 & 438,02 & 1,98 & $\mathbf{0 , 0 1 3}$ \\
$\begin{array}{l}\text { Grupo } * \\
\text { Tempo }\end{array}$ & 16 & 439,12 & 0,64 & 0,846 \\
Memória & 1 & 643,40 & 142,85 & $<\mathbf{0 , 0 0 1}$ \\
$\begin{array}{l}\text { Depressão } \\
\text { Nota: df=grau de liberdade; F=valor do teste }\end{array}$ & 666,53 & 114,53 & $<\mathbf{0 , 0 0 1}$ \\
\hline
\end{tabular}

Os sintomas apresentados pelos participantes foram leves em sua grande maioria. A ocorrência de sintomas moderadamente intensos foram raros, aparecendo em 19 ocasiões no grupo lítio e em 15 momentos dentro do grupo placebo. Sintomas muito intensos foram relatados 3 vezes e somente no grupo placebo. Dentre os pacientes do grupo lítio a única ocorrência de sintomas moderados acima de $1 \%$ foi em relação à queixa de aumento de atividade onírica $(1,2 \%$ de ocorrência ao longo de 4 anos). Englobando todos os sintomas de leves a intensos, observou-se diferenças significativas em 11 dos sintomas mais comumente referidos pelos pacientes (Tabela 21). Os dois sintomas reportados mais comuns, com diferença significativa, nos grupos placebo e lítio foram dificuldade de memória $(p<0,007)$ e astenia/cansaço $(p<0,001)$. Apesar disto, os sintomas mais comumente atribuídos ao uso do lítio, segundo a avaliação médica foram: tremor, poliúria e aumento da atividade onírica. 
Tabela 21. Sintomas mais comuns referidos pelos pacientes através do questionário UKU ao longo de 48 meses

\begin{tabular}{|c|c|c|c|c|c|c|c|}
\hline \multirow[t]{2}{*}{ Sintomas referidos } & \multicolumn{2}{|c|}{ Placebo } & \multicolumn{2}{|c|}{ Lítio } & \multirow[t]{2}{*}{$\chi^{2}$} & \multirow{2}{*}{$\begin{array}{l}\mathrm{d} \\
\mathrm{f}\end{array}$} & \multirow[t]{2}{*}{$p$} \\
\hline & $\mathrm{N}$ & $\%$ & $\mathrm{~N}$ & $\%$ & & & \\
\hline Dificuldade de memória & 146 & $\begin{array}{l}4 \\
4\end{array}$ & 136 & $\begin{array}{l}3 \\
4\end{array}$ & 7,35 & 1 & 0,007 \\
\hline Astenia/lassidão/cansaço & 83 & $\begin{array}{l}2 \\
5\end{array}$ & 152 & $\begin{array}{l}3 \\
8\end{array}$ & 13,49 & 1 & $<0,001$ \\
\hline Dificuldade de concentração & 69 & $\begin{array}{l}2 \\
1\end{array}$ & 86 & $\begin{array}{l}2 \\
1\end{array}$ & 0,00 & 1 & 1,000 \\
\hline Perda de peso & 60 & $\begin{array}{l}1 \\
8\end{array}$ & 53 & $\begin{array}{l}1 \\
3\end{array}$ & 3,14 & 1 & 0,076 \\
\hline Ganho de peso & 59 & $\begin{array}{l}1 \\
8\end{array}$ & 86 & $\begin{array}{l}2 \\
1\end{array}$ & 0,85 & 1 & 0,357 \\
\hline Depressão & 59 & $\begin{array}{l}1 \\
8\end{array}$ & 58 & $\begin{array}{l}1 \\
4\end{array}$ & 1,93 & 1 & 0,165 \\
\hline Constipação & 58 & $\begin{array}{l}1 \\
8\end{array}$ & 66 & $\begin{array}{l}1 \\
6\end{array}$ & 0,37 & 1 & 0,541 \\
\hline Tensão/inquietude & 54 & $\begin{array}{l}1 \\
6\end{array}$ & 84 & $\begin{array}{l}2 \\
1\end{array}$ & 2,67 & 1 & 0,102 \\
\hline Poliúria/polidipsia & 52 & $\begin{array}{l}1 \\
6\end{array}$ & 129 & $\begin{array}{l}3 \\
2\end{array}$ & 23,86 & 1 & $<0,001$ \\
\hline Sonolência/sedação & 52 & $\begin{array}{l}1 \\
6\end{array}$ & 121 & $\begin{array}{l}3 \\
0\end{array}$ & 18,79 & 1 & $<0,001$ \\
\hline $\begin{array}{l}\text { Diminuição da duração do } \\
\text { sono }\end{array}$ & 51 & $\begin{array}{l}1 \\
5\end{array}$ & 55 & $\begin{array}{l}1 \\
4\end{array}$ & 0,07 & 1 & 0,792 \\
\hline Parestesias & 47 & $\begin{array}{l}1 \\
4\end{array}$ & 72 & $\begin{array}{l}1 \\
8\end{array}$ & 1,84 & 1 & 0,175 \\
\hline $\begin{array}{l}\text { Aumento da atividade } \\
\text { onírica }\end{array}$ & 43 & $\begin{array}{l}1 \\
3\end{array}$ & 83 & $\begin{array}{l}2 \\
1\end{array}$ & 7,44 & 1 & 0,006 \\
\hline Diminuição da salivação & 38 & $\begin{array}{l}1 \\
1\end{array}$ & 41 & $\begin{array}{l}1 \\
0\end{array}$ & 0,11 & 1 & 0,740 \\
\hline Tremor & 35 & $\begin{array}{l}1 \\
1\end{array}$ & 86 & $\begin{array}{l}2 \\
1\end{array}$ & 12,26 & 1 & $<0,001$ \\
\hline Tontura ortostática & 35 & $\begin{array}{l}1 \\
1\end{array}$ & 74 & $\begin{array}{l}1 \\
8\end{array}$ & 6,38 & 1 & 0,012 \\
\hline Palpitacões/ taquicardia & 34 & $\begin{array}{l}1 \\
0\end{array}$ & 59 & $\begin{array}{l}1 \\
5\end{array}$ & 3,70 & 1 & 0,054 \\
\hline $\begin{array}{l}\text { Aumento da duração do } \\
\text { sono }\end{array}$ & 0 & 0 & 75 & $\begin{array}{l}1 \\
9\end{array}$ & 68,25 & 1 & $<0,001$ \\
\hline Aumento da salivação & 0 & 0 & 51 & $\begin{array}{l}1 \\
3\end{array}$ & 44,38 & 1 & $<0,001$ \\
\hline Prurido & 0 & 0 & 47 & $\begin{array}{l}1 \\
2\end{array}$ & 40,62 & 1 & $<0,001$ \\
\hline Rigidez & 0 & 0 & 40 & $\begin{array}{l}1 \\
0\end{array}$ & 33,12 & 1 & $<0,001$ \\
\hline
\end{tabular}


Com relação a interferência dos efeitos colaterais nas atividades de vida diária percebidos pelo médico avaliador e pelos pacientes, houve associação significativa entre o uso do lítio em ambas as percepções, envolvendo sintomas leves em sua maioria $(p<0.001$; Tabelas 22 e 23). O impacto dos efeitos colaterais percebidos pelo médico e pelos pacientes demonstraram correlação significante $(p<0.001$; Tabela 24). 
Tabela 22. Interferência dos efeitos colaterais nas atividades de vida diária entre os pacientes segundo a percepção do paciente ao longo de 48 meses

\begin{tabular}{|c|c|c|c|c|c|c|}
\hline & \multicolumn{6}{|c|}{ Interferência dos efeitos colaterais } \\
\hline & & 0 & 1 & 2 & 3 & Total \\
\hline \multirow[t]{4}{*}{ Grupo } & Placebo & 302 & 25 & 2 & 2 & 331 \\
\hline & & $91,20 \%$ & $7,60 \%$ & $\begin{array}{c}0,60 \\
\%\end{array}$ & $0,60 \%$ & $100 \%$ \\
\hline & Lítio & 330 & 70 & 3 & 0 & 403 \\
\hline & & $81,90 \%$ & $17,40 \%$ & $\begin{array}{c}0,70 \\
\%\end{array}$ & $0,00 \%$ & $100 \%$ \\
\hline \multirow[t]{2}{*}{ Total } & & 632 & 95 & 5 & 2 & 734 \\
\hline & & $86,10 \%$ & $12,90 \%$ & $\begin{array}{c}0,70 \\
\%\end{array}$ & $0,30 \%$ & $100 \%$ \\
\hline
\end{tabular}

Tabela 23. Interferência dos efeitos colaterais nas atividades de vida diária entre os pacientes segundo a percepção do médico ao longo de 48 meses

\begin{tabular}{|c|c|c|c|c|c|c|}
\hline & \multicolumn{6}{|c|}{ Interferência dos efeitos colaterais } \\
\hline & & 0 & 1 & 2 & 3 & Total \\
\hline \multirow[t]{4}{*}{ Grupo } & Placebo & 279 & 49 & 2 & 1 & 331 \\
\hline & & $84,30 \%$ & $14,80 \%$ & $0,60 \%$ & $0,30 \%$ & $100 \%$ \\
\hline & Lítio & 290 & 110 & 3 & 0 & 403 \\
\hline & & $72,00 \%$ & $27,30 \%$ & $0,70 \%$ & $0,00 \%$ & $100 \%$ \\
\hline \multirow[t]{2}{*}{ Total } & & 569 & 159 & 5 & 1 & 734 \\
\hline & & $77,50 \%$ & $21,70 \%$ & $0,70 \%$ & $0,10 \%$ & $100 \%$ \\
\hline
\end{tabular}


Tabela 24. Correlação entre as interferências dos efeitos colaterais observados pelos participantes e pelo médico avaliador durante o seguimento de 4 anos

\begin{tabular}{|c|c|c|c|c|c|c|}
\hline & & \multicolumn{5}{|c|}{ Observação médica } \\
\hline & & 0 & 1 & 2 & 3 & Total \\
\hline \multirow{4}{*}{$\begin{array}{l}\text { Observação } \\
\text { do paciente }\end{array}$} & 0 & 563 & 69 & 0 & 0 & 632 \\
\hline & 1 & 6 & 89 & 0 & 0 & 95 \\
\hline & 2 & 0 & 1 & 4 & 0 & 5 \\
\hline & 3 & 0 & 0 & 1 & 1 & 2 \\
\hline Total & & 569 & 159 & 5 & 1 & 734 \\
\hline
\end{tabular}

Náuseas/vômitos foi o único sintoma significativamente associado ao uso do lítio segundo a percepção da interferência dos efeitos colaterais tanto pelo médico avaliador como pelo paciente $(p<0.001)$. A gravidade do sintoma e seu impacto na interferência das atividades diárias do paciente foi observado pelo médico em oito sintomas da UKU: tensão/inquietude $(p=0.044)$, aumento da atividade onírica ( $p=0.018)$, náuseas/vômitos $(p=0.001)$, eritema $(p=0.042)$, eritema morbiliforme ( $p=0.007)$, aumento de pigmentação $(p=0.003)$, ginecomastia $(p=0.038)$, outras formas de cefaléia $(p=0.003)$. Ao contrário, somente em três sintomas foram observados associação significativa entre gravidade e o uso do lítio segundo a percepção dos pacientes: alteração da acomodação visual ( $p=0.004)$, náuseas/vômitos $(p<0,001)$ e enxaqueca $(p=0.022)$.

Apesar da ocorrência de alguns sintomas associados ao uso do lítio ou com sua gravidade e a interferência em atividades de vida diária, não foi observada alteração da conduta médica, resultando em suspensão da droga, em nenhum momento (Tabela 25). 
Tabela 25. Consequência da conduta médica em razão dos efeitos colaterais observados pelo médico ao longo de 48 meses

\begin{tabular}{lcccccc}
\hline & \multicolumn{5}{c}{ Consequência dos efeitos colaterais } \\
Grupo & Placebo & 328 & 1 & 2 & 3 & Total \\
& & 0 & 0 & 3 & 331 \\
& Lítio & $99,10 \%$ & $0,00 \%$ & $0,00 \%$ & $0,90 \%$ & $100 \%$ \\
\hline & $98,80 \%$ & $0,50 \%$ & $0,50 \%$ & $0,20 \%$ & $100 \%$ \\
\hline Total & 726 & 2 & 2 & 4 & 734 \\
\hline & $98,90 \%$ & $0,30 \%$ & $0,30 \%$ & $0,50 \%$ & $100 \%$ \\
\hline
\end{tabular}




\section{DISCUSSÃO}

Segundo o nosso conhecimento este é o primeiro ensaio clínico randomizado e controlado por placebo a relatar os resultados da evolução de múltiplos parâmetros clínicos e biológicos em usuários de lítio, destacando-se as funções renal e tireoidiana, acompanhados durante 4 anos de seguimento (McKnight et al., 2012). O presente estudo também é o primeiro ensaio clínico sobre a avaliação do metabolismo glicêmico nestes pacientes. Este estudo fez parte de um temático sobre o uso do lítio na modificação de fatores neurobiológicos da DA, no qual a avaliação de segurança consistiu em um de seus braços, desenhado desde o início do estudo para avaliação da evolução clínica e laboratorial dos participantes.

A função renal estimada através do acompanhamento de creatinina e das fórmulas aMDRD e CKD-EPI não demonstrou piora ou declínio progressivo nos usuários de lítio comparados ao grupo placebo. Este achado é condizente com a literatura mais atual sobre a influência do lítio na função renal (McKnight et al., 2012). Não foi observada diferença significativa entre as duas fórmulas, apesar da aMDRD demonstrar melhor evidência para avaliação de idosos (Fliser, 2008; Early et al., 2012). As variáveis com maior influência sobre a função renal (i.e., idade, hipertensão arterial e diabetes mellitus) foram avaliadas conjuntamente. Apesar da diferença significativa observada entre os grupos com relação à idade, as médias etárias encontradas não produziriam impacto quando utilizadas dentro das equações aMDRD ou CKD-EPI. Ainda, mesmo utilizando a idade como variável dependente da função renal expressa por creatinina, aMDRD e CKD-EPI, não houve interação (grupo versus tempo) significativa durante o seguimento de 4 anos. Mesmo 
considerando a presença de hipertensão arterial e diabetes mellitus não houve piora da função renal em ambos os grupos avaliados. As médias da aMDRD e CKD-EPI praticamente se mantiveram constantes, com leve diminuição ao final do estudo no grupo lítio medido através da CKD-EPI. Apesar destes achados negativos, deve-se notar o declínio da função renal, através das duas equações, em ambos os grupos, verificada nos dois primeiros anos do estudo. A CKD-EPI evidenciou diferença significativa entre os grupos nos primeiros 24 meses de estudo, não se mantendo significativa após este período. As razões para esta queda não são claras e devem ser achados de observação. Não houve razão clínica para estas alterações durante o estudo ou após revisão dos prontuários ao final do seguimento.

Ainda com relação à função renal, nossos resultados estão de acordo com a maioria das observações dos estudos mais relevantes descritos na literatura, sendo seis estudos caso-controle com três retrospectivos (Hullin et al., 1979; Coşkunol et al., 1997; Turan et al., 2002) e três prospectivos (Bendz et al., 1985; Hetmar et al., 1987; Bendz et al., 1996). Estes estudos recentemente foram incluídos em metanálise (McKnight et al., 2012) com a conclusão de que, em geral, não há evidência de significativa perda de função glomerular através da utilização de lítio (-6,22, -14.65 a 2,20; $p=0,148)$. Hullin et al. (1979) avaliaram 106 pacientes com transtorno afetivo unipolar e bipolar que tinham sido tratados cronicamente com lítio em baixas concentrações séricas por um período médio de 8 anos. A depuração de creatinina de 24 horas não foi significativamente diferente em uma amostra representativa de 30 pacientes que tomaram lítio e 30 pacientes psiquiátricos, pareados por idade e sexo, que utilizavam outros psicotrópicos. Coskunol et al. (1977) compararam 107 pacientes com transtorno bipolar com 29 sujeitos com outras condições psiquiátricas. 
Os níveis de creatinina sérica e depuração de creatinina não foram significativamente diferentes entre os grupos. Não houve também associação estatisticamente significativa entre a depuração da creatinina e a duração da doença ou do uso de lítio ou da dosagem utilizada no tratamento. Bendz e colaboradores (1985) avaliaram 46 pacientes com transtornos de humor utilizando lítio entre 1 a 11 anos em comparação com 32 controles pareados. A função renal foi avaliada transversalmente no final do tratamento com lítio e após cerca de 3 meses de sua retirada (entre 7 semanas e 26 meses). Apesar da depuração da creatinina ter sido estatisticamente semelhante entre os três grupos (ou seja, usuários de lítio atuais, ex-usuários e controles), a função glomerular melhorou ao longo do tempo no subgrupo de pacientes que interromperam o uso do lítio. Em outro estudo prospectivo, 32 pacientes que receberam lítio por um período médio de 10 anos tiveram sua função renal reavaliada após dois anos de seguimento (Hetmar et al., 1987). O grupo controle foi composto por 53 pacientes com transtornos de humor que nunca tinham sido tratados com lítio. Nas avaliações iniciais assim como no final do seguimento, a funções glomerulares não foram estatisticamente significativas entre os dois grupos. Um resultado semelhante a este também foi relatado por Bendz e colegas (1996) em um estudo controlado com 13 pacientes que realizaram tratamento com lítio por pelo menos 15 anos em comparação com 13 controles que nunca haviam utilizado lítio. A função renal foi avaliada uma vez durante o tratamento com lítio e duas vezes após a sua retirada (ou seja, após 5 e 9 semanas sem o uso do lítio). Durante a utilização do lítio, os pacientes apresentaram uma função glomerular significativamente menor em comparação aos controles. Contudo, após a interrupção do lítio, essas diferenças desapareceram. Contrariamente, Turan e colaboradores (2002) observaram evidência 
estatística de disfunção renal entre usuários de longo prazo de lítio (> 3 anos) em comparação com não usuários de lítio e usuários de curto prazo ( $<3$ anos).

Dentre os objetivos secundários, observou-se um aumento significativo de TSH entre os usuários de lítio, sem alteração da tiroxina livre, consistindo em quadros de hipotireoidismo subclínico sem indicação de tratamento uma vez que os níveis de TSH não se elevaram ou se mantiveram sustentados por duas medidas acima de $10 \mu \mathrm{U} / \mathrm{mL}$ (Mooradian, 2011). Contudo, esta diferença não foi sustentada, perdendo significância ao longo de 4 anos. O risco para o hipotiroidismo clínico é cerca de 6 vezes maior entre os utilizadores de lítio, estando relacionado com a inibição da absorção de iodo, do acoplamento de iodotirosina, e da secreção de tiroxina, resultando no aumento da secreção de TSH (Granjean e Aubry, 2009b). Talvez o regime de baixa dose pode ter minimizado as alterações acima mencionadas na homeostase da tireóide, particularmente dentro da janela de tempo utilizada em nosso estudo. Possivelmente, uma dose maior ou maior tempo de acompanhamento, evidenciaria casos de hipotireoidismo clínico. Este argumento se justifica através da observação de nossa amostra com uma maior tendência ao hipotireoidismo no grupo tratado com lítio. Ambos os grupos lítio e placebo possuíam número de casos de hipotireoidismo semelhantes (8 e 7 , respectivamente). Ao longo do tempo, surgiram 2 casos novos e 3 alterações do TSH (compatível com hipotireoidismo subclínico) contra nenhum caso novo e 1 alteração do TSH para hipotireoidismo subclínico no grupo placebo. Na literatura, há maior prevalência de quadros clínicos e subclínicos de hipotireoidismo em usuários de lítio, sendo 8 a 10 vezes maior do que a da população geral (Kleiner et al., 1999; Johnston e Eagles, 1999). Em recente metanálise que incluiu 8 estudos caso-controle, o risco para hipotireoidismo clínico 
entre usuários de lítio foi de 5.78, significativamente (McKnight et al., 2012). Contudo, há variação da incidência de alterações subclínicas ou clínicas da tireóide entre pacientes idosos segundo a literatura (Sawin et al., 1979; Head \& Dening, 1998; Fahy \& Lawlor, 2001).

Observou-se aumento do número de leucócitos totais às custas de neutrófilos dentre os participantes do grupo lítio de forma significante. O número de linfócitos demonstrou queda não significativa ao longo do tempo. Segundo a literatura, o lítio está associado com um aumento do número de neutrófilos de até 1,5 vezes o valor inicial (Inayat e Gallicchio, 2006). Contudo, as razões desse efeito ainda permanecem obscuras.

Não observou-se alteração significativa do metabolismo glicêmico no grupo lítio comparado ao placebo. Contudo, nos últimos dois anos observou-se aumento crescente, com posterior queda, da resistência insulínica através do índice HOMAIR. Este efeito foi caracterizado pelo aumento da insulinemia, contudo sem alteração da glicemia. $\mathrm{O}$ aumento da resistência insulínica deveria ter provocado um aumento da glicemia de jejum consequentemente. Este achado apesar de original é difícil de ser explorado sem novos estudos em razão da escassez de informações publicadas na literatura. Alguma alteração no metabolismo glicêmico já foi descrita, incluindo o aparecimento de diabetes mellitus, contudo sem exploração da causalidade (Vendsborg e Prytz, 1976; Kuruvilla et al., 2001). Em estudo experimental com ratos recebendo litemia baixa, observou-se aumento dos níveis de glicose, elevação da peroxidade lipídica e redução da glutationa sanguíneas, indicando estresse oxidativo (Ahmad et al., 2011). Na avaliação histopatológica neste estudo, fígado e rins, apresentaram deformidades estruturais e alterações histológicas nos ratos tratados 
com lítio. Estudos experimentais com intoxicação por lítio já observaram redução de glicogênio hepático e renal juntamente com elevação da glicemia. Uma possível explicação seria a de que o lítio poderia interferir no tempo do metabolismo de carboidratos durante a gliconeogênese e a glicogenólise, resultando em elevação glicêmica. Contudo, em outro estudo experimental com desenho e achados histopatológicos semelhantes, as alterações do metabolismo glicêmico não foram encontradas (Sharma \& Iqbal, 2005).

Observou-se aumento significativo na incidência de diabetes mellitus e ganho ponderal nos pacientes tratados com lítio. Apesar de uma possível associação do incremento de peso com a ocorrência do diabetes, somente 3 dos 8 pacientes com ganho de peso (mediana de 5,5 kg) tiveram aumento expressivo clinicamente (acima de $10 \mathrm{~kg}$ ). Dentre estes 3 pacientes, somente 1 desenvolveu diabetes no final do primeiro ano do estudo. O ganho de peso entre 4-10 kg é encontrado em 30\% dos pacientes aproximadamente segundo a literatura e nossos achados se enquadram dentro dessa evidência (Grandjean e Aubry, 2009b). Infelizmente, nenhum estudo explorou o efeito do lítio em uma população com sobrepeso e/ou obesidade comparados com controles para se avaliar possíveis efeitos específicos no primeiro grupo com relação ao ganho de peso. Semelhantemente, há escassa literatura explorando o metabolismo glicêmico ou diretamente o diabetes mellitus em usuários de lítio (Vestergaard e Schou, 1987). Estudos futuros devem explorar melhor a relação entre o lítio e as variáveis ganho de peso, metabolismo glicêmico e diabetes mellitus.

No grupo lítio observou-se aumento da incidência de arritmias diagnosticadas clinicamente e por Holter de 24 horas. Todos os pacientes relataram sintomas 
associados como palpitação, lipotímia e tontura. Contudo, somente a queixa de tontura foi significativamente mais presente no grupo lítio e que constitui uma queixa inespecífica do uso dessa medicação. Dessa forma, os sintomas avaliados não puderam predizer o desenvolvimento das arritmias. Alterações inespecíficas de repolarização ventricular no eletrocardiograma, sem repercussão clínica, foram descritas concomitantes ao uso do lítio, perfazendo um total de 13 a $100 \%$ dos pacientes, dependendo do estudo (Bierbrauer et al., 2006). Revisando cada caso individualmente, 3 participantes do grupo lítio e 1 do grupo placebo foram afastados em razão de arritmias supra-ventriculares (3) ou ventriculares (1). A suspeita da associação entre o uso de lítio e a ocorrência de arritmias não foi feita pelos médicos responsáveis diretos pelos pacientes (p.ex. médicos particulares ou conveniados) em razão da presença de múltiplos fatores cardiovasculares predisponentes. Nenhum dos 3 quadros de arritmias apresentados pelos pacientes do grupo lítio foram semelhantes entre si. De qualquer forma, a melhor exploração desse efeito atribuído ao uso do lítio também deve ser foco de pesquisas futuras.

O uso do lítio demonstrou-se seguro e com poucos efeitos colaterais. Em nosso estudo, tais sintomas foram leves e toleráveis em sua maioria, com o mínimo de interferência na capacidade dos pacientes em realizar suas atividades de vida diária. Com certeza o regime de baixa dosagem adotado neste ensaio contribuiu para uma melhor tolerabilidade assim como para uma boa adesão. Outro ponto a se destacar foi a intensa rede assistencial na qual o paciente tinha livre acesso aos clínicos para avaliações de seus sintomas, o que pode prevenir intoxicações e abandonos sem justificativa. O paciente sabia o dia e horário que encontraria a equipe e poderia agendar uma visita fora desse período se fosse necessário. Este 
processo nos pareceu extremamente importante para a adequada condução de nossa amostra. Como será discutido a frente, somente por sintomas relatados, sem maior profundidade através de entrevista e exame clínico, o médico não conseguiu diferenciar em diversos casos os usuários de lítio dos que receberam placebo. Logicamente nossa população tem a particularidade de ser idosa e ter outras morbidades clínicas e este fato deve ser testado com populações mais jovens, com menor prevalência de doenças associadas e com transtornos psiquiátricos primários.

Com relação ao número de sintomas de efeitos colaterais avaliados através da escala UKU, observou-se diferença significativa entre os grupos e em relação ao tempo de observação. Os pacientes do grupo lítio demonstraram maior número de sintomas (4,98 no grupo lítio versus 4,07 no grupo placebo). Na análise de interação dessas duas variáveis (grupo de tratamento e número total de sintomas) com o tempo total de observação, verificou-se a perda dos achados significantes progressivamente ao longo do seguimento.

O tratamento com lítio é, sem dúvida, associado a uma maior incidência de efeitos adversos desagradáveis, sendo os mais comuns: desconforto abdominal, diarréia, tremor, poliúria, noctúria, ganho de peso, edema e diversas formas de eritemas (Grandjean e Aubry, 2009b; Rybalowski et al., 2006). Dentre estes sintomas referidos na literatura, somente tremor e poliúria foram significativamente associados ao lítio em nosso estudo. Os sintomas gastrointestinais são geralmente as queixas mais relatadas. Contudo, os sintomas predominantes neste estudo foram neurológicos e / ou psiquiátricos, tais como o aumento da atividade onírica, sintomas de depressão e queixas de memória. Dentre as queixas relatadas destacaram-se significativamente no grupo lítio: dificuldade de memória, astenia, poliúria, sonolência, aumento da 
atividade onírica, aumento da duração do sono, aumento da salivação, tremor, tontura, prurido e rigidez. Uma razão plausível para estes achados pode ser devido ao fato de que nossa amostra foi constituída por adultos idosos com CCL. Queixas de dificuldade de memória ou sintomas depressivos produziram favorecimento da diferença no número de sintomas entre os grupos de forma significativa.

Na prática clínica, segundo a literatura, os efeitos mais pronunciados e com maior repercussão para o paciente são a sede, a poliúria, a xerostomia, o ganho de peso, as alterações cognitivas e a fadiga, diferentemente do encontrado em nosso estudo (Grandjean e Aubry, 2009b). As interferências dos sintomas encontrados sobre a qualidade de vida foram leves e englobaram os sintomas tensão/inquietude, aumento da atividade onírica, náuseas/vômitos, eritema, eritema morbiliforme, aumento de pigmentação, ginecomastia, alteração da acomodação visual, náuseas/vômitos, enxaqueca e outras formas de cefaléia segundo as perspectivas dos médicos e dos pacientes. Nenhum destes sintomas exigiu suspensão da medicação.

Os sintomas relacionados aos efeitos colaterais apresentaram pouco impacto clínico nas atividades diárias dos pacientes, apesar de terem sido percebidos tanto pelo médico observador como pelos pacientes de forma significativa. Náusea ou vômitos foi o único sintoma significativamente associado ao uso do lítio segundo a percepção sobre a interferência dos efeitos colaterais tanto pelo médico avaliador como pelo paciente. Este fato é curioso uma vez que tremor e polidipsia são corriqueiramente mais associados ao uso da medicação. Outro fato que chamou nossa atenção foi a percepção da gravidade do efeito colateral pelo médico. Os sintomas que foram significativos foram: tensão, aumento da atividade onírica, náuseas/vômitos, eritema, eritema morbiliforme, aumento de pigmentação, 
ginecomastia, outras formas de cefaléia. Tais sintomas não são claramente associados ao lítio ou são inespecíficos. Dessa forma, a discriminação de efeitos colaterais com negativa influência sobre o cotidiano dos pacientes pode não ser identificada adequadamente.

Os sintomas associados aos efeitos colaterais representam uma das principais causas de interrupção do tratamento com lítio, tendo as formulações de liberação prolongada uma menor associação com este evento (Granjean e Aubry, 2009b). Em nosso estudo, observamos uma taxa de abandono ao uso do lítio muito menor do que na literatura. Segundo a literatura, $15-20 \%$ dos pacientes abandonam o tratamento com lítio em razão dos efeitos adversos, mesmo dentro de ambientes de ensaios clínicos controlados (Kleindienst et al., 2002; Calabrese et al., 2005). Dentre os idosos a taxa de abandono é potencialmente maior, apesar dos estudos divergirem quanto a isso. Num estudo prévio, $76 \%$ dos pacientes foram intolerantes aos efeitos adversos (no caso: tremores, náuseas, vômitos, declínio cognitivo, sedação ou fadiga), com litemia média de 0,63 (Stoudemire et al., 1988), enquanto em outro estudo, com litemias entre 0,3 e $0,5 \mathrm{mmol} / \mathrm{L}$, os efeitos adversos relatados não foram significantes (Hardy et al., 1997). Contudo, a adesão pode ser melhorada com o fornecimento de informações precisas acerca da droga, supervisão terapêutica constante e apoio psicológico (Schou, 1997). Durante nosso estudo, todos os participantes tinham livre acesso à equipe clínica e eram constantemente orientados sobre sua condição física.

O estudo possui algumas potenciais limitações que devem ser salientadas. $\mathrm{Na}$ verdade, as peculiaridades da nossa amostra devem ser discutidas como uma potencial limitação contra a generalização dos nossos achados. Nosso estudo 
envolveu pacientes com CCL, diferentemente da maioria dos estudos com lítio nos quais populações com transtornos do humor são estudadas. Além disso, embora clinicamente saudáveis no início do estudo, muitos participantes (em ambos os grupos) desenvolveram diversas comorbidades médicas, presumivelmente não relacionadas com o tratamento devido às taxas semelhantes de prevalência e incidência em ambos os grupos e tendo em conta a longa duração do ensaio. Esse fato comprometeu o seguimento de um grande número de pacientes durante os 4 anos de seguimento propostos. A maioria dos estudos sobre a segurança e tolerabilidade do tratamento crônico com lítio foram realizados em amostras de pacientes adultos mais jovens e com transtornos do humor, que exigem não apenas uma janela terapêutica distinta para o uso do lítio, mas também a prescrição concomitante de outras drogas psicotrópicas. Portanto, os resultados da presente investigação podem ser mais facilmente extrapolados para o tratamento de pacientes idosos bipolares, que têm maior probabilidade de serem tratados em um regime de baixa litemia. Mesmo a dose utilizada de carbonato de lítio encontra-se um pouco abaixo da usual para pacientes idosos. Apesar da litemia utilizada produzir efeitos terapêuticos observados, seu potencial efeito adverso sistêmico ainda não foi estudado sistematicamente. E, finalmente, o nosso estudo não foi desenhado para realizar uma avaliação do padrão-ouro da função renal por TFG utilizando inulina ou mesmo com a depuração da creatinina urinária de 24 horas (Fliser, 2008), pois a complexidade deste método provavelmente teria um impacto negativo sobre a adesão dos pacientes ao estudo em razão de sua idade, interferindo na probabilidade de atingir o objetivo principal deste estudo. 
Em conclusão, nossos dados ao final de um estudo randomizado e controlado demonstram que a prescrição de carbonato de lítio em esquema de baixa litemia é tolerável e seguro para o tratamento a longo prazo de idosos com CCL, possuindo implicações relevantes de forma extrapolada para o tratamento de idosos com transtorno bipolar. Diversas questões tais como o surgimento de diabetes mellitus e arritmias foram levantadas ao final deste estudo e merecem avaliações sistemáticas posteriores. 


\section{REFERÊNCIAS}

Ahmad M, Elnakady Y, Faroog M, Wadaan M. Lithium induced toxicity in rats: blood serum chemistry, antioxidative enzymes in red blood cells and histopathological studies. Biol Pharm Bull. 2011;34:272-7.

Bailey B, McGuigan M. Lithium poisoning from a poison control center perspective. Ther Drug Monit 2000 Dec;22(6):650-5.

Baptista T, Lacruz A, de Mendoza S, Guillén MM, Burguera JL, de Burguera M, Hernández L. Endocrine effects of lithium carbonate in healthy premenopausal women: relationship with body weight regulation. Prog Neuropsychopharmacol Biol Psychiatry. 2000;24:1-16.

Baptista T, Alastre T, Contreras Q, Martinez JL, Araujo de Baptista E, Burguera JL, de Burguera M, Hernández L. Effects of lithium carbonate on reproductive hormones in healthy men: relationship with body weight regulation. A pilot study. Prog Neuropsychopharmacol Biol Psychiatry. 1997;21:937-50.

Barclay ML, Brownlie BE, Turner JG, Wells JE. Lithium associated thyrotoxicosis: a report of 14 cases, with statistical analysis of incidence. Clin Endocrinol. 1994;40:759-64.

Bassilios N, Martel P, Godard V, Froissart M, Grünfeld JP, Stengel B; Réseau Néphropar. Monitoring of glomerular filtration rate in lithium-treated outpatients. An ambulatory laboratory database surveillance. Nephrol Dial Transplant. 2008;23:5625 .

Bastürk M, Karaaslan F, Esel E, et al. Effects of short and long-term lithium treatment on serum prolactin levels in patients with bipolar affective disorder. Prog Neuro- psychopharmacol Biol Psychiatr 2001;25:315-22.

Bell EC, Wilson MC, Wilman AH, et al. Differential effects of chronic lithium and valproate on brain activation in healthy volunteers. Hum Psychopharmacol 2005;20(6):415-24.

Bendz H. Kidney function in a selected lithium population. A prospective, controlled, lithium-withdrawal study. Acta Psychiatr Scand. 1985;72:451-63.

Bendz H, Aurell M, Lanke J. A historical cohort study of kidney damage in longterm lithium patients: continued surveillance needed. Eur Psychiatry. 2001;16:199206.

Bendz H, Aurell M, Balldin J, Mathé AA, Sjödin I. Kidney damage in long-term lithium patients: a cross-sectional study of patients with 15 years or more on lithium. Nephrol Dial Transplant. 1994;9:1250-4. 
Bendz H, Sjödin I, Aurell M. Renal function on and off lithium in patients treated with lithium for 15 years or more. A controlled, prospective lithium-withdrawal study. Nephrol Dial Transplant. 1996;11:457-60.

Bendz H, Sjödin I, Toss G, Berglund K. Hyperparathyroidism and long-term lithium therapy. A cross-sectional study and the effect of lithium withdrawal. J Intern Med. 1996;240:357-65.

Bendz H, Schön S, Attman PO, Aurell M. Renal failure occurs in chronic lithium treatment but is uncommon. Kidney Int. 2010;77:219-24.

Bierbrauer J, Albrecht J, Müller-Oerlinghausen B. Lithium and its cardiovascular effects. In: Bauer M, Grof P, Müller-Oerlinghausen B, editors. Lithium in neuropsychiatry: the comprehensive guide. Abingdon: Informa, 2006. p.295-301.

Birch NJ, Hullin RP. The distribution and binding of lithium following its long-term administration. Life Sci II 1972 Nov 22; 11(22):1095-9.

Bocchetta A, Bernardi F, Pedditzi M, Loviselli A, Velluzzi F, Martino E, Del Zompo M. Thyroid abnormalities during lithium treatment. Acta Psychiatr Scand.

1991;83:193-8.

Bowden CL. Key treatment studies of lithium in manic-depressive illness: efficacy and side effects. J Clin Psychiatry. 1998;59 Suppl 6:13-9.

Boton R, Gaviria M, Batlle DC. Prevalence, pathogenesis, and treatment of renal dysfunction associated with chronic lithium therapy. Am J Kidney Dis. 1987;10:329-45.

Caer-Frouard M, Weill-Engerer S, Piette F. Médicaments et mémoire: des interactions à connaître chez le sujet âgé. Presse Med. 2006;35:91-6.

Calabrese JR, Shelton MD, Rapport DJ, Youngstrom EA, Jackson K, Bilali S, Ganocy SJ, Findling RL. A 20-month, double-blind, maintenance trial of lithium versus divalproex in rapid-cycling bipolar disorder. Am J Psychiatry. 2005;162:2152-61.

Castells X, Vallano A, Rigau D, Pérez J, Casas M, Capellà D. Trends in lithium prescription in Spain from 1985 to 2003. J Affect Disord. 2006 Apr;91(2-3):273-6.

Castrogiovanni P. A novel slow-release formulation of lithium carbonate (carbolithium once-a-day) vs. standard carbolithium: a comparative pharmacokinetic study. Clin Ther. 2002;153:107-15.

Chugh S, Yager H. End-stage renal disease after treatment with lithium. J Clin Psychopharmacol. 1997;17:495-7. 
Cipriani A, Pretty H, Hawton K, Geddes JR. Lithium in the prevention of suicidal behavior and all-cause mortality in patients with mood disorders: a systematic review of randomized trials. Am J Psychiatry 2005;162:1805-19.

Clarke WB, Clarke RM, Olson EK, et al. Binding of li- thium and boron to human plasma proteins. Biol Trace Elem Res 1998;65:237-49.

Cook BL, Smith RE, Perry PJ, et al. Theophylline-lithium interaction. J Clin Psychiatry 1985;46(7):278-9.

Cooper TB, Simpson GM, Lee JH, et al. Evaluation of a slow-release lithium carbonate formulation. Am J Psychiatry 1978 Aug; 135(8):917-22.

Coşkunol H, Vahip S, Mees ED, Başçi A, Bayindir O, Tuğlulaŕ I. Renal side-effects of long-term lithium treatment. J Affect Disord. 1997 Mar;43(1):5-10.

Dawson AH, Whyte IM. Therapeutic drug monitoring in drug overdose. Br J Clin Pharmacol 1999 Sep;48(3):278-83.

Earley A, Miskulin D, Lamb EJ, Levey AS, Uhlig K. Estimating equations for glomerular filtration rate in the era of creatinine standardization: a systematic review. Ann Intern Med. 2012 Jun 5;156(11):785-95.

Eastham JH, Jeste DV, Young RC. Assessment and treatment of bipolar disorder in the elderly. Drugs Aging. 1998 Mar;12(3):205-24.

Eiam-Ong S, Dafnis E, Spohn M, Kurtzman NA, Sabatini S. H-K-ATPase in distal renal tubular acidosis: urinary tract obstruction, lithium, and amiloride. Am J Physiol. 1993 Dec;265(6 Pt 2):F875-80.

El Khoury A, Tham A, Mathe AA, et al. Decreasedplasma prolactin release in euthymic lithium-treated women with bipolar disorder. Neuropsychobiology 2003;48:14-8.

Fahy S, Lawlor BA. Lithium use in octogenarians. Int J Geriatr Psychiatry. 2001;16:1000-3.

Farres MT, Ronco P, Saadoun D, Remy P, Vincent F, Khalil A, Le Blanche AF. Chronic lithium nephropathy: MR imaging for diagnosis. Radiology. 2003; 229(2):570-4.

Finley PR, Warner MD, Peabody CA. Clinical relevance of drug interactions with lithium. Clin Pharmacokinet 1995 Sep;29(3):172-91.

Fliser D. Assessment of renal function in elderly patients. Curr Opin Nephrol Hypertens 2008;17(6):604-8. 
Forlenza OV, Diniz BS, Radanovic M, Santos FS, Talib LL, Gattaz WF. Diseasemodifying properties of long-term lithium treatment for amnestic mild cognitive impairment: randomised controlled trial. Br J Psychiatry. 2011;198:351-6.

Freeman MP, Gelenberg AJ. Bipolar disorder in women: reproductive events and treatment considerations. Acta Psychiatr Scand 2005;112(2):88-96.

Froissart M, Rossert J, Jacquot C, Paillard M, Houillier P. Predictive performance of the modification of diet in renal disease and Cockcroft-Gault equations for estimating renal function. J Am Soc Nephrol. 2005;16:763-73.

Frye MA, Denicoff KD, Bryan AL, Smith-Jackson EE, Ali SO, Luckenbaugh D, Leverich GS, Post RM. Association between lower serum free T4 and greater mood instability and depression in lithium-maintained bipolar patients. Am J Psychiatry. 1999 Dec;156(12):1909-14.

Gai MN, Thielemann AM, Arancibia A. Effect of three different diets on the bioavailability of a sustained release lithium carbonate matrix tablet. Int J Clin Pharmacol Ther 2000;38:320-6.

Geddes JR, Burgess S, Hawton K, Jamison K, Goodwin GM. Long-term lithium therapy for bipolar disorder: systematic review and meta-analysis of randomized controlled trialls. Am J Psychiatry 2004;161:217-22.

Grandjean EM, Aubry, JM (a). Lithium: Updated Human Knowledge Using an Evidence-Based Approach. Part II: Clinical Pharmacology and Therapeutic Monitoring. CNS Drugs 2009;23(4):331-49.

Grandjean EM, Aubry, JM (b). Lithium: updated human knowledge using an evidence-based approach: part III: clinical safety. CNS Drugs. 2009;23(5):397-418.

Groleau G. Lithium toxicity. Emerg Med Clin North Am 1994;12(2):511-31.

Greil W, Stoltzenburg MC, Mairhofer ML, Haag M. Lithium dosage in the elderly. A study with matched age groups. J Affect Disord. 1985;9:1-4.

Grünfeld JP, Rossier BC. Lithium nephrotoxicity revisited. Nat Rev Nephrol. 2009;5(5):270-6.

Guedj F, Saba G, Olie JP. Lithium: principes et règles d'utilisation. Rev Prat. 1996;46:1401-7.

Hampel H, Ewers M, Burger K, Annas P, Mortberg A, Bogstedt A, et al. Lithium trial in Alzheimer's disease: a randomized, single-blind, placebo- controlled, multicenter 10-week study. J Clin Psychiatry 2009;70:922-31.

Hansen HE, Amdisen A. Lithium intoxication: report of 23 cases and review of 100 cases from the literature. Q J Med 1978 Apr;47(186):123-44. 
Hardy BG, Shulman KI, Zucchero C. Gradual discontinuation of lithium augmentation in elderly patients with unipolar depression. J Clin Psychopharmacol 1997;17:22-6.

Harvey NS, Merriman S. Review of clinically important drug interactions with lithium. Drug Saf 1994 Jun;10(6):455-63.

Head L, Dening T. Lithium in the over 65s:who is taking it and who is monitoring it? A survey of older adults on lithium in the Cambridge Mental Health Services catchment area. Int J Geriatr Psychiatry. 1998 Mar;13(3):164-71.

Hetmar O, Clemmesen L, Ladefoged J, Rafaelsen OJ. Lithium: long-term effects on the kidney. III. Prospective study. Acta Psychiatr Scand. 1987;75:251-8.

Hewick DS, Newbury P, Hopwood S, Naylor G, Moody J. Age as a factor affecting lithium therapy. Br J Clin Pharmacol. 1977;4:201-5.

Holroyd S, Rabins PV. A retrospective chart review of lithium side effects in a geriatric outpatient population. Am J Geriatr Psychiatry. 1994;2:346-51.

Honig A, Arts BM, Ponds RW, Riedel WJ. Lithium induced cognitive side-effects in bipolar disorder: a qualitative analysis and implications for daily practice. Int Clin Psychopharmacol. 1999;14(3):167-71.

Hullin RP, Coley VP, Birch NJ, Thomas TH, Morgan DB. Renal function after longterm treatment with lithium. Br Med J. 1979;1:1457-9.

Hunter R. Steady-state pharmacokinetics of lithium carbonate in healthy subjects. $\mathrm{Br}$ J Clin Pharmacol 1988;25(3):375-80.

Inayat MS, Gallicchio VS. The effects of lithium on the immune system. In: Bauer M, Grof P, Müller-Oerlinghausen B, editors. Lithium in neuropsychiatry: the comprehensive guide. Abingdon: Informa, 2006:399-414.

Jaeger A, Sauder P, Kopferschmitt J, et al. When should dialysis be performed in lithium poisoning? A kinetic study in 14 cases of lithium poisoning. J Toxicol Clin Toxicol 1993;31(3):429-47.

Janowsky DS, Soares J, Hatch JP, Zunta-Soares G, Hu Q, Davis JM. Lithium effect on renal glomerular function in individuals with intellectual disability. J Clin Psychopharmacol. 2009;29:296-9.

Janowsky DS, Buneviciute J, Hu Q, Davis JM. Lithium-induced renal insufficiency: a longitudinal study of creatinine increases in intellectually disabled adults. J Clin Psychopharmacol. 2011;31:769-73.

Jaunay EVG, Guelfi JD. Syndrome sérotoninergique: quels traitements, et quand? Presse Med 2001 Nov 17;30(34):1695-700. 
Jensen SB, Rickers H. Glomerular filtration rate during lithium therapy. A longitudinal study. Acta Psychiatr Scand. 1984 Sep;70(3):235-8.

Johnson FN. The history of lithium therapy. London: Macmillan, 1984.

Johnston AM, Eagles JM. Lithium-associated clinical hypothyroidism: prevalence and risk factors. Br J Psychiatry 1999;175:336-9.

Jorgensen F, Larsen S, Spanager B, Clausen E, Tango M, Brinch E, Brun C. Kidney function and quantitative histological changes in patients on long-term lithium therapy. Acta Psychiatr Scand. 1984 Nov;70(5):455-62.

Juurlink DN, Mamdani MM, Kopp A, Rochon PA, Shulman KI, Redelmeier DA. Drug-induced lithium toxicity in the elderly: a population-based study. J Am Geriatr Soc. 2004 ;52(5):794-8.

Kallner A, Ayling PA, Khatami Z. Does eGFR improve the diagnostic capability of S-Creatinine concentration results? A retrospective population based study. Int J Med Sci. 2008;5(1):9-17.

Kallner G, Petterson U. Renal, thyroid and parathyroid function during lithium treatment: laboratory tests in 207 people treated for 1-30 years. Acta Psychiatr Scand 1995;91(1):48-51.

Keck Jr PE, McElroy SL, Bennett JA. Pharmacologic loading in the treatment of acute mania. Bipolar Disord 2000 Mar;2(1):42-6.

Kleindienst N, Greil W. Inter-episodic morbidity and dropout under carbamazepine and lithium in the maintenance treatment of bipolar disorder. Psychol Med 2002;32(3):493-501.

Kleiner J, Altshuler L, Hendrick V, Hershman JM. Lithium-induced subclinical hypothyroidism: review of the literature and guidelines for treatment. J Clin Psychiatry 1999;60(4):249-55.

Kosten TR, Forrest JN. Treatment of severe lithium-induced polyuria with amiloride. Am J Psychiatry 1986;143(12):1563-8.

Kotnik P, Nielsen J, Kwon TH, Krzisnik C, Frokiaer J, Nielsen S. Altered expression of COX-1, COX-2, and mPGES in rats with nephrogenic and central diabetes insipidus. Am J Physiol Renal Physiol. 2005;288(5):F1053-68.

Kripalani M, Shawcross J, Reilly J, Main J. Lithium and chronic kidney disease. BMJ. 2009 Jul 3;339:b2452.

Kuruvilla PK, Alexander J. Lithium toxicity presenting as non-convulsive status epilepticus (NCSE). Aust N Z J Psychiatry 2001;35(6):852. 
Kusalic M, Engelsmann F. Renal reactions to changes of lithium dosage. Neuropsychobiology. 1996;34(3):113-6.

Kusalic M, Engelsmann F. Effect of lithium maintenance therapy on thyroid and parathyroid function. J Psychiatry Neurosci 1999;24(3):227-33.

Lazarus JH. The effects of lithium therapy on thyroid and thyrotropin-releasing hormone. Thyroid 1998;8(10):909-13.

Lazarus JH, Kirov G, Harris BB. Effect of lithium on the thyroid and endocrine glands. In: Bauer M, Grof P, Müller-Oerlinghausen B, editors. Lithium in neuropsychiatry: the comprehensive guide. UK: Taylor \& Francis, 2006. p.259-70.

Lee CF, Yang YY, Hu OY. Single dose pharmacokinetic study of lithium in Taiwanese/Chinese bipolar patients. Aust N Z J Psychiatry 1998 Feb; 32(1):133-6.

Lepkifker E, Sverdlik A, Iancu I, Ziv R, Segev S, Kotler M. Renal insufficiency in long-term lithium treatment. J Clin Psychiatry. 2004 Jun;65(6):850-6.

Levey AS, Bosch JP, Lewis JB, Greene T, Rogers N, Roth D. A more accurate method to estimate glomerular filtration rate from serum creatinine: a new prediction equation. Modification of Diet in Renal Disease Study Group. Ann Intern Med. 1999;130:461-70.

Levey AS, Atkins R, Coresh J, Cohen EP, Collins AJ, Eckardt KU, et al. Chronic kidney disease as a global public health problem: approaches and initiatives. A position statement from Kidney Disease Improving Global Outcomes. Kidney Int. 2007;72:247-59.

Lindeman RD, Tobin J, Shock NW. Longitudinal studies on the rate of decline in renal function with age. J Am Geriatr Soc. 1985 Apr;33(4):278-85.

Livingstone C, Rampes H. Lithium: a review of its metabolic adverse effects. J Psychopharmacol 2006;20(3):347-55.

Litovitz TL, Klein-Schwartz W, White S, et al. 1999 annual report of the American Association of Poison Control Centers Toxic Exposure Surveillance System. Am J Emerg Med 2000 Sep;18(5):517-74.

Lokkegaard H, Andersen NF, Henriksen E, Bartels PD, Brahm M, Baastrup PC, et al. Renal function in 153 manic-depressive patients treated with lithium for more than five years. Acta Psychiatr Scand. 1985 Apr;71(4):347-55. 
Mak TW, Shek CC, Chow CC, et al. Effects of lithium therapy on bone mineral metabolism: a two-year pro- spective longitudinal study. J Clin Endocrinol Metab 1998 Nov;83(11):3857-9.

Markowitz GS, Radhakrishnan J, Kambham N, Valeri AM, Hines WH, D'Agati VD. Lithium nephrotoxicity: a progressive combined glomerular and tubulointerstitial nephropathy. J Am Soc Nephrol. 2000;11(8):1439-48.

Marples D, Christensen S, Christensen EI, Ottosen PD, Nielsen S. Lithium-induced downregulation of aquaporin-2 water channel expression in rat kidney medulla. $\mathrm{J}$ Clin Invest. 1995;95(4):1838-45.

Martines-Maldonado M, Stavroulaki-Tsapara A, Tsaparas N, Suki WN, Eknoyan G. Renal effects of lithium administration in rats: alterations in water and electrolyte metabolism and the response to vasopressin and cyclic-adenosine monophosphate during prolonged administration. J Lab Clin Med. 1975 Sep;86(3):445-61.

McCann SM, Daly J, Kelly CB. The impact of long-term lithium treatment on renal function in an outpatient population. Ulster Med J. 2008;77:102-5.

Macdonald A, Briggs K, Poppe M, Higgins A, Velayudhan L, Lovestone S. A feasibility and tolerability study of lithium in Alzheimer's disease.Int J Geriatr Psychiatry 2008;23:704-11.

McKhann G, Drachman D, Folstein M, Katzman R, Price D, Stadlan, E.M. Clinical diagnosis of Alzheimer's disease: report of the NINCDS-ADRDA work group under the auspices of the Department of Health and Human Services task force on Alzheimer's disease. Neurology 1984;34(7):939-44.

McKnight RF, Adida M, Budge K, Stockton S, Goodwin GM, Geddes JR. Lithium toxicity profile: a systematic review and meta-analysis. Lancet. 2012;379:721-8.

Miller KK, Daniels GH. Association between lithium use and thyrotoxicosis caused by silent thyroiditis. Clin Endocrinol (Oxf) 2001;55(4):501-8.

Mitchell PB. Therapeutic drug monitoring of psychotropic medications. Br J Clin Pharmacol 2000;49(4):303-12.

Mooradian AD. Subclinical hypothyroidism in the elderly: to treat or not to treat? Am J Ther 2011;18(6):477-86.

Moore CM, Demopulos CM, Henry ME, et al. Brain-to- serum lithium ratio and age: an in vivo magnetic resonance spectroscopy study. Am J Psychiatry 2002 Jul;159(7):1240-2.

Morriss R, Benjamin B. Lithium and eGFR: a new routinely available tool for the prevention of chronic kidney disease. Br J Psychiatry 2008;193:93-5. 
Movig KL, Baumgarten R, Leufkens HG, van Laarhoven JH, Egberts AC. Risk factors for the development of lithium-induced polyuria. Br J Psychiatry. 2003 Apr;182:319-23.

Mula M, Monaco F, Trimble MR. Use of psychotropic drugs in patients with epilepsy: interactions and seizure risk. Expert Rev Neurother 2004;4(6):953-64.

Murray N, Hopwood S, Balfour DJ, Ogston S, Hewick DS. The influence of age on lithium efficacy and side-effects in out-patients. Psychol Med. 1983;13:53-60.

National Institute for Health and Clinical Excellence (NICE). Bipolar disorder: the management of bipolar disorder in adults, children and adolescents, in primary and secondary care: quick reference guide. London: National Institute for Health and Clinical Excellence; 2006.

Ohgami H, Terao T, Shiotsuki I, Ishii N, Iwata N. Lithium levels in drinking water and risk of suicide. Br J Psychiatry. 2009;194:464-5.

Pachet AK, Wisniewski AM. The effects of lithium on cognition: an updated review. Psychopharmacology (Berl) 2003;170(3):225-34.

Paul R, Minay J, Cardwell C, Fogarty D, Kelly C. Meta-analysis of the effects of lithium usage on serum creatinine levels. J Psychopharmacol. 2010;24:1425-31.

Petersen RC, Smith GE, Waring SC, Ivnik RJ, Tangalos EG, Kokmen E. Mild Cognitive Impairment: Clinical Characterization and Outcome. Arch Neurol 1999;56(6):303-8.

Pogarell O, Folkerts M, Hegerl U. Adverse neurological and neurotoxic effects of lithium therapy. In: Bauer M, Grof P, Müller-Oerlinghausen B, editors. Lithium in neuropsychiatry: the comprehensive guide. UK: Taylor \& Francis; 2006. p. 271-82.

Pöge U, Gerhardt T, Stoffel-Wagner B, Palmedo H, Klehr HU, Sauerbruch T, Woitas RP. Can modifications of the MDRD formula improve the estimation of glomerular filtration rate in renal allograft recipients? Nephrol Dial Transplant. 2007; 22:3610-5.

Povlsen UJ, Hetmar O, Ladefoged J, Bolwig TG. Kidney functioning during lithium treatment: a prospective study of patients treated with lithium for up to ten years. Acta Psychiatr Scand. 1992 Jan;85(1):56-60.

Presne C, Fakhouri F, Noel LH, et al. Lithium-induced nephropathy: rate of progression and prognostic factors. Kidney Int 2003;64(2):585-92.

Reiss RA, Haas CE, Karki SD, et al. Lithium pharmaco- kinetics in the obese. Clin Pharmacol Ther 1994 Apr;55(4):392-8. 
Roque A, Herédia V, Ramalho M, de Campos R, Ferreira A, Azevedo R, Semelka R. MR findings of lithium-related kidney disease: preliminar observations in four patients. Abdom Imaging. 2012;37:140-6.

Rowe JW, Andres R, Tobin JD, Norris AH, Shock NW. The effect of age on creatinine clearance in men: a cross-sectional and longitudinal study. J Gerontol. 1976;31:155-63.

Rybakowski JK, Suwalska A. Gastrointestinal metabolic and body-weight changes during treatment with lithium. In: Bauer M, Grof P, Müller-Oerlinghausen B, eds. Lithium in neuropsychiatry: the comprehensive guide. UK: Taylor \& Francis; 2006. p.283-94.

Rule AD, Larson TS, Bergstralh EJ, Slezak JM, Jacobsen SJ, Cosio FG (2004). "Using serum creatinine to estimate glomerular filtration rate: accuracy in good health and in chronic kidney disease". Ann. Intern. Med. 2004;141(12):929-37.

Sawin CT, Chopra D, Azizi F, Mannix JE, Bacharach P. The aging thyroid. Increased prevalence of elevated serum thyrotropin levels in the elderly. JAMA. 1979;242:247-50.

Schou M. Lithium treatment during pregnancy, delivery, and lactation: an update. J Clin Psychiatry 1990 Oct;51(10):410-3.

Schou M, Vestergaard P. Prospective studies on a lithium cohort. 2. Renal function. Water and electrolyte metabolism. Acta Psychiatr Scand. 1988 Oct;78(4):427-33.

Schou M. Serum lithium monitoring of prophylactic treatment: critical review and updated recommendations. Clin Pharmacokinet 1988;15(5):283-6.

Schou M. The combat of non-compliance during prophylactic lithium treatment. Acta Psychiatr Scand 1997;95(5):361-3.

Schou M, Kampf D. Lithium and the kidneys. In: Bauer M, Grof P, MüllerOerlinghausen B, eds. Lithium in neuropsychiatry: the comprehensive guide. UK: Taylor \& Francis; 2006. p. 251-8.

Schou M, Vestergaard P. Use of propranolol during li- thium treatment: an enquiry and a suggestion. Pharmaco- psychiatry 1987 May;20(3):131.

Serretti A, Artioli P. Predicting response to lithium in mood disorders: role of genetic polymorphisms. Am J Pharmacogenomics 2003;3(1):17-30.

Sharma SD, Iqbal M. Lithium induced toxicity in rats: a hematological, biochemical and histopathological study. Biol Pharm Bull. 2005;28:834-7. 
Shorter E. The history of lithium therapy. Bipolar Disord. 2009;11(Suppl 2):4-9.

Shulman KI, Herrmann N. Bipolar disorder in old age. Can Fam Physician. 1999;45:1229-37.

Simard M, Gumbiner B, Lee A, et al. Lithium carbonate intoxication: a case report and review of the literature. Arch Intern Med 1989 Jan;149(1):36-46.

Singh LK, Nizamie SH, Akhtar S, Praharaj SK. Improving tolerability of lithium with a once-daily dosing schedule. Am J Ther. 2011;18:288-91.

Smith RE, Helms PM. Adverse effects of lithium therapy in the acutely ill elderly patient. J Clin Psychiatry. 1982;43:94-9.

Smith LA, Cornelius V, Warnock A, Tacchi MJ, Taylor D. Pharmacological interventions for acute bipolar mania: a systematic review of randomized placebocontrolled trials. Bipolar Disord. 2007 Sep;9(6):551-60.

Spirtes MA. Lithium levels in monkey and human brain after chronic, therapeutic, oral dosage. Pharmacol Bio- chem Behav 1976 Aug; 5(2):143-7.

Sproule BA, Hardy BG, Shulman KI. Differential pharmacokinetics of lithium in elderly patients. Drugs Aging 2000;16(3):165-77.

Stip E, Dufresne J, Lussier I, et al. A double-blind, placebo-controlled study of the effects of lithium on cognition in healthy subjects: mild and selective effects on learning. J Affect Disord 2000;60(3):147-57.

Stoudemire A, Hill CD, Lewison BJ, Marguardt M, Dalton S. Lithium intolerance in a medical-psychiatric population. Gen Hosp Psychiatry. 1998;20:85-90.

Soares JC, Boada F, Keshavan MS. Brain lithium measurements with (7)Li magnetic resonance spectroscopy (MRS): a literature review. Eur Neuropsychopharmacol 2000;10(3):151-8.

Stone, KA. Lithium-induced nephrogenic diabetes insipidus. J. Am. Board Fam. Pract. 1999;12(1)43-7.

Szalat A, Mazeh H, Freund HR. Lithium-associated hy- perparathyroidism: report of four cases and review of the literature. Eur J Endocrinol 2009 Feb;160(2):317-23.

Terhaag B, Scherber A, Schaps P, et al. The distribution of lithium into cerebrospinal fluid, brain tissue and bile in man. Int J Clin Pharmacol Biopharm 1978 Jul;16(7):333-5.

Thornhill DP. Pharmacokinetics of ordinary and sustained- release lithium carbonate in manic patients after acute dosage. Eur J Clin Pharmacol 1978 Dec 1;14(4):267-71. 
Tredget J, Kirov A, Kirov G. Effects of chronic lithium treatment on renal function. J Affect Disord. 2010;126:436-40.

Tuazon J, Casalino D, Syed E, Batlle D. Lithium-associated kidney microcysts. ScientificWorld Journal. 2008;8:828-9.

Turan T, Eşel E, Tokgöz B, Aslan S, Sofuoğlu S, Utaş C, Keleştimur F. Effects of short- and long-term lithium treatment on kidney functioning in patients with bipolar mood disorder. Prog Neuropsychopharmacol Biol Psychiatry. 2002 Apr;26(3):561-5.

Türck D, Heinzel G, Luik G. Steady-state pharmaco- kinetics of lithium in healthy volunteers receiving con- comitant meloxicam. Br J Clin Pharmacol 2000 Sep;50(3):197-204.

Using lithium safely. Drug Ther Bull 1999;37(3): 22-4.

van Melick EJ, Meinders AE, Hoffman TO, Egberts TC. Renal effects of long-term lithium therapy in the elderly: a cross-sectional study. Int J Geriatr Psychiatry. 2008;23(7):685-92.

Vendsborg PB, Prytz S. Glucose tolerance and serum lipids in man after long-term lithium administration. Acta Psychiatr Scand 1976;53:64-9.

Verhave JC, Fesler P, Ribstein J, du Cailar G, Mimran A. Estimation of renal function in subjects with normal serum creatinine levels: influence of age and body mass index. Am J Kidney Dis 2005; 46(2):233-41.

Vestergaard P, Schou M. Does long-term lithium treatment induce diabetes mellitus? Neuropsychobiol 1987; 17:130-2.

Vestergaard P, Rejnmark L, Mosekilde L. Reduced relative risk of fractures among users of lithium. Calcif Tissue Int 2005;77:1-8.

Viguera AC, Cohen LS, Baldessarini RJ, et al. Managing bipolar disorder during pregnancy: weighing the risks and benefits. Can J Psychiatry 2002 Jun;47(5):426-36.

Viguera AC, Newport DJ, Ritchie J, et al. Lithium in breast milk and nursing infants: clinical implications. Am J Psychiatry 2007 Feb;164(2):342-5.

Walker RG. Lithium nephrotoxicity. Kidney Int Suppl. 1993 Jul;42:S93-8.

Waller DG, Edwards JG, Papasthatis-Papayanni S. A longitudinal assessment of renal function during treatment with lithium. Q J Med. 1988 Jul;68(255):553-8.

Ward ME, Musa MN, Bailey L. Clinical pharmacokinetics of lithium. J Clin Pharmacol 1994;34:280-5. 
Watson WA, Litovitz TL, Rodgers Jr GC, et al. 2004 annual report of the American Association of Poison Control Centers Toxic Exposure Surveillance System. Am J Emerg Med 2005 Sep;23(5):589-666.

Wilkinson D, Holmes C, Woolford J, Stammers S, North J. Prophylactic therapy with lithium in elderly patients with unipolar major depression. Int J Geriatr Psychiatry. 2002;17:619-22.

Wilting I, de Vries F, Thio BM, Cooper C, Heerdink ER, Leufkens HG, Nolen WA, Egberts AC, van Staa TP. Lithium use and the risk of fractures. Bone. 2007;40(5):1252-8.

Young AH, Hammond JM. Lithium in mood disorders: increasing evidence base, declineing use? Br J Psychiatry 2007;191:474-6. 


\section{APÊNDICES}

Antecedentes significativos:

Comorbidades relevantes:

Medicamentos em uso:

Relato / queixas do paciente:

Exame fisico:

Observações: 
Escala UKU de Efeitos Colaterais (i)

\begin{tabular}{|c|c|c|c|c|c|c|c|c|c|}
\hline & \multirow{2}{*}{ Sintomas } & \multirow{2}{*}{\begin{tabular}{|c|} 
Não Aval. \\
9 \\
\end{tabular}} & \multicolumn{4}{|c|}{ Intensidade } & \multicolumn{3}{|c|}{ Relação Causal } \\
\hline & & & 0 & 1 & 2 & 3 & imp & pos & prb \\
\hline 1.1 & Dificuldade de concentração & & & & & & & & \\
\hline 1.2 & Astenia/lassidão/cansaço & & & & & & & & \\
\hline 1.3 & Sonolência/sedação & & & & & & & & \\
\hline 1.4 & Dificuldade de memória & & & & & & & & \\
\hline 1.5 & Depressäo & & & & & & & & \\
\hline 1.6 & Tensãolinquietaçäo & & & & & & & & \\
\hline 1.7 & Aumento da duraçäo do sono & & & & & & & & \\
\hline 1.8 & Diminuição da duração do sono & & & & & & & & \\
\hline 1.8 & Aumento da atividade onírica & & & & & & & & \\
\hline 1.10 & Indiferença emocional & & & & & & & & \\
\hline 2.1 & Distonia & & & & & & & & \\
\hline 2.2 & Rigidez & & & & & & & & \\
\hline 2.3 & Hipocinesia/ acinesia & & & & & & & & \\
\hline 2.4 & Hipercinesia & & & & & & & & \\
\hline 2.5 & Tremor & & & & & & & & \\
\hline 2.6 & Acatisia & & & & & & & & \\
\hline 2.7 & Convulsões epilépticas & & & & & & & & \\
\hline 2.8 & Parestesias & & & & & & & & \\
\hline 3.1 & Alteração da acomodação visual & & & & & & & & \\
\hline 3.2 & Aumento da salivaçăo & & & & & & & & \\
\hline 3.3 & Diminuição da salivação & & & & & & & & \\
\hline 3.4 & Náuseas/ vómitos & & & & & & & & \\
\hline 3.5 & Diarréia & & & & & & & & \\
\hline 3.6 & Constipação & & & & & & & & \\
\hline 3.7 & Distúrbios da miç̧ăo & & & & & & & & \\
\hline 3.8 & Poliúria/ polidipsia & & & & & & & & \\
\hline 3.9 & Tontura ortostática & & & & & & & & \\
\hline 3.10 & Palpitacóes/ taquicardia & & & & & & & & \\
\hline 3.11 & Aumento da tendência para suar & & & & & & & & \\
\hline 4.1 & Eritema & & & & & & & & \\
\hline 4.1.a & Eritema morbiliforme & & & & & & & & \\
\hline 4.1.b & Eritema petequial & & & & & & & & \\
\hline 4.1.c & Eritema urticariforme & & & & & & & & \\
\hline 4.1.d & Eritema psoriático & & & & & & & & \\
\hline 4.1.e & Eritema näo classificado & & & & & & & & \\
\hline 4.2 & Prurido & & & & & & & & \\
\hline 4.3 & Fotossensibilidade & & & & & & & & \\
\hline 4.4 & Aumento de pigmentação & & & & & & & & \\
\hline 4.5 & Ganho de peso & & & & & & & & \\
\hline 4.6 & Perda de peso & & & & & & & & \\
\hline 4.7 & Menorragia & & & & & & & & \\
\hline 4.8 & Amenorréia & & & & & & & & \\
\hline 4.9 & Galactorréia & & & & & & & & \\
\hline 4.10 & Ginecomastia & & & & & & & & \\
\hline 4.11 & Aumento da desejo sexual & & & & & & & & \\
\hline 4.12 & Diminuição da desejo sexual & & & & & & & & \\
\hline 4.13 & Disfunção erétil & & & & & & & & \\
\hline 4.14 & Disfunção ejaculatória & & & & & & & & \\
\hline 4.15 & Disfunção orgástica & & & & & & & & \\
\hline 4.16 & Secura vaginal & & & & & & & & \\
\hline 4.17 & Cefaléia & & & & & & & & \\
\hline $4.17 . a$ & Tipo tensăo & & & & & & & & \\
\hline $4.17 . \mathrm{b}$ & Enxaqueca & & & & & & & & \\
\hline $4.17 . c$ & Outras formas & & & & & & & & \\
\hline 4.18 & Dependência física & & & & & & & & \\
\hline 4.19 & Dependência psíquica & & & & & & & & \\
\hline
\end{tabular}


Avaliação global da interferência dos efeitos colaterais nas atividades diárias do paciente:

\begin{tabular}{|l|l|l|}
\hline Intensidade dos efeitos colaterais & $\begin{array}{c}\text { Avaliado pelo } \\
\text { Paciente }\end{array}$ & $\begin{array}{c}\text { Avaliado pelo } \\
\text { Médico }\end{array}$ \\
\hline 0 Sem efeitos colaterais & & \\
\hline 1 Efeitos colaterais leves que não interferem na atividade do paciente & & \\
\hline 2 Efeitos colaterais que interferem moderadamente na atividade do paciente & & \\
\hline 3 Efeitos colaterais que interferem marcadamente na atividade do paciente & & \\
\hline
\end{tabular}

\begin{tabular}{|l|l|}
\cline { 2 - 2 } \multicolumn{1}{l|}{} & Conseqüência \\
\hline 0 Nenhuma ação & \\
\hline $\begin{array}{l}\text { Avaliação mais freqũente do paciente, mas sem redução de dose, e/ou tratamento } \\
\text { medicamentoso ocasional do efeito colateral }\end{array}$ & \\
\hline 2 Redução da dose elou tratamento medicamentoso contínuo dos efeitos colaterais & \\
\hline 3 Descontinuação do fármaco ou mudança para outro fármaco & \\
\hline
\end{tabular}

\begin{tabular}{|c|c|c|}
\hline Hemograma & $\square$ Normal & $\square$ Alterado: \\
\hline VHS & $\square$ Normal & $\square$ Alterado: \\
\hline Glicemia & $\square$ Normal: ...................... & $\square$ Alterado: \\
\hline Insulinemia & $\square$ Normal: & $\square$ Alterado: \\
\hline $\mathrm{Na}^{+} / \mathrm{K}^{+}$ & $\square$ Normal & $\square$ Alterado: \\
\hline Uréia / Creat. & $\square$ Normal & $\square$ Alterado: \\
\hline $\mathrm{Ca}^{++} / \mathrm{P}$ & $\square$ Normal & $\square$ Alterado: \\
\hline TGO / TGP & $\square$ Normal & $\square$ Alterado: \\
\hline Colesterol & $\square$ Normal & $\square$ Alterado: \\
\hline Triglicérides & $\square$ Normal & $\square$ Alterado: \\
\hline Folato / B12: & $\square$ Normal & 口 Alterado: \\
\hline VDRL & $\square$ Normal & $\square$ Alterado: \\
\hline T4L / TSH & $\square$ Normal & $\square$ Alterado: \\
\hline \multirow[t]{3}{*}{ Anticorpos: } & $\square$ Normal & $\square$ Alterado: \\
\hline & $\square$ Normal & $\square$ Alterado: \\
\hline & $\square$ Normal & $\square$ Alterado: \\
\hline
\end{tabular}

